Review

Archive for

Organic Chemistry

Arkivoc 2018, part i, 50-113

\title{
Recent applications of aziridine ring expansion reactions in heterocyclic synthesis
}

\author{
Girija S. Singh, ${ }^{* a}$ Siji Sudheesh, ${ }^{a}$ and Ngonye Keroletswe ${ }^{b}$ \\ ${ }^{a}$ Chemistry Department, University of Botswana, Private Bag: 0022, Gaborone, Botswana \\ ${ }^{b}$ Botswana Institute for Technology Research and Innovation, Private Bag: 0082, Gaborone, Botswana \\ E-mail: singhgs@mopipi.ub.bw
}

Received 08-01-2017

Accepted 09-18-2017

Published on line 11-12-2017

\section{Abstract}

The inherent reactivity of the aziridine ring due to ring-strain makes it valuable building blocks for the synthesis of other heterocyclic motifs of biological relevance. Of particular significance is the generation of azomethine ylides from them and cycloaddition of ylides with alkenes, alkynes, and heterocumulenes. The ring undergoes opening followed by cyclization with a variety of reagents either in the presence of a catalyst or without any catalyst. This review article discusses the recent applications of aziridines in syntheses of four-to seven-membered heterocycles of biological relevance such as azetidines, 2-azetidinones, pyrroles, imidazoles, oxazoles, thiazoles, piperidines, pyrazines, pyrimidines, benzoxazines, morpholines, azepanes, benzodiazepines, benzoxazepines, and benzothiazepines.

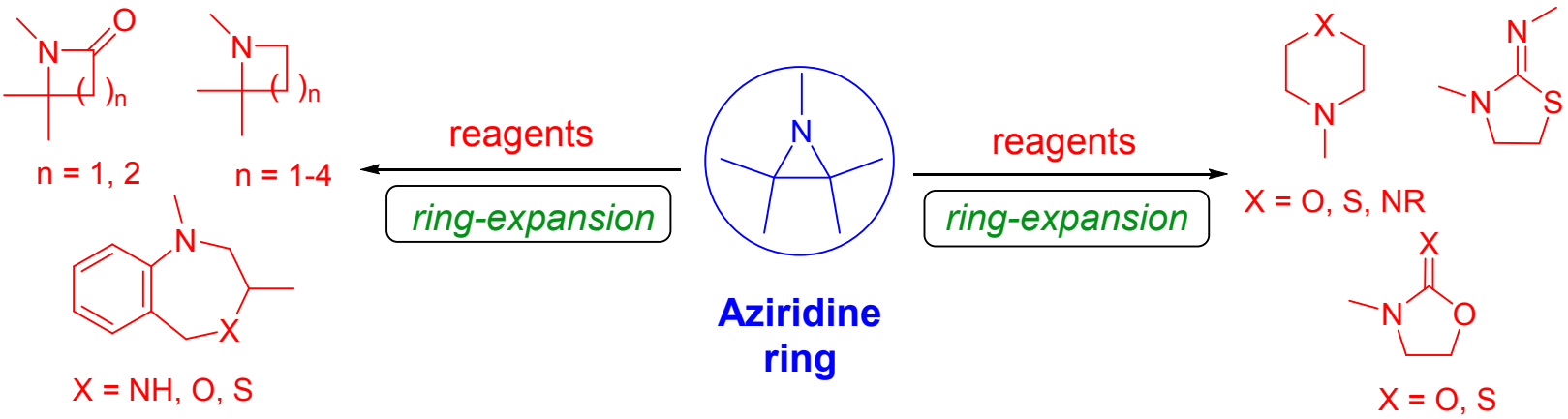

Keywords: Aziridines, azetidines, pyrroles, imidazoles, benzoxazines, azepanes, benzoxazepines 


\section{Table of Contents}

1. Introduction

\subsection{Synthesis of aziridines}

2. Reactivity of Aziridines: Synthetic Methods for Heterocycles from Aziridines

3. Synthesis of Four-Membered Heterocycles

3.1 Synthesis of azetidines

Synthesis of $\beta$-lactams

4. Synthesis of Five-Membered Heterocycles

\subsection{Synthesis of pyrroles and indoles}

4.2 Synthesis of dihydropyrroles

4.3 Synthesis of pyrrolidines

4.4 Synthesis of pyrrolidinones

4.5 Synthesis of imidazoles

4.6 Synthesis of imidazolines

4.7 Synthesis of imidazolidines

4.8 Synthesis of imidazolidin-2-ones, imidazolidine-2-thiones, and 2-iminoimidazolidines

4.9 Synthesis of oxazoles

4.10 Synthesis of oxazolidines

4.11 Synthesis of oxazolidin-2-ones and oxazolidine-2-thiones

4.12 Synthesis of isoxazolidines

4.13 Synthesis of 2-iminothiazolidines

5. Synthesis of Six-Membered Heterocycles

5.1 Synthesis of piperidines and tetrahydroisoquinolines

5.2 Synthesis of dihydropyridin-2-ones

5.3 Synthesis of piperazines

5.4 Synthesis of pyrimidines

5.5 Synthesis of dihydroxazines

5.6 Synthesis of benzoxazines and benzothiazines

5.7 Synthesis of morpholines and thiomorpholines

6. Synthesis of Seven-Membered Heterocycles

6.1 Synthesis of azepanes

6.2 Synthesis of diazepinones

6.3 Synthesis of benzodiazepines, benzoxazepines and benzothiazepines

7. Concluding Remarks

Acknowledgements

References

\section{Introduction}

Azacyclopropanes, commonly known as aziridines, are a well-known class of compounds in the realm of heterocyclic chemistry and medicinal chemistry. ${ }^{1}$ Aziridine ring is extremely reactive due to ring-strain associated with it which makes it a powerful building block in organic synthesis. The unique reactivity of 
aziridines has been exploited by synthetic organic chemists for developing synthetic protocols to several novel heterocyclic compounds either directly or through the formation of diverse 1,2-difunctionalized compounds through ring-opening followed by cyclization or cycloaddition.

Although access to strained three- and four-membered heterocycles is a challenging endeavor aziridines having a broad range of functionalities are easily accessible by several routes described in literature. The reactivity of aziridines depends largely on type of substituents presents on the ring. The presence of a strong electron-withdrawing group on the ring activates the ring and such aziridines are referred to as activated aziridines. Aziridines bearing arylsulfonyl groups on ring nitrogen, a carboxylate group or a vinylic group on ring carbon(s) have drawn considerable interest of researchers. The synthesis and reactivity of aziridines have been reviewed from time to time. ${ }^{2,3}$ Some review articles focusing on specific type of aziridines such as aziridine-2-carboxylates, ${ }^{4} \quad$ 2-haloaziridines, ${ }^{5} \quad$ 2-methyleneaziridines, ${ }^{6}$ and 2-vinylaziridines ${ }^{7,8}$ have been published. This review paper aims to describe recent applications (2008 to early 2017) of aziridines, whether activated or non-activated, in synthesis of other heterocyclic frameworks by aziridine ring expansion. It is wellknown that heterocyclic compounds containing one or more nitrogen atoms, or nitrogen atom(s) together with sulfur or oxygen atoms are biologically very important class of compounds. Hence the article will focus on synthesis of different types of heterocycles rather than the different types of reactions of aziridines. Although the review of synthetic methods of aziridines is not the objective of this article it would be wise to give a brief idea about how the aziridines are accessed in laboratory. Accordingly, selected examples from different methods reported in recent literature are described here.

\subsection{Synthesis of aziridines}

There are a number of methods known in literature for synthesizing aziridines (Figure 1). The main approaches to construct the aziridine motif can be broadly classified as i) cyclization of 2-aminoalcohols, ii) addition of nitrenes or nitrenoids to alkenes, and iii) reactions of sulfur ylides or carbenes/carbenoids with imines. Looking at significance of asymmetry in structure of the molecules in biological systems, efforts are on to synthesize enantioenriched aziridines. ${ }^{9,10}$

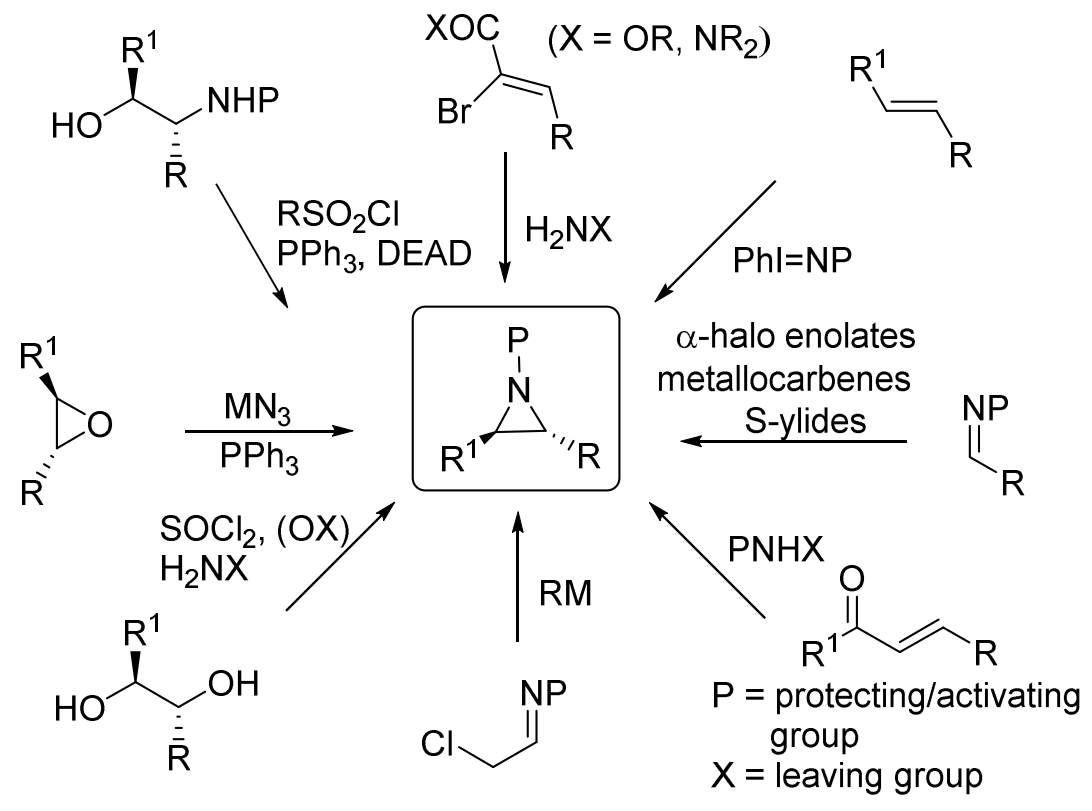

Figure 1. Main synthetic approaches to aziridines. 
i) Cyclization of 2-aminoalcohols: A one-step cyclization of 2-aminoalcohol 1 with $p$-toluenesulfonyl chloride $(\mathrm{TsCl})$, aqueous $\mathrm{NaOH}$ and tetrabutylammonium iodide in a biphasic system leads to the formation of a tricyclic aziridine, 2,4-diamino-5,6-methylene-5,6,7,8-tetrahydropyrido[3,2-d]pyrimidine 2 in 50\% yield (Scheme 1)..$^{11}$
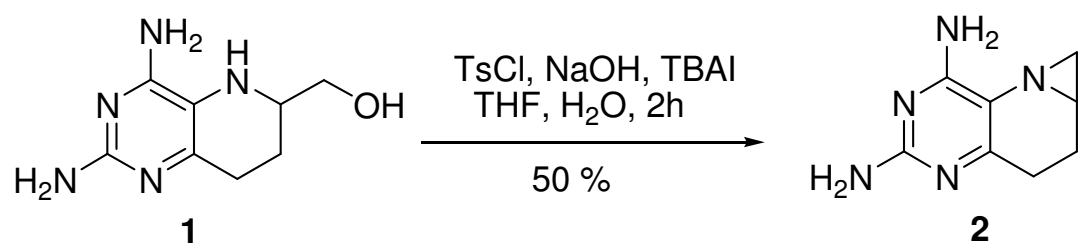

\section{Scheme 1}

The formation of $\mathrm{N}$-tosyl-2-trifluoromethylaziridine $\mathbf{5}$ is reported from 3-amino-1,1,1-trifluoropropan-1-ol 3. ${ }^{12}$ The latter compound undergoes a selective $N$-tosylation on treatment with $\mathrm{Ts} C \mathrm{l}$ in pyridine to form $\mathrm{N}$ sulfonamide 4 . The cyclization of the $N$-sulfonamide under the Mitsunobu conditions yielded the aziridine $\mathbf{5}$ (Scheme 2). This aziridine finds use in synthesis of pyrrolidines, piperidines and azepanes that will be dealt with in respective sections. ${ }^{13}$
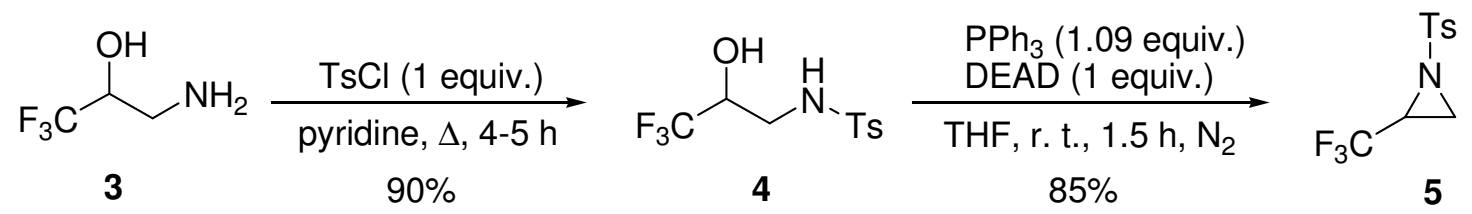

\section{Scheme 2}

ii) Addition of nitrenes or nitrenoids to alkenes: Menjo and coworkers have reported an excellent asymmetric synthesis of fused bicyclic aziridines 9 by reaction of alkenes 6 with $N$-tosyloxycarboxybenzyl carbamate 7 in the presence of $\mathrm{N}$-neopentyl-1,2-diphenylethylenediamine catalyst $\mathbf{8}$ (Scheme 3 ). ${ }^{14}$ Recently, this group has discovered another diamine similar to 8 but $\mathrm{CH}_{2} \mathrm{CMe}_{3}$ group replaced with a 4,4-dimethylcyclohexyl group for the asymmetric aziridination using same reagent. ${ }^{15}$

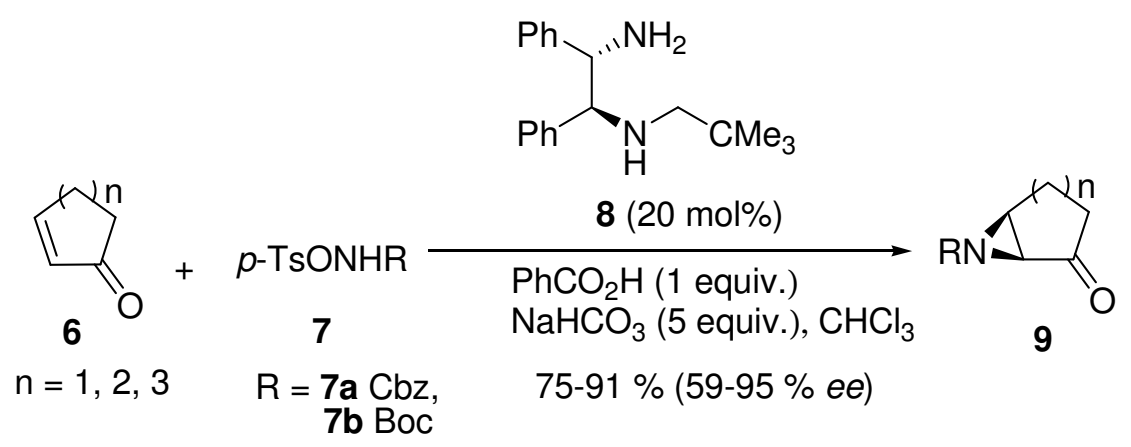

\section{Scheme 3}

Halskov and coworkers have reported the formation of aziridines 12-14 in very good yields and excellent enantioselectivity (except for aziridine 14 that had only $40 \%$ ee) by the reaction of $N$-tosyl-tert- 
butyloxycarbonyl carbamate, 7b, with five- to seven-membered cyclic 2,4-dienals 10 using trimethylsilyl (TMS)-protected prolinol catalyst 11 (Scheme 4). ${ }^{16}$<smiles>[R7]C1=CCC([Pb])CC1=CC=O</smiles>

10

$$
\begin{aligned}
& \mathrm{R}^{1}=\text { alkyl } \\
& \mathrm{R}^{2}=\mathrm{H}^{\mathrm{H}},{ }^{5} \pi \\
& \mathrm{R}^{3}={ }^{5} \pi, \mathrm{H}
\end{aligned}
$$

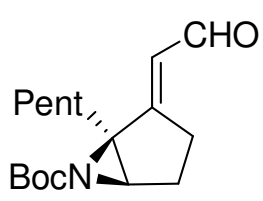

13

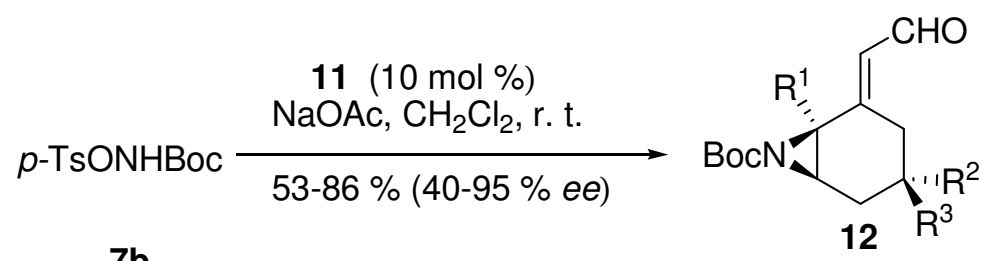

$7 b$

$>95: 5 \gamma, \delta: \alpha, \beta$ $>95: 5 E: Z$

(7 examples)

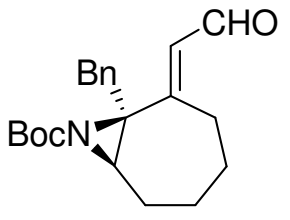

14

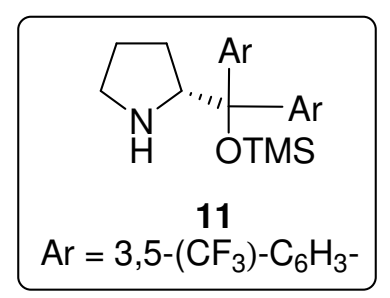

\section{Scheme 4}

Liang and coworkers have reported the formation of $N$-tosylaziridines $\mathbf{1 7}$ by reactions of olefins $\mathbf{1 5}$ with $p$ toluenesulfonyl azide 16 in the presence of iron porpholactone, (mesotetrakis(pentafluorophenyl)porpholactonato dianion, $\left[\mathrm{Fe}\left(\mathrm{F}_{20}-\mathrm{TPPL}\right) \mathrm{Cl}\right]$ ) as a catalyst (Scheme 5$) .{ }^{17}$ However, $p$ methoxystyrene and $\alpha$-methylstyrene furnished tetrahydropyrrole and allylic amidation products, respectively, instead of aziridine derivatives from this reaction.

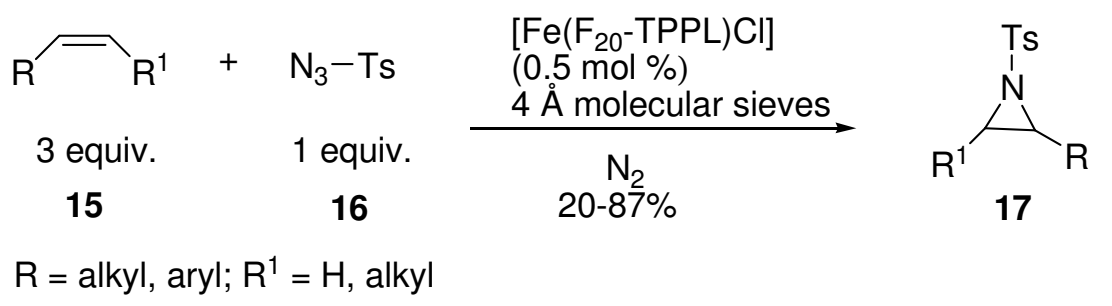

\section{Scheme 5}

iii) Reactions of sulfur ylides or carbenes/carbenoids with imines: A one-pot, highly diastereoselective synthesis of functionalized cis-vinylaziridines, $\mathbf{2 1}$ and $\mathbf{2 2}$ containing a quaternary carbon center is reported through a sulfur ylide-mediated aziridination of five- and six-membered cyclic imines 18 and 19 in the presence of a palladium catalyst (Scheme 6). ${ }^{18}$ 
<smiles>[R]C1=NS(=O)(=O)[X]2CCCCC21</smiles>

R<smiles>[R]C=CC[S+](C)Br</smiles>

1. $t$-BuOK, THF, $\mathrm{O}^{\circ} \mathrm{C}$

2. $\mathrm{Pd}\left(\mathrm{PPh}_{3}\right)_{4}(10 \mathrm{~mol} \%)$

$52-86 \%$ (cis/trans >99:1)<smiles>[R]C1=NS(=O)(=O)Oc2ccccc21</smiles>

19 $R^{2}$
$\mathrm{R}=$ Alkyl, aryl.; $\mathrm{X}=\mathrm{O}, \mathrm{C}$

$\mathrm{R}^{1}=\mathrm{Ph}, \mathrm{CO}_{2} \mathrm{Me}$, TMS

$\mathrm{R}^{2}=\mathrm{Ph}, \mathrm{Me}$

$\therefore=\mathrm{H}, \mathrm{Ph}$<smiles>[R7]C=C[C@H]1N2[C@]1([R])[C@@H]1CC[C][Y]1S2(=O)=O</smiles>

21

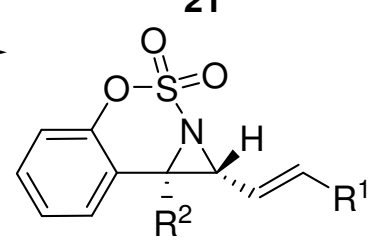

22

\section{Scheme 6}

In another example, Aggarwal and coworkers used dissolved sulfonium salt $\mathbf{2 4}$ in acetonitrile before adding the imines $\mathbf{2 3}$ and potassium carbonate. ${ }^{18}$ The solution was then stirred at room temperature overnight. The reaction led to the formation of aziridines 17 in good yields with good trans selectivity (Scheme 7). ${ }^{19}$

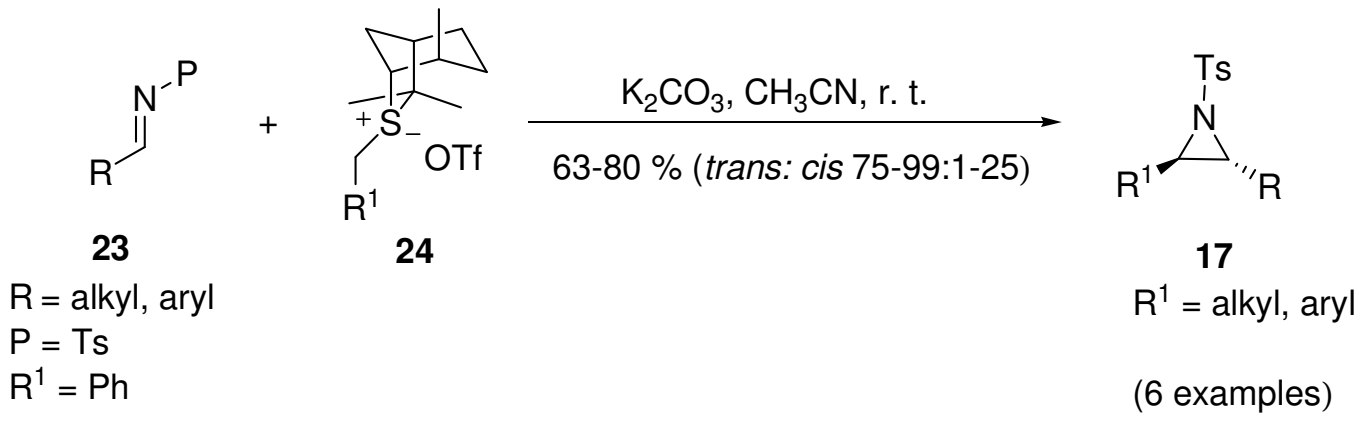

\section{Scheme 7}

The Aza-Darzens reaction is reported as a convenient method to access aziridnes. ${ }^{20}$ Aza-Darzens reaction involves an $\alpha$-haloenolate or an $\alpha$-halocarbanion and an imine. Stockman and coworkers have reported the synthesis of 2,3-disubstituted and 2,2',3-trisubstituted aziridines by an aza-Darzens reaction of the tertbutanesulfinyl imines with ethyl bromoacetate. ${ }^{20}$ Larson and co-workers reported the first asymmetric azaDarzens addition using 3-chloropentane-2,4-dione $\mathbf{2 6}$ and $\mathbf{N}$-benzoyl imines $\mathbf{2 5}$ to give $\mathbf{N}$-benzoyl-2,2-diacetyl3-arylaziridines $\mathbf{2 7}$ using vaulted biphenanthrol magnesium salt $\left(\mathrm{Mg}[\mathrm{P} 3]_{2}\right)$ as a catalyst (Scheme 8$)^{21}$

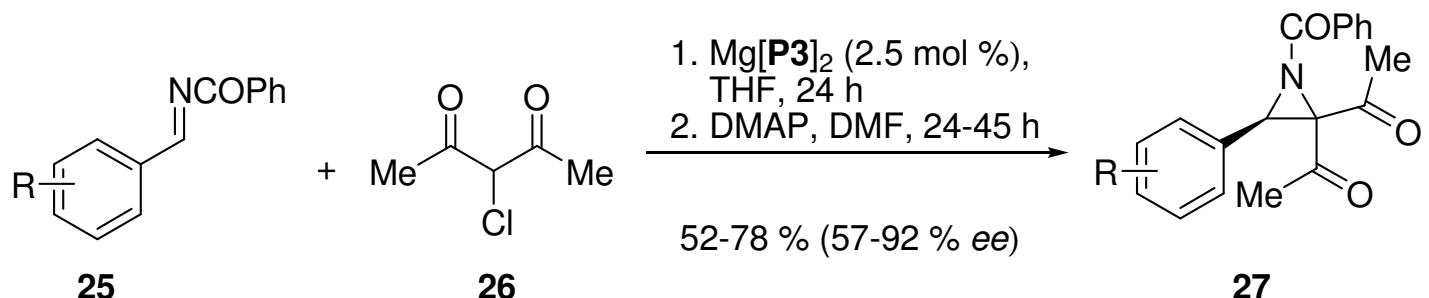

$$
\mathrm{R}=\mathrm{H}, \mathrm{Me}, \mathrm{OMe}, \mathrm{F}, \mathrm{Cl}, \mathrm{Br}
$$

(9 examples)

\section{Scheme 8}


Khoumeri and coworkers have synthesized a mixture of cis/trans 2,3-diaryl $N$-tosylaziridines 32, with cisisomers being the major products by reaction of 1,1-dichloromethyl-4-nitrobenzene 28 with aromatic $N$ tosylimines 31 in the presence of tetrakis(dimethylamino)ethylene (TDAE) (Scheme 9). ${ }^{22}$ However, when the nitro group was on ortho-position, as in 1,1-dichloromethyl)-2-nitrobenzene 29 and 1,1-(dichloromethyl)-4,5dimethoxy-2-nitrobenzene $\mathbf{3 0}$, only the trans-aziridines 33 and 34, respectively, are obtained.<smiles>O=[N+]([O-])c1ccc(C(Cl)Cl)cc1</smiles>

28<smiles>[R]c1cc(C(Cl)Cl)c([N+](=O)[O-])cc1[R]</smiles>

$$
29 \mathrm{R}=\mathrm{R}^{1}=\mathrm{H} \quad \mathrm{X}=\mathrm{H}, 2-\mathrm{Me}, 2-\mathrm{Cl}, 2-\mathrm{Br} \text {, }
$$$$
30 \mathrm{R}=\mathrm{R}^{1}=\mathrm{OCH}_{3}
$$

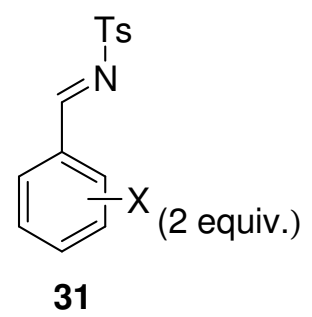

TDAE (1 equiv.)

THF, $-20^{\circ} \mathrm{C}$ to r. t.

$61-81 \%$

(21 examples)

$3-\mathrm{F}, 3-\mathrm{CF}_{3}, 4-\mathrm{F}$

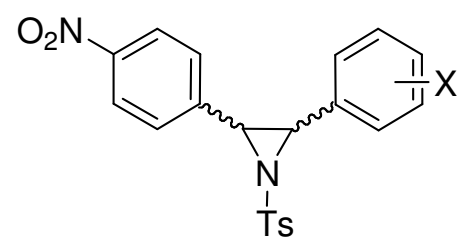

32

trans-(2R,3S); cis $(2 S, 3 R)$; cis- $(2 R, 3 R)$ and trans $(2 S, 3 S)$<smiles>[X]c1ccc([C@@H]2[C@H](c3cc([R7])c([R])cc3[N+](=O)[O-])N2[3H])cc1</smiles>

$33 \mathrm{R}=\mathrm{R}^{1}=\mathrm{H}$ (trans-(2S,3S); trans $(2 R, 3 R)$ )

$34 \mathrm{R}=\mathrm{R}^{1}=\mathrm{OCH}_{3}$ (trans-(2S,3S); trans $(2 R, 3 R)$ )

\section{Scheme 9}

Wulff's research group has carried out several studies on catalytic reactions of diazo compounds with imines, mediated by boroxinate catalysts derived from VANOL and VAPOL ligands mainly for achieving aziridines in enantiopure forms. ${ }^{23-25}$ The reactions of imines with diazoacetates ${ }^{26}$ and with diazomethyl ketones, ${ }^{27}$ catalyzed by either a VAPOL or VANOL catalysts, have been reported to provide cis-aziridines. The reaction of sec-diazoacetamides with imines, however, results in formation of trans-aziridines. ${ }^{28}$ The reaction of imines $\mathbf{2 3}$ with $\alpha$-diazo compounds $\mathbf{3 5}$ in the presence of the VANOL/ VAPOL- B $_{3}$ catalyst furnishes either cisor trans- aziridines 36 depending on the reaction conditions (Scheme 10). ${ }^{29}$ For example, a N-BUDAMprotected imine 23 reacts with $\alpha$-diazoacetamides 35 in toluene at $-20{ }^{\circ} \mathrm{C}$ to give pure trans-aziridine acetamides $\mathbf{3 6}$ in $90 \%$ yield and $96 \%$ ee. The same imine $\mathbf{2 3}$ reacts with ethyl diazoacetate $\mathbf{3 5}$ under similar reaction conditions to give a $99 \%$ isolated yield of the pure cis-aziridine acetate $\mathbf{3 6}$ in $98 \%$ ee. Hence, the face selectivity is caused by the catalyst or diazo compound rather than the imine. 


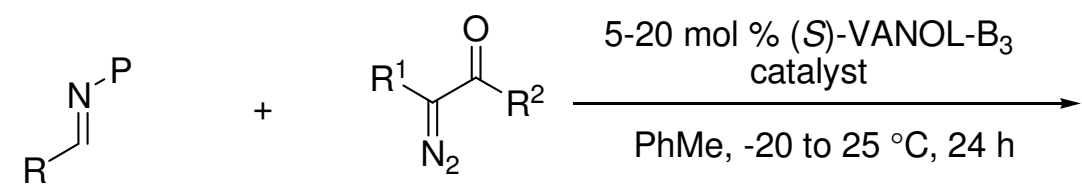

23
35<smiles></smiles>

36

$$
\begin{aligned}
& \mathrm{P}=\mathrm{Bh}, \mathrm{BUDAM}, \text { Boc, DAM, MEDAM } \\
& \mathrm{R}=\text { aryl, alkyl } \\
& \mathrm{R}^{1}=\mathrm{H}, \mathrm{R}^{2}=\mathrm{NHR}^{3}, \mathrm{OEt}, \mathrm{N}\left(\mathrm{R}^{3}\right)_{2} \\
& \quad \text { where } \mathrm{R}^{3}=\text { alkyl, aryl }
\end{aligned}
$$

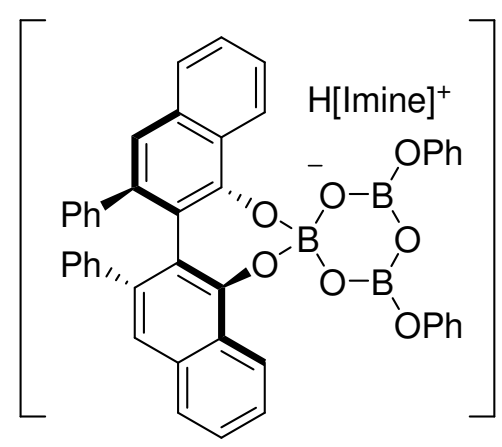

(S)-VANOL-B ${ }_{3}$ catalyst

\section{Scheme 10}

The $\alpha$-diazo compounds $\mathbf{3 5}$ without amidic protons, furnish cis-aziridines $\mathbf{3 6}$ selectively whereas those with amidic proton afford trans-aziridines $\mathbf{3 6}$ under similar reaction conditions. ${ }^{30}$ Thus, the presence or absence of an amidic proton plays an important role in diastereoselection. The $N$-Boc-protected imines $\mathbf{2 3}$ react with $\alpha$ diazopropanoate $35\left(R^{2}=\mathrm{OEt}\right)$ and $\alpha$-diazo- $N$-propanoyloxazolidinone $35\left(\mathrm{R}^{2}=N\right.$-acyloxazolidinone $)$ in dichloromethane at $-78{ }^{\circ} \mathrm{C}$ in the presence of VANOL-B $B_{3}$ catalyst to give trans-trisubstituted aziridines 36 selectively (Scheme 11). ${ }^{25}$<smiles>[R]C=NP</smiles>

23

$\mathrm{R}=$ Aryl, alkyl

$\mathrm{P}=\mathrm{Boc}$

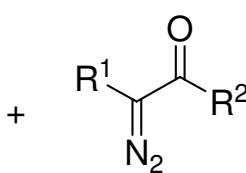

35

$\mathrm{R}^{1}=\mathrm{Me}, \mathrm{Et}, n-\mathrm{Pr}$

$\mathrm{R}^{2}=\mathrm{OEt}, \mathrm{N}$-acyloxazolidinone cat. $(R)$-VANOL

$\underset{\mathrm{CH}_{2} \mathrm{Cl}_{2},-78^{\circ} \mathrm{C}}{\stackrel{(10-20 \mathrm{~mol} \%)}{\longrightarrow}}$

trans- $(2 S, 3 R)-36$

(23 examples)<smiles>[R]C1[C@@H]([R])N1C(=O)OCc1ccccc1</smiles>

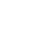

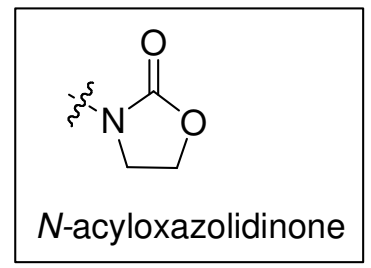

$N$-acyloxazolidinone

\section{Scheme 11}

\section{Ring-Opening of Aziridines: Synthetic Methods for Heterocycles from Aziridines}

The chemistry of aziridines has drawn considerable interest in recent years with an objective to construct medium-size aza-, diaza-, oxoaza- and thioaza- heterocycles (Figure 1). A brief account of synthetic methods in preceding section has shown that aziridines with different types of substituents are easily accessible in laboratory by a number of methods. Aziridine ring, however, has inherent reactivity due to high ring-strain associated with it. As a result, a number of nucleophiles have been employed successfully for aziridine ringopening. Both C-C and C-N bonds of aziridine ring can undergo cleavage (Scheme 12). ${ }^{31}$ The regioselectivity in 
ring-opening depends on substituents present on the ring. ${ }^{32,33}$ Usually the electron-withdrawing groups on ring favor the cleavage of $\mathrm{C}-\mathrm{N}$ bond. The presence of an electron-releasing group favors the cleavage of $\mathrm{C}-\mathrm{C}$ bond. Besides electronic effects, sometimes steric effect also governs the nucleophilic attack on the ring. ${ }^{32}$ De Kimpe and coworkers observed that in non-activated 2-substituted aziridines, the ring-opening depends on the nature of nucleophile, the type of activation of the aziridine ring, and nature of the substituent on the ring. ${ }^{32}$ Paasche and coworkers have performed computational analysis of the underlying potential energy surfaces and reaction paths to get an insight into the thermodynamic and kinetic factors governing the cleavage of $\mathrm{C}-\mathrm{C}$ and $\mathrm{C}-\mathrm{N}$ bonds in differently substituted aziridines. ${ }^{34}$ This study revealed that the $\mathrm{C}-\mathrm{C}$ bond cleavage and nucleophilic attack is a stepwise reaction while the $\mathrm{C}-\mathrm{N}$ bond cleavage and nucleophilic attack is a concerted process. The substitution pattern on the aziridine ring did not affect the reaction course but affected the reaction barrier. The barrier for the $\mathrm{C}-\mathrm{C}$ bond cleavage decreased on replacing hydrogen atom with electronwithdrawing substituents such as nitrophenyl or carboxylate. The barrier for the $\mathrm{C}-\mathrm{N}$ bond cleavage, however, increased with cumulative substitution. The computed data predicted that a shift from $\mathrm{C}-\mathrm{N}$ to $\mathrm{C}-\mathrm{C}$ bond cleavage required stabilizing substituents at both carbon atoms.

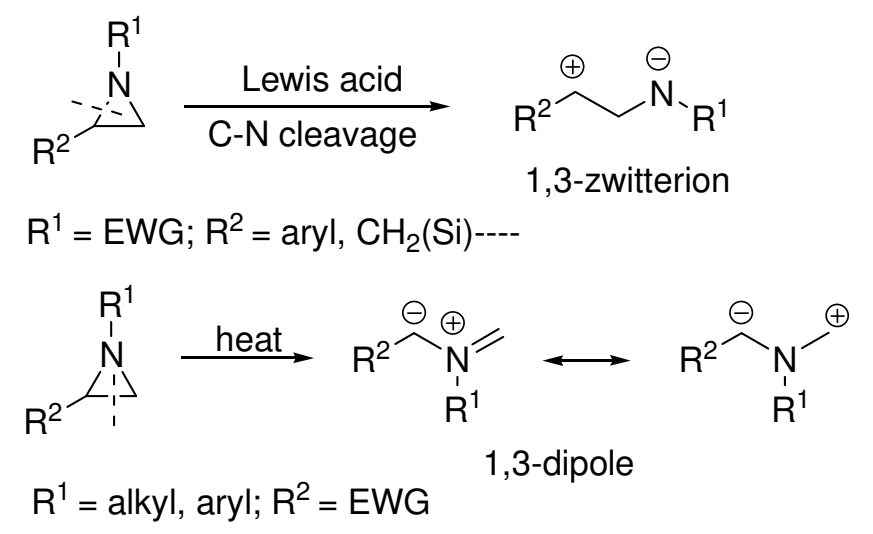

\section{Scheme 12}

The 1,3-dipole, generated by cleavage of aziridine ring, can be trapped with diverse types of dipolarophiles to synthesize heterocyclic compounds. The ring-opening of aziridines and subsequent cyclization or cycloaddition have led to discovery of interesting synthetic methodologies for four- to seven-membered heterocyclic motifs (Figure 2) such as azetidines, $\beta$-lactams, pyrroles, imidazoles, oxazoles, pyrimidines, pyrazines, oxazines, morpholines, thiomorpholines azepanes, benzodiazapines, benzoxazepines, and benzothiazepines. In the succeeding sections, the synthesis of these heterocyclic frameworks from aziridines by different methods is described. The literature is arranged here according to the ring size. Within a particular ring size, the synthetic methods are discussed according to ring-type. 


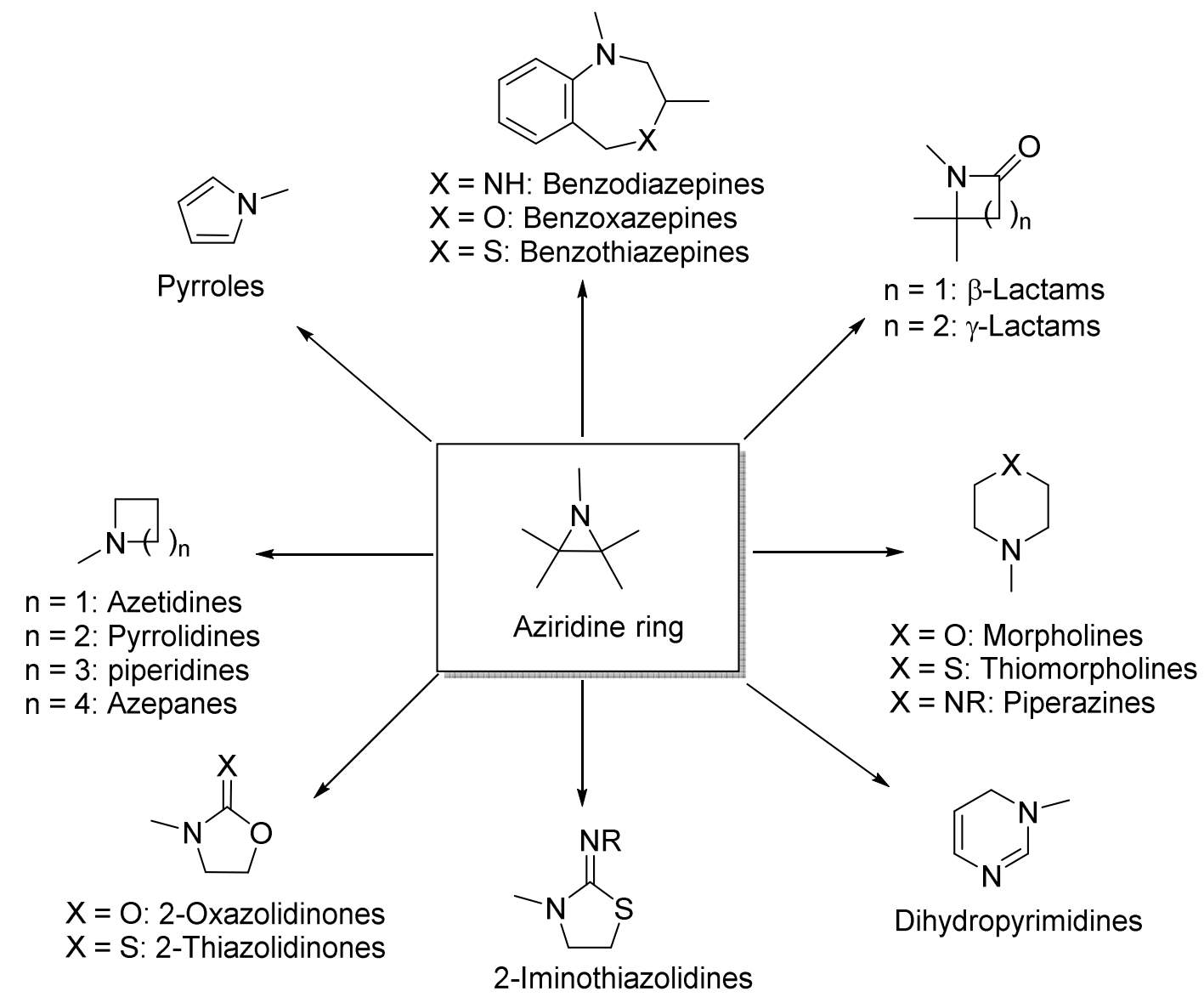

Figure 2. Heterocyclic compounds from aziridines.

\section{Synthesis of Four-membered Heterocycles}

\subsection{Synthesis of azetidines}

The transformation of a three-membered ring to a four-membered ring is a difficult to achieve endeavor and hence the literature is scarce on this type of transformation. Azetidines constitute an important class of azaheterocyclic compounds from synthetic, mechanistic, and biological points of views. ${ }^{35}$

De Kimpe and coworkers have designed and developed the synthesis of several novel aziridines and investigated their reactivity towards different reagents for entry into other heterocyclic systems of biological relevance. A novel aziridine to azetidine rearrangement protocol has been developed by the conversion of 2bromomethyl-2-methylaziridines $37 .{ }^{36}$ Treatment of aziridines $\mathbf{3 7}$ with sodium borohydride is suggested to form a bicyclic intermediate $\mathbf{3 8}$ that undergoes reaction with methanol to form the azetidines $\mathbf{3 9}$ (Scheme 13). The cyclization of aziridines $\mathbf{3 7}$ to the bicyclic intermediate $\mathbf{3 9}$, which is in contrast with the well-known chemistry of 2-(bromomethyl)aziridines $\mathbf{3 7}$ bearing no additional substituent at C-2-position, was interpreted as the Thorpe-Ingold effect due to the gem-disubstitution at the aziridine carbon atom, resulting in a more favorable geometric positioning of the nucleophilic nitrogen atom with respect to the halogenated carbon atom. 
De Kimpe group has extended their work with $\mathbf{N}$-benzylaziridines $\mathbf{4 0}$ towards different anionic nucleophiles such as oxygen, sulfur and carbon. ${ }^{37}$ The solvent had a significant influence on the reaction outcome, enabling the selective formation of either functionalized aziridines in dimethylformamide or azetidines $\mathbf{4 2}$ in acetonitrile (Scheme 13).

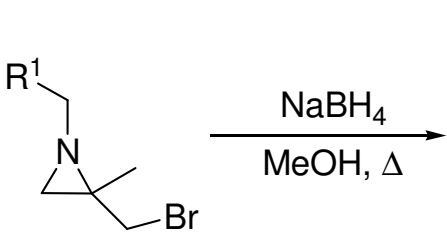

37

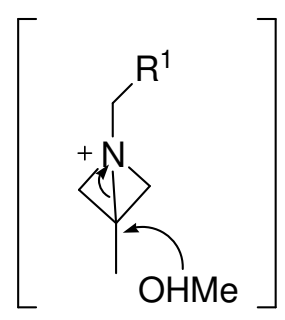

38

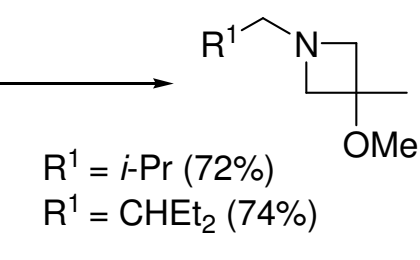

39

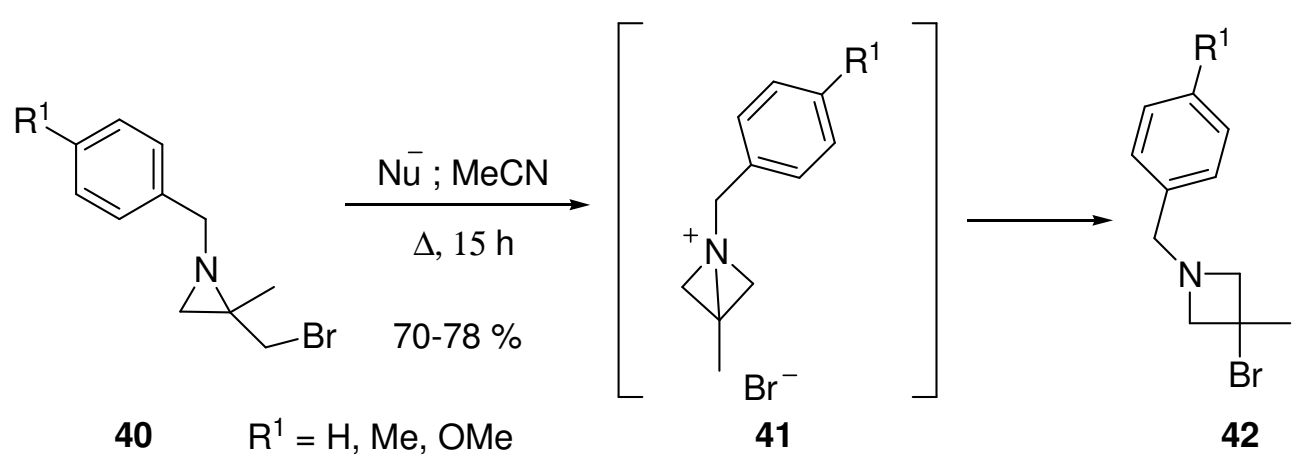

\section{Scheme 13}

A regioselective ring-opening of the cis- $N$-tosyl-2-tosyloxymethyl-3-trifluoromethylaziridines 43 with phenols, followed by rearrangement leads to an easy entry to azetidine ring system (Scheme 14)..$^{38} \mathrm{~A}$ similar treatment of these aziridines with aryl thiols leads to the formation of $\mathrm{N}$-tosyl-2-arylthiomethyl-3trifluoromethylaziridines. The phenolate ion attacks at C-2 position of the aziridine ring leading to cleavage of the $\mathrm{C}-\mathrm{N}$ bond resulting into formation of an intermediate 44. An intramolecular displacement of the tosylate group from intermediate $\mathbf{4 4}$ leads to the formation of cis-azetidines $\mathbf{4 5 .}$

The cleavage of alkyl 2-(bromomethyl)aziridine-2-carboxylates by $\mathrm{HCl}$ is reported to occur by the reaction at sterically more hindered carbon atom (C-2) leading to cleavage of the $\mathrm{C}-\mathrm{N}$ bond. A subsequent basepromoted cyclization of the ring-opened product gives alkyl 3-chloroazetidine-3-carboxylates. ${ }^{39}$ 
<smiles>[3H]N1C[C@](C[O-])(C[OH2+])[C@H]1C(F)(F)F</smiles>

43

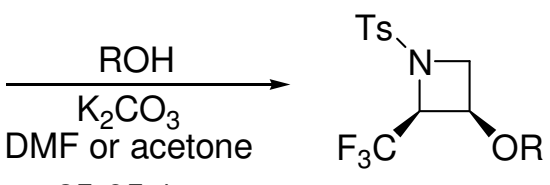

$25-95 \%$

(5 examples)

Phenols: $\mathrm{PhOH}, 2$-naphthol,

4- $\mathrm{F}-\mathrm{C}_{6} \mathrm{H}_{4} \mathrm{OH}, 3-\mathrm{MeC}_{6} \mathrm{H}_{4} \mathrm{OH}$,

4-allyl-2-methylphenol

\section{Scheme 14}

\subsection{Synthesis of $\boldsymbol{\beta}$-lactams}

$\beta$-Lactams are four-membered cyclic amides that constitute the most famous group of antibiotics. Besides being used as antibiotics, ${ }^{40,41}$ they are also used as $\beta$-lactamase inhibitors, ${ }^{42}$ and cholesterol absorption inhibitors. $^{43}$

Fontana and coworkers have reported the palladium-catalyzed carbonylative ring-expansion of vinylaziridines for the synthesis of $\beta$-lactams. ${ }^{44}$ The reaction of 3-aryl-2-vinylaziridines 46 with carbon monoxide in the presence of trisdibenzylideneacetone palladium(III) trichloromethane catalyst and triphenyl phosphite afforded four isomeric $\beta$-lactams $47 \mathrm{a}-\mathbf{d}$ at room temperature (Scheme 15$)$. The trans- $E$ - $\beta$-lactams 47c were the major products. Alkyl substituents on vinyl aziridines did not give any $\beta$-lactam except in the presence of 50 bar of carbon monoxide, where trans-Z- $\beta$-lactams 47a were obtained. However, a full chirality transfer to the trans-E- $\beta$-lactam $47 \mathrm{c}$ could be achieved by using enantioenriched alkyl substituted vinyl aziridine 46. A palladium(0)-mediated isomerization of vinyl aziridines followed by carbonylation and ring closure was proposed as the plausible mechanism for the formation of major product.

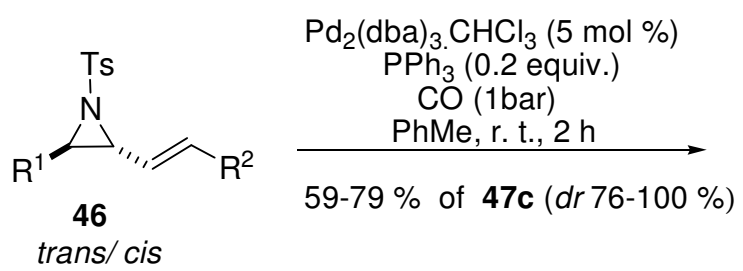

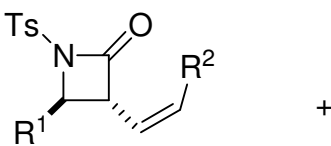

$47 a$

$+$

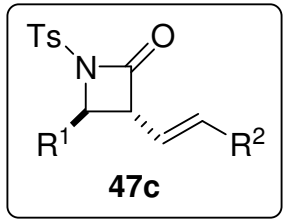

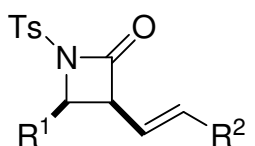

47b

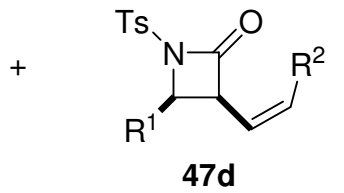

$\mathrm{R}^{1}=\mathrm{Ph}, p$-Me-Ph, $p$-MeO-Ph, $p$-Cl-Ph

$\mathrm{R}^{2}=\mathrm{Ph}, \mathrm{Me}, p-\mathrm{Me}-\mathrm{Ph}, p-\mathrm{MeO}-\mathrm{Ph}, p-\mathrm{Cl}-\mathrm{Ph}$

\section{Scheme 15}

Wulff and coworkers have reported the reactions of 3-alkylaziridine-2-carboxylic acids 48 with oxalyl chloride leading to an exclusive formation of 2-azetidinones 49 (Scheme 16). ${ }^{45}$ The ring-expansion occurs in stereospecific manner with high yields and diastereoselection. The reaction with trans-1-benzyl-3- 
cyclohexylaziridine-2-carboxylic acid yielded exclusively the trans- $\beta$-lactam. The reaction also provided $\beta$ bromo- $\beta$-lactams with oxalyl bromide but some isomerization to trans- $\beta$-lactam was observed.

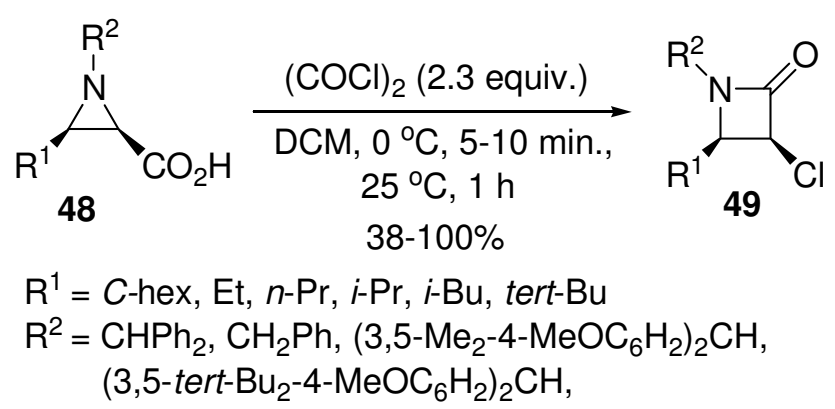

\section{Scheme 16}

A highly diastereoselective synthesis of 3-halogenated-4-trifluoromethyl cis and trans- $\beta$-lactams $\mathbf{5 0}$ is reported from 1-alkyl/aryl-3-(trifluoromethyl)aziridine-2-carboxylic acids 48. The latter compounds are converted into cis and trans- $\beta$-lactams by different halogenating reagents, such as $\mathrm{POCl}_{3}, \mathrm{PCl}_{5}, \mathrm{SOBr}_{2}$, $\mathrm{PPh}_{3} / \mathrm{NBS}, \mathrm{PPh}_{3} \mathrm{Br}_{2}$ (Scheme 17). ${ }^{46}$

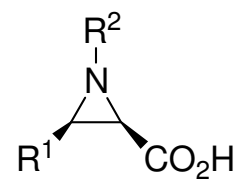

48

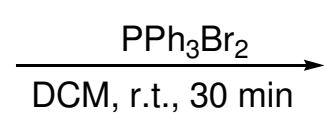

$38-85 \%$

$\mathrm{R}^{1}=\mathrm{CF}_{3}$ $\mathrm{R}^{2}=\mathrm{CH}_{2} \mathrm{Ph}, p-\mathrm{MeO}-\mathrm{CH}_{2} \mathrm{Ph}, \mathrm{Ph}_{2} \mathrm{CH}, p-\mathrm{MeO}-\mathrm{Ph}$

\section{Scheme 17}

\section{Synthesis of Five-membered Heterocycles}

\subsection{Synthesis of pyrroles and indoles}

Pyrroles are well-known structural subunits in natural products and in compounds for industrial purposes. Polypyrroles have applications in material science, non-linear optics and supramolecular chemistry as molecular sensors and devices. ${ }^{47}$ Yoshida and coworkers have reported the synthesis of 3-iodopyrroles by an electrophilic cyclization of $N$-tosyl or $N$-benzyl-substituted propargylic aziridines. ${ }^{48}$ The annulation of $N$-tosylsubstituted substrates required a platinum catalyst while, the $N$-benzyl-substituted aziridines could be annulated through iodine-promoted cycloisomerization. In the case of $N$-tosyl compounds $\mathbf{5 1}$, the aziridine is activated by coordination of platinum with ring-nitrogen and alkynyl group forming complex 52, which promotes the aziridine ring-opening by nucleophilic attack of water on ring-carbon bearing the alkynyl group. The attack of the sulfonamide nitrogen in resulting product 53 on the distant alkyne carbon leads to the formation of a dihydropyrrole $\mathbf{5 4}$ that undergoes aromatization by elimination and subsequent iododemetalation with iodine to form 3-iodopyrroles 55 (Scheme 18). The mechanism for $N$-benzyl substrates suggested by the authors involved the formation of a cyclic iodonium ion $\mathbf{5 7}$ by the coordination of the 
propargylic triple bond to an iodine cation followed by the attack of the aziridine nitrogen producing the cyclized cationic intermediate 58, which then underwent aromatization by elimination of a proton to furnish 3iodopyrroles 59 (Scheme 19). This group has further reported the platinum-catalyzed cascade cyclization/ring expansion of alkynyl-aziridines, spiro-fused to cyclobutane, forming bicyclic pyrroles 61 (Scheme 20). ${ }^{49}$<smiles>[R]C#CC1C([R7])N1[AsH]</smiles>

51<smiles>[R]C1=C([P]Cl)C(O)C([R])N1[As]</smiles>

54

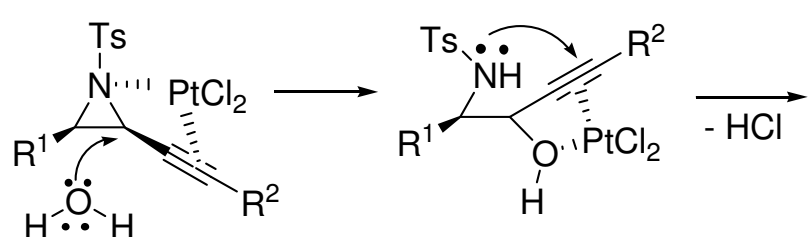

53

\section{Scheme 18}<smiles>[R]C#C[C@@H]1[C@@H]([R17])N1Cc1ccccc1</smiles>

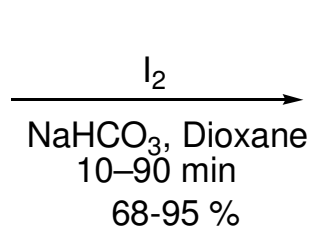<smiles>[R]c1cc(I)c(Br)n1Br</smiles><smiles>[Y5]c1cc(I)c([R])n1[3H]</smiles>

55
57

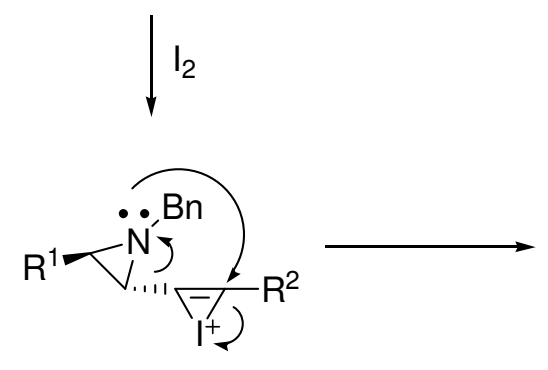

$\mathrm{R}^{1}=C$-hex, $n-\mathrm{Bu}, t-\mathrm{Bu}$, Naphthyl

$\mathrm{R}^{2}=\mathrm{Ph}, \mathrm{CH}_{2} \mathrm{Ph}$, allyl, $-\left(\mathrm{CH}_{2}\right)_{3} \mathrm{OH}$, siloxypropyl, $i-\mathrm{Pr}$

\section{Scheme 19}
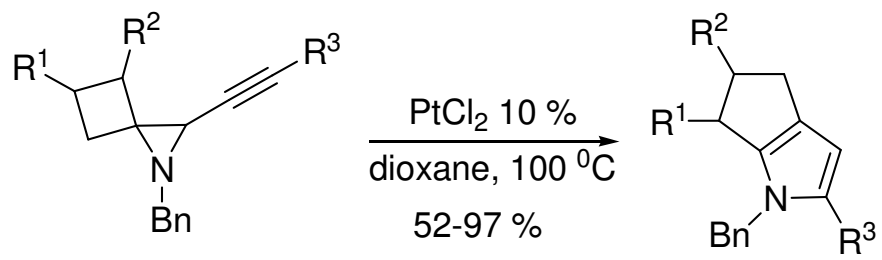

$60 R^{1}=H$, alkyl; $R^{2}=H$, alkyl; $R^{3}=$ alkyl 61 
Wang and coworkers have reported an efficient method for the synthesis of polyfunctionalized pyrroles 67 by a cascade of regioselective ring-opening of $\mathrm{N}-\mathrm{H}$ aziridines 62 followed by [3+2]-cycloaddition with $\beta$ nitroolefins 63 under aerobic conditions (Scheme 21). ${ }^{50}$ The reaction is assumed to proceed through an azomethine ylide, generated by a regioselective $\mathrm{C}-\mathrm{C}$ bond cleavage. A copper-catalyzed regioselective [3+2]annulation of the ylide 64 with nitroalkenes forms pyrrolidines 65 . An elimination of $\mathrm{HNO}_{2}$ from pyrrolidines 65 followed by dehydrogenation of the resulting dihydropyrroles 66 leads to the formation of pyrroles 67 . When the reaction was carried out in an inert atmosphere, a significantly low yield of the product was obtained suggesting the necessity of oxygen for dehydrogenative aromatization step.

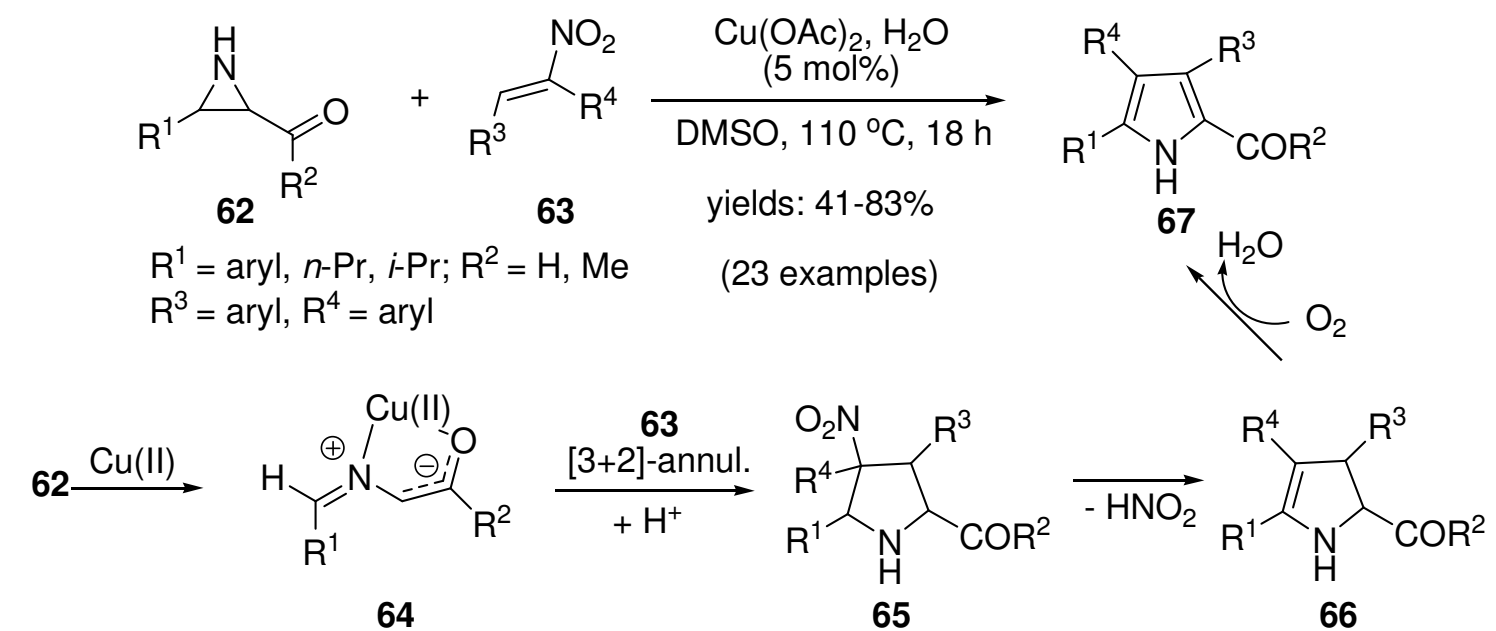

\section{Scheme 21}

Ghorai and coworkers have reported recently a regioselective ring-opening of $\mathrm{N}$-tosyl-substituted 2-(2haloaryl)-3-alkylaziridines 68 with thiophenol, followed by copper-powder-mediated intramolecular cyclization/aromatization to access 2-alkylindoles in good yields (Scheme 22). ${ }^{51}$ The reaction was also extended to 3-(2-chlorophenyl)-1-tosylaziridine-2-carboxylate to get an indole with a carboethoxy group on C2 position. The authors proposed a Lewis acid-catalyzed $S_{N} 2$-type ring-opening with thiophenol as proposed in an earlier study published same year. ${ }^{52}$ The ring-opening product 69 undergoes $\mathrm{C}-\mathrm{N}$ cyclization under influence of copper powder to give product 70. The $\mathrm{Cu}(\mathrm{I})$-mediated generation of radical cation $\mathbf{7 1}$ from product $\mathbf{7 0}$, followed by its desulfonylation gives a cationic intermediate $\mathbf{7 2}$ which undergoes aromatization to give the final product. 


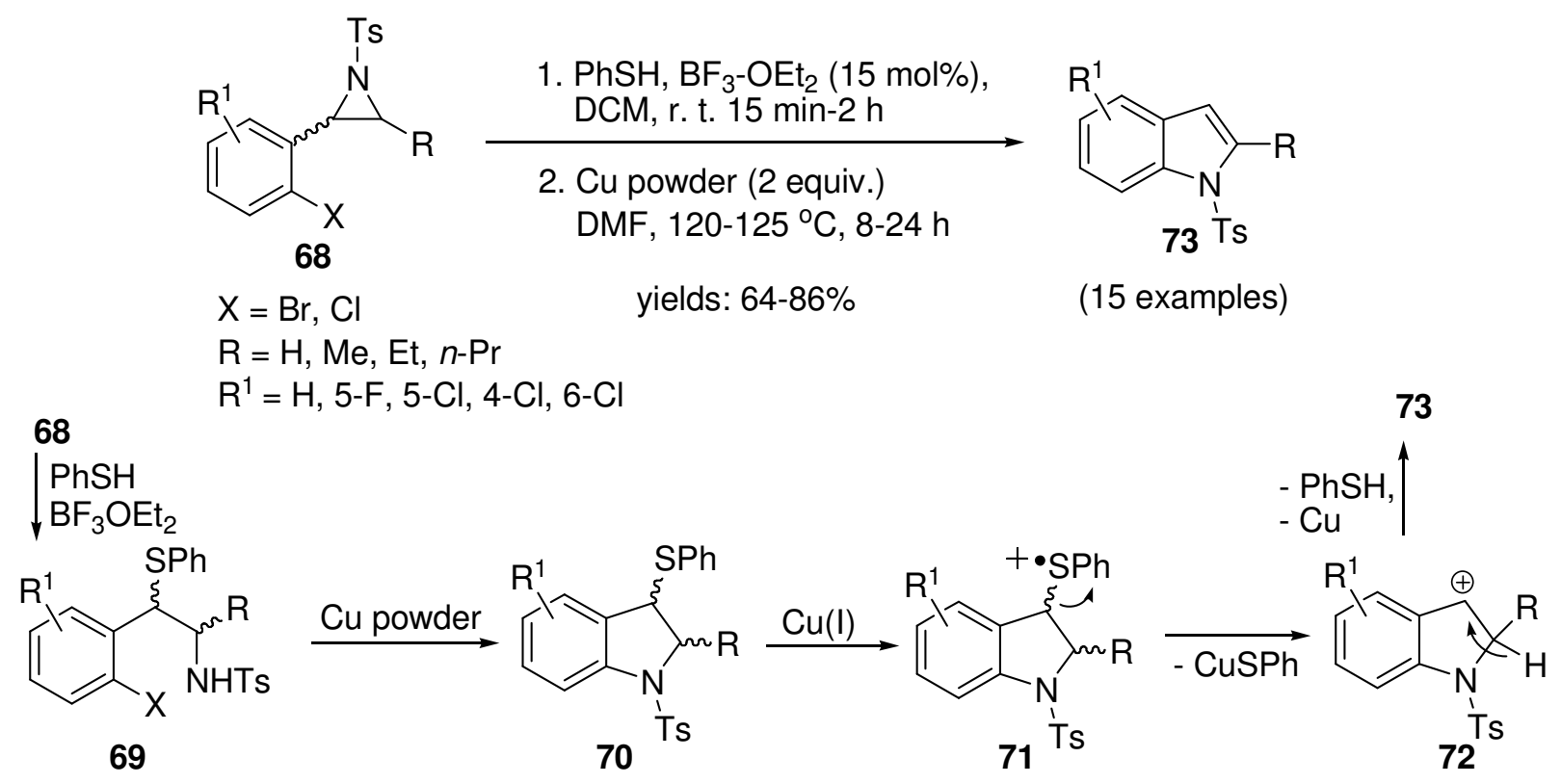

\section{Scheme 22}

\subsection{Synthesis of dihydropyrroles}

The dihydropyrrole structural unit makes up the functional core of some natural products and pharmaceutical agents as well as serves as precursors for many $N$-heterocycles of synthetic and biological interest. ${ }^{53} \mathrm{Gold}^{\mathrm{N}}$ catalysts have been applied in cascade-type reactions for the conversion of various 2-(aryloxyprop-1ynyl)aziridines 74a-h to spiro[isochroman-4,2'-pyrrolines] 75a-h (Scheme 23). ${ }^{54}$ The reaction exploited both the $\sigma$ - and $\pi$-Lewis acid properties of the gold salt for a Friedel-Crafts type intramolecular rearrangement followed by the cyclization of an aminoallene intermediate. In case of more hindered aziridines, however, the cascade reaction stopped at aminoallene intermediate product stage.

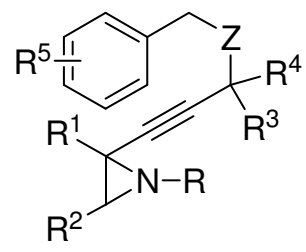

$74 a-h$

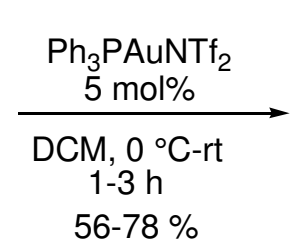

$56-78 \%$<smiles>CC1=CC2(COCc3ccccc32)N(P)C1</smiles>

75c $R=$ Ns, Ts<smiles>CS(=S)(=S)N1COCc2ccccc21</smiles>

75 e<smiles>[Y5]C1(S)OCC(C)=CC12c1ccccc1COC2(C)C</smiles>

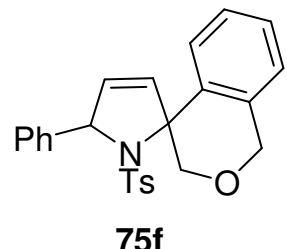<smiles>[Z]CC12C=C(C)C3=CC=CC31CN(C)C2</smiles>

75g Z $=\mathrm{CH}_{2}$, NTs

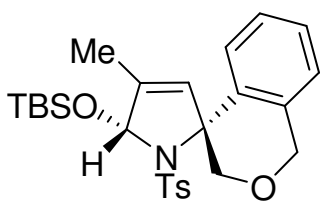

75d<smiles>CC1=CC2(COCc3ccc4ccccc4c32)[NH+]([SH3+])C1</smiles>

$75 \mathrm{~h}$

\section{Scheme 23}


Njardarson and coworkers have reported annulation of several $N$-tosyl- and $N$-phthalimide-protected vinyl aziridines 76 to dihydropyrroles 77 in high yields using $\mathrm{Cu}(\mathrm{hfacac})_{2}$ as a Lewis acid catalyst (Scheme 24). ${ }^{55}$ The formation of the product has been explained through the Lewis acid-catalyzed [1,3]-sigmatropic rearrangement. Later, they applied the same methodology to reveal the stereospecificity of this arrangement. ${ }^{56}$ The mechanistic studies concluded that several key factors impacted the rate of this catalytic reaction. ${ }^{57}$ The reaction was significantly accelerated by using an electron-poor sulfonamide (nosyl instead of tosyl) and modestly accelerated when electron-rich olefins were employed, compared to electron-poor olefins. Moreover, a $\mathrm{M}(\mathrm{hfacac})_{2}$ additive could accelerate the reaction, with $\mathrm{Zn}(\mathrm{hfacac})_{2}$ providing the optimal results.

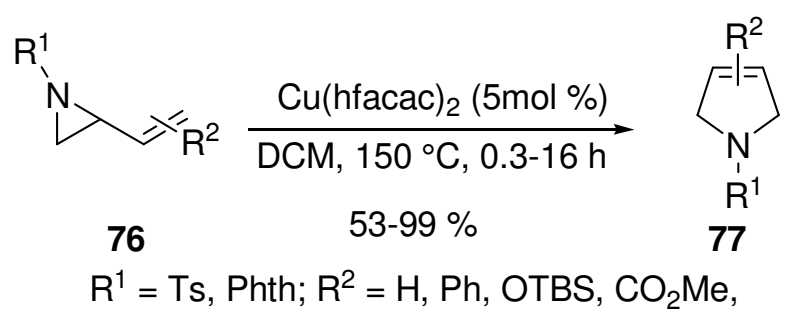

\section{Scheme 24}

The reactions of aziridines with buta-2,3-dienoate are reported to form pyrrolidines and pyrroles by $\mathrm{C}-\mathrm{C}$ bond cleavage and $\mathrm{C}-\mathrm{N}$ bond cleavage of aziridines, respectively, followed by [3+2]-cycloaddition. ${ }^{58,59}$ The preference for cleavage depends on substitution pattern of aziridines, and solvent used. In a recent communication, Laia and Pinho e Melo have reported the thermal reactivity of an alkyne or allene-bearing aziridines, derived from salicylaldehyde. Thermolysis of aziridines results into a pericyclic ring-opening generating azomethine ylides. The latter intermediate undergoes an intramolecular [3+2]-cycloaddition with the allene or alkyne moiety present in it to form the pyrrole derivatives. ${ }^{60}$ The two representative examples of formation of pyrrolidine $\mathbf{7 9}$ and dihydropyrrole $\mathbf{8 1}$ from aziridines $\mathbf{7 8}$ and 80, respectively, are shown in scheme (Scheme 25). According to the report, aziridine-2-carboxylates furnished higher yields in comparison to 2-benzoylaziridines. Also, the carbon-carbon triple bond was observed to be more activated dipolarophile in comparison to allene.

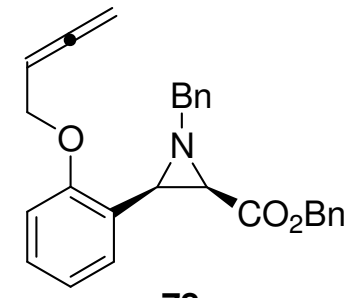

78

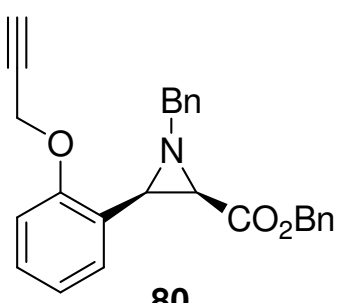

80
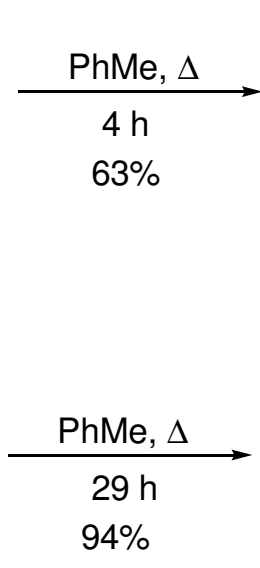<smiles>O=C(OCc1ccccc1)c1cc2c(n1Cc1ccccc1)-c1ccccc1OC2</smiles>

81

\section{Scheme 25}


Activated aziridines $\mathbf{8 2}$ containing sulfonyl, nosyl, and tosyl groups on ring-nitrogen has been reported to undergo a Lewis acid-catalyzed domino ring-opening cyclization reaction with malononitrile at low temperatures to give 4,5-dihydropyrroles 83 in excellent yields (Scheme 26). ${ }^{61}$ The formation of products has been explained by an $\mathrm{S}_{\mathrm{N}}$ 2-type pathway. A malononitrile anion, formed after proton abstraction from malonate by $t$-BuOK, attacked the Lewis acid-activated aziridine intermediate 84 to generate another intermediate $\mathbf{8 5}$, which cyclized to intermediate $\mathbf{8 6}$. Subsequent protonation of intermediate $\mathbf{8 6}$ by aqueous $\mathrm{NH}_{4} \mathrm{Cl}$ gave intermediate $\mathbf{8 7}$ which then tautomerized to dihydropyrrole products 83 (Scheme 27). ${ }^{61}$

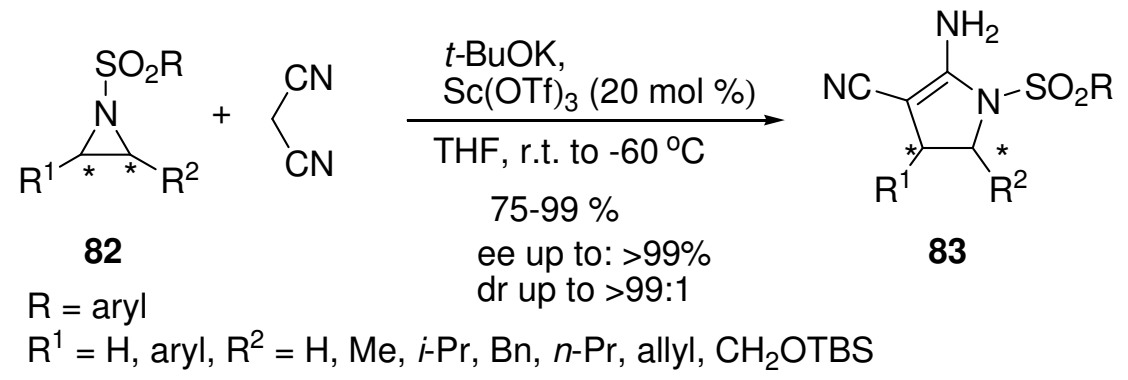

\section{Scheme 26}

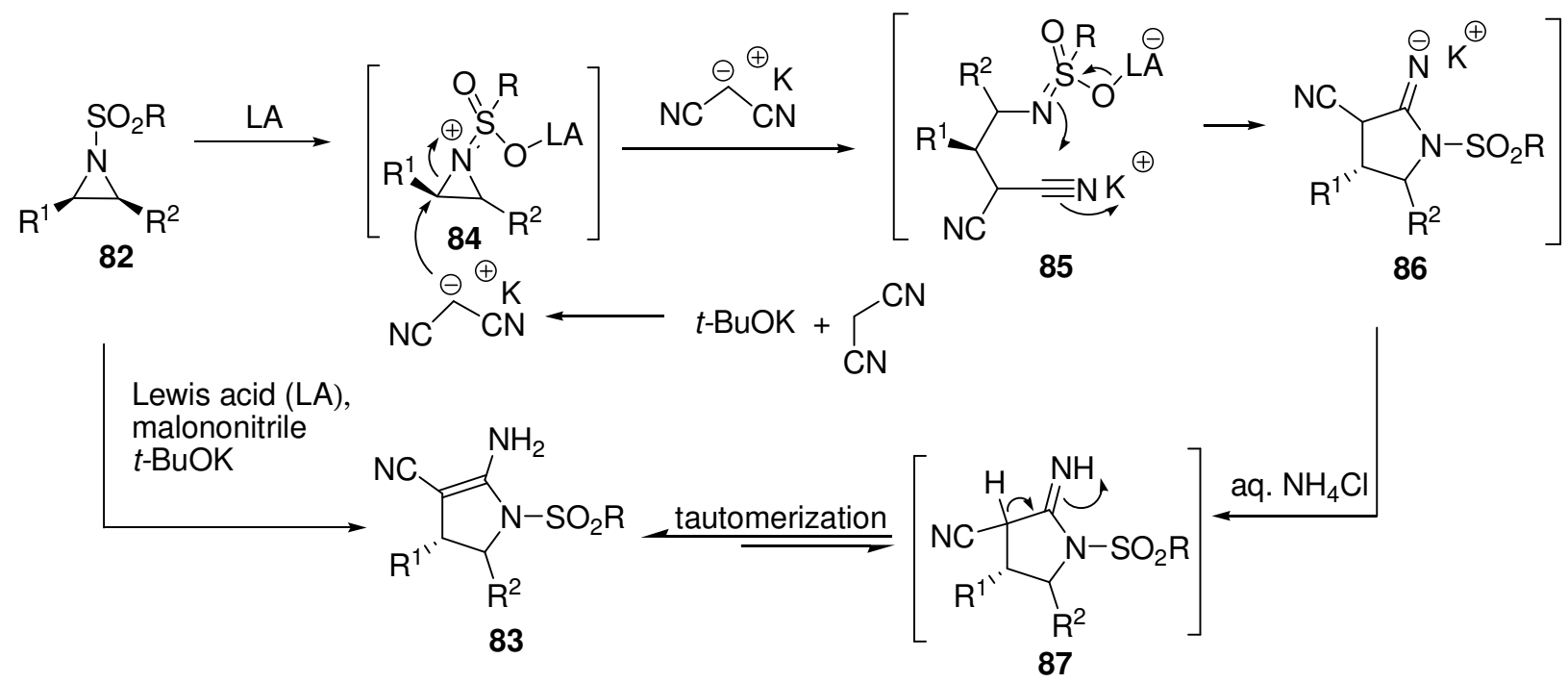

\section{Scheme 27}

\subsection{Synthesis of pyrrolidines}

Pyrrolidine motif occurs in alkaloids from natural resources such as nicotine, epibatidine and hygrine. ${ }^{62}$ They are also found in the leaves of tobacco and carrots. ${ }^{63}$ In addition, pyrrolidines are compounds of medicinal importance. The drugs like procyclidine and bepridil are pyrrolidine derivatives. ${ }^{63}$ L-Proline and its derivatives having pyrrolidine ring are well-known chiral organocatalysts. ${ }^{64}$ Obviously, the construction of pyrrolidine ring is of utmost importance to synthetic and medicinal organic chemists.

Aziridines as masked azomethine ylides are well-known precursors for synthesis of pyrrolidines by [3+2]cycloaddition. Many research groups have reported palladium-catalyzed [3+2]-cycloaddition of aziridines leading to pyrrolidines. Lowe and coworkers have reported the reaction of trans-3-styryl-2-phenyl- $N$ tosylaziridines $\mathbf{8 8}$ with methyl vinyl ketone $(X=M e)$ or with ethyl thioacrylate $(X=S E t) \mathbf{8 9}$ in the presence of a 
palladium catalyst, a phosphine and an additive to give a diastereomeric mixture of pyrrolidines 90 a-d in 60 $66 \%$ yields with excellent enantioselectivity (ee 92-93\%) (Scheme 28). ${ }^{65}$ The reaction was promoted by nonpolar solvents - pentane, diethyl ether or mixtures of diethyl ether/pentane, and sterically hindered phosphines; $(\mathrm{o} \text {-tol })_{3} \mathrm{P},(2-\mathrm{furyl})_{3} \mathrm{P}$ and $(4-\mathrm{F}-\mathrm{Ph})_{3} \mathrm{P}$. The presence of a styryl group on $\mathrm{C}-2$ position of the aziridine furnished excellent diastereoselectivities but moderate yields. Replacing the styryl group with a 4chlorophenyl group or 1-propenyl group lowered both the diastereoselectivity and yield. In addition to lowering the diastereoselectivity, the prop-1-enyl group switched the stereoselectivity to compound 90c as the major diastereomer. The 2-vinyl-3-phenyl-aziridine 88 offered only two diastereomers, 2,3-cis-3,4-transsubstituted pyrrolidine 90c as the major diastereomer and 2,3-cis-3,4-cis-substituted pyrrolidine 90d as the minor one.

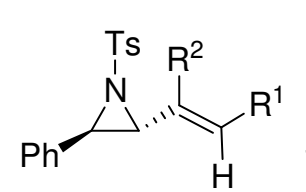

88<smiles>[X]C(=O)C=C</smiles>

89
$\left[\mathrm{Pd}_{2}(\mathrm{dba})_{3} \mathrm{CHCl}_{3}\right](5 \mathrm{~mol} \%)$ Phosphine $n-\mathrm{Bu}_{4} \mathrm{NCl}$ solvent

yields: $60-66 \%$ ee: $92-93 \%$ ee

$\mathrm{R}^{1}=\mathrm{H}, \mathrm{Ph}, p-\mathrm{Cl}-\mathrm{Ph}$

$\mathrm{R}^{2}=\mathrm{H}$, Me; $\mathrm{X}=\mathrm{Me}$, SEt

Solvent $=$ pentane, $\mathrm{Et}_{2} \mathrm{O}, \mathrm{Et}_{2} \mathrm{O} / \mathrm{C}_{5} \mathrm{H}_{12},(\mathrm{o}-\mathrm{tol})_{3} \mathrm{P}$, $(2 \text {-furyl })_{3} \mathrm{P},(4-\mathrm{F}-\mathrm{Ph})_{3} \mathrm{P}$
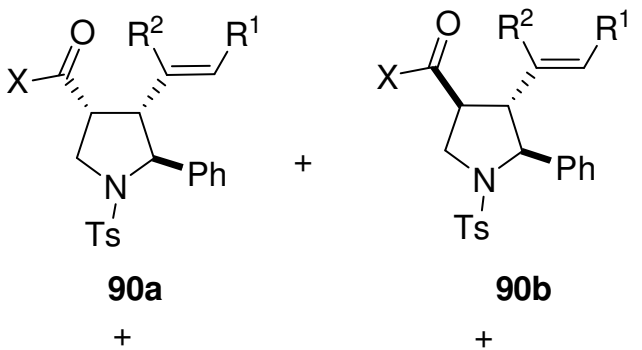

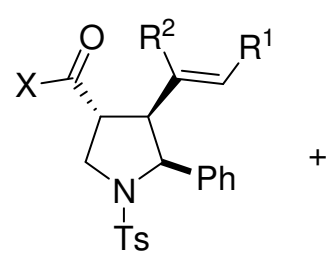

$90 \mathrm{c}$

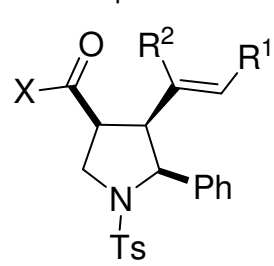

90d

\section{Scheme 28}

The scope of the reaction was extended to trans-2-(trimethylsilyl)vinyl-3-phenyl- $N$-tosylaziridine 91 to get 2,3-cis-3,4-trans substituted pyrrolidine bearing a $Z$ olefin side chain 92 a as the major product. ${ }^{65}$ Aziridine 91 also reacted with ethyl thioacrylate $\mathbf{8 9}$ to give the diastereomer $\mathbf{9 2 a}$ as the major product (Scheme 29).

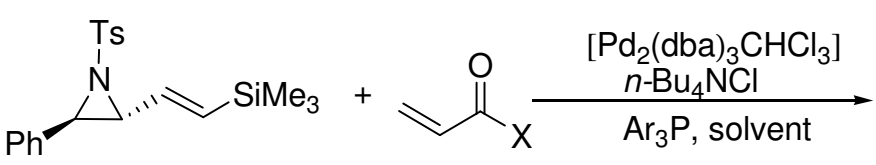

91

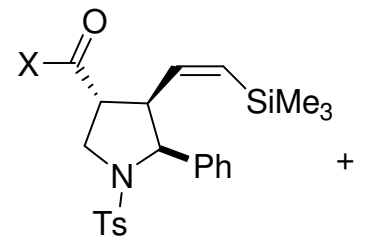

92a

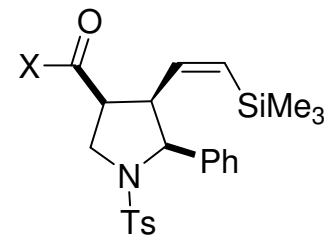

92b

99:1 e.r.

\begin{tabular}{|l|c|l|}
\hline Solvent & $X$ & $\begin{array}{l}\% \text { Yield (92a:92b ee }) \\
\text { major product }\end{array}$ \\
\hline $\begin{array}{l}\text { (2-furyl })_{3} \mathrm{P}, \text { pent/TBME } \\
\text { Me }\end{array}$ & $60 \%(94: 6$ ee $)$ \\
\hline (2-furyl $)_{3} \mathrm{P}, \mathrm{Et}_{2} \mathrm{O}$ & $\mathrm{SEt}$ & $73 \%(20: 80$ ee $)$ \\
\hline
\end{tabular}

\section{Scheme 29}


Aggarwal and coworkers have demonstrated the application of pyrrolidines, synthesized from the reaction of 2-vinylaziridine with Michael acceptors in the total synthesis of (-)- $\alpha$-kainic acid and (+)-allo-kainic acid, pharmacological tools used in neurological disorders. ${ }^{65,66}$ The reaction of vinylaziridine 93 with fumarate 94 furnished trisubstituted pyrrolidine 95 in the presence of $\mathrm{MgI}_{2}$ (Scheme 30). ${ }^{66}$ The latter promoted the $\mathrm{S}_{\mathrm{N}} 2$ type ring-opening and concomitant cyclization with fumarate Michael acceptors forming 2,3,4-trisubstituted pyrrolidine $\mathbf{9 5}$. The auxiliary was then removed by basic hydrolysis to afford acid $\mathbf{9 6}$ that was then converted into a diazoketone by treatment with oxalyl chloride and trimethylsilyldiazomethane. Sonication of this intermediate in the presence of silver benzoate promoted the Arndt-Eistert homologation to furnish the diester. The saponification of the ethyl esters and removal of the tosyl group gave (+)-allo-kainic acid $\mathbf{9 7 .}$ Sengoden and Punniyamurthy, have employed 2-arylaziridines with free $\mathrm{NH}$ - or $\mathrm{N}$-alkyl and $\mathrm{N}$-aryl group in a highly efficient [3+2]-cycloaddition reaction with different heterocumulenes resulting into formation of 2iminopyrrolidines, 2-iminooxazolidines, and 2-iminothiazolidines, etc. in very good yields. ${ }^{67}$ The reaction was catalyzed by an iron catalyst $\left(\mathrm{Fe}\left(\mathrm{NO}_{3}\right)_{2} \cdot 9 \mathrm{H}_{2} \mathrm{O}\right)$ in water as a solvent.

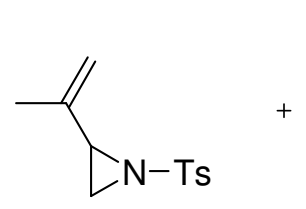

93<smiles>CCOC(=O)/C=C/C(=O)N1C(=O)OCC1Br</smiles>

94
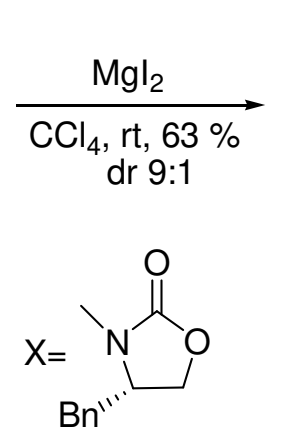

1. $(\mathrm{COCl})_{2}, 70^{\circ} \mathrm{C}, 2 \mathrm{~h}$, then $\mathrm{Me}_{3} \mathrm{SiCHN}_{2}, \mathrm{MeCN}, 0^{\circ} \mathrm{C}, 24 \mathrm{~h}$ $63 \%$

2. $\left.\left.\left.\mathrm{AgOBz}, \mathrm{Et}_{3} \mathrm{~N}, \mathrm{EtOH},\right)\right)\right)$, rt, $30 \mathrm{~min}$ then $\mathrm{NaOH}, \mathrm{THF} / \mathrm{H}_{2} \mathrm{O}$, rt, $2 \mathrm{~h}$ then $\mathrm{Li}, \mathrm{NH}_{3}, \mathrm{THF},-78^{\circ} \mathrm{C}$
$50 \%$<smiles>[X]C(=O)C1C(C(=O)OCC)CN([As])C1C(=O)OCC</smiles>

95

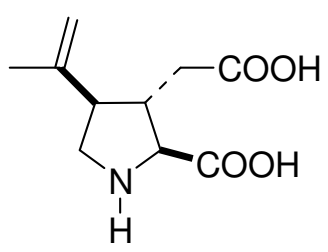

97
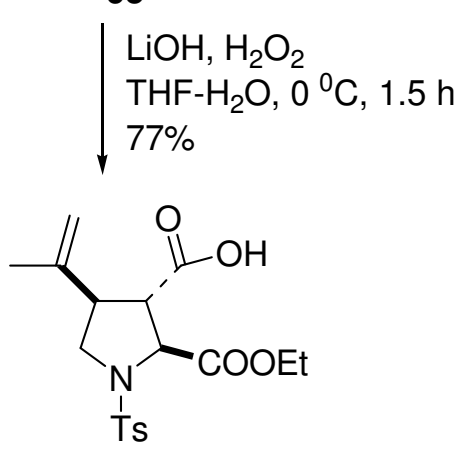

96

\section{Scheme 30}

Lei and coworkers have reported the Lewis acid $\mathrm{Y}(\mathrm{OTf})_{3}$-catalyzed ring-expansion of $N$-tosyl aziridine dicarboxylates 98 with electron-rich olefin 3,4-dihydro-2H-pyran 99 leading to the formation of functionalized pyrrolidines $\mathbf{1 0 0}$ in good yields with moderate to excellent diastereoselectivities (Scheme 31). ${ }^{68}$ The use of commercially available chiral ligand Pybox in the reaction offered moderate enantioselectivity (ee 57-59\%) in the reactions. The selective coordination of the Lewis acid with dicarboxylates of aziridines led to the cleavage of $\mathrm{C}-\mathrm{C}$ bond of aziridines $\mathbf{9 8}$ through intermediate $\mathbf{1 0 1}$ forming metalloazomethine ylides $\mathbf{1 0 2}$. The ylides went into the formal [3+2] dipolar cycloaddition with electron-rich acyclic olefins or 3,4-dihydro-2H-pyran 99 via a stepwise reaction pathway involving intermediate 103 to produce substituted pyrrolidines 100. 


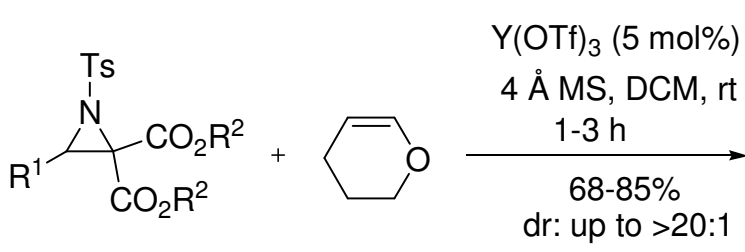

98

99

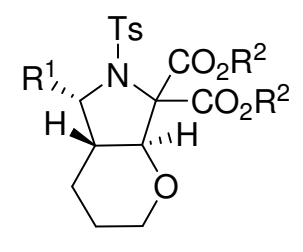

100
$-\mathrm{Y}(\mathrm{OTf})_{3}{ }^{100}$

$\mathrm{R}^{1}=\mathrm{Ph}, p-\mathrm{CIPh}, p-\mathrm{BrPh}, p-\mathrm{NO}_{2} \mathrm{Ph}, p-\mathrm{MePh}$, $p$-i-PrPh, 2-BrPh, 3-MePh, 4-MePh; $\mathrm{R}^{2}=\mathrm{Me}$, Et, $i$-Pr

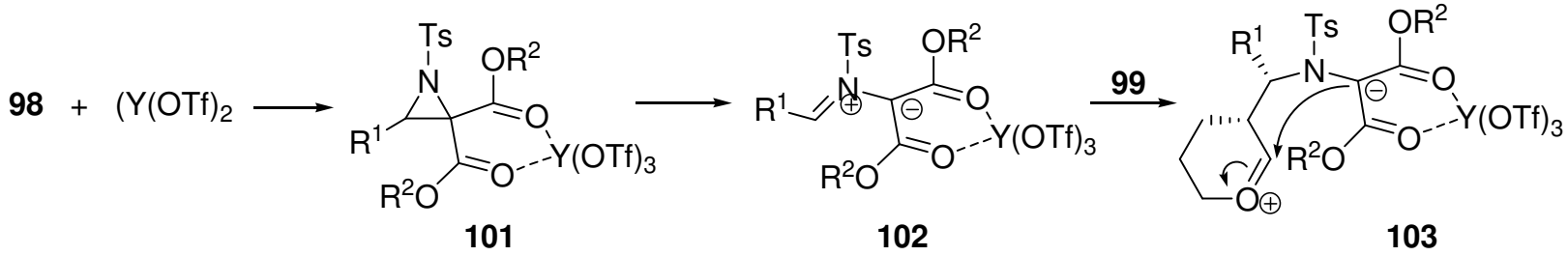

\section{Scheme 31}

Yadav and coworkers have exploited the application of organocatalysts in synthesis and reactions of aziridines. ${ }^{69}$ Rai and Yadav have reported the reaction of enamines 108, generated in situ from the reaction of aldehydes 104 and a pyrrolidine derivative 106, with 2-arylaziridines 105 forming pyrrolidines 107 as a single diastereomer in very good yields (Scheme 32). ${ }^{70}$ The presence of a chiral carbon in aziridines was the main driving force in formation of a single diastereomer. Usually in such aziridines, the nucleophilic attack occurs at benzylic carbon of the ring. The present study, however, revealed the nucleophilic attack at other carbon atom presumably due to bulky nucleophile (steric control). The authors have explained the C-C bond formation step between the $\beta$-carbon of enamine and methylene carbon $\left(\mathrm{CH}_{2}\right)$ of aziridine as the origin of stereoselectivity. This bond-formation took place from the Si-face of the trans-enamine because the Re-face was covered by the bulky ( $\left.\mathrm{Me}_{3} \mathrm{SiO}\right) \mathrm{Ph}_{2}$ group.

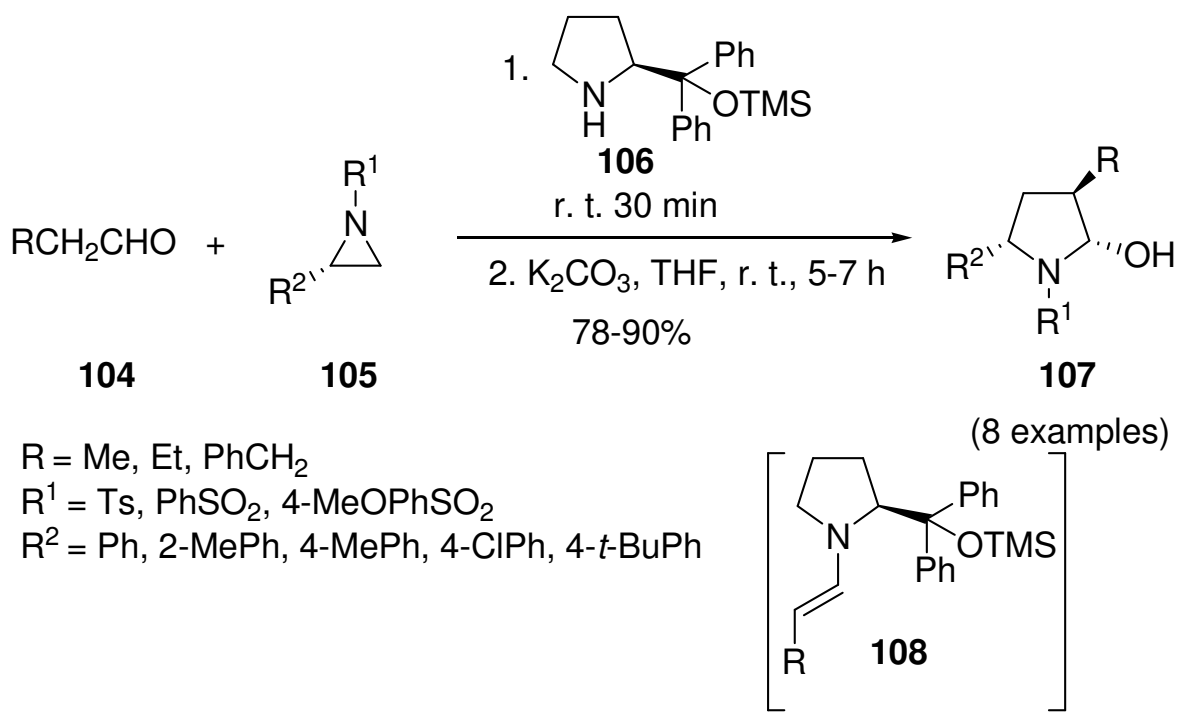

\section{Scheme 32}


More recently, Mal and coworkers have reported a one-pot method for the synthesis of indoline-fused pyrrolidines 112 (Scheme 33) by a domino ring-opening cyclization of activated aziridines 110 with indoles 109 having substituents at $\mathrm{C}-3$ and other positions. ${ }^{71} \mathrm{~A}$ Lewis acid-catalyzed $\mathrm{S}_{\mathrm{N}} 2$-type ring-opening followed by cyclization leads to the formation of hexahydropyrrolo[2,3-b]indoles 109 . The latter compounds, on detosylation, afforded the corresponding products with a free $\mathrm{NH}$ group in excellent yields (up to 95\%) with very high enantioselectivity (up to $>99 \%$ ). According to proposed mechanism, the Lewis acid coordinates to aziridine ring nitrogen, generating a highly reactive intermediate 113. A $\mathrm{S}_{\mathrm{N}} 2$-type nucleophilic attack by indole through its C-3 position on intermediate $\mathbf{1 1 3}$ leads to the formation of an iminium ion $\mathbf{1 1 4}$. The product $\mathbf{1 1 1}$ is then formed by an intramolecular nucleophilic attack by nitrogen on iminium ion.

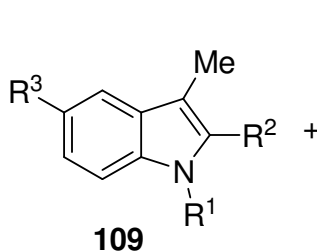

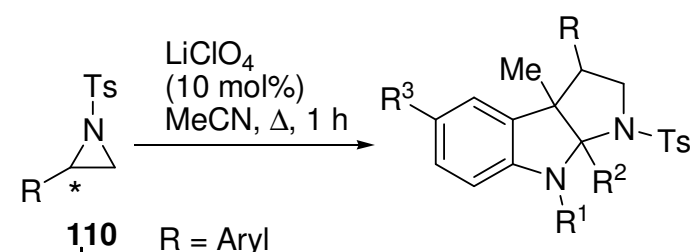

$\downarrow_{\text {LA }}^{110} \mathrm{R}=$ Aryl

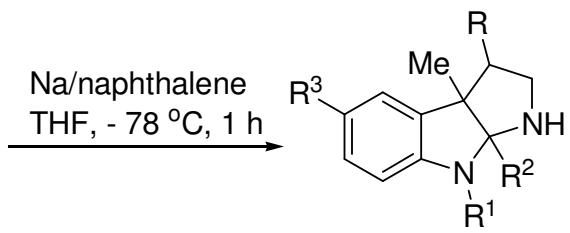

112

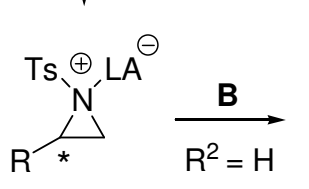

113

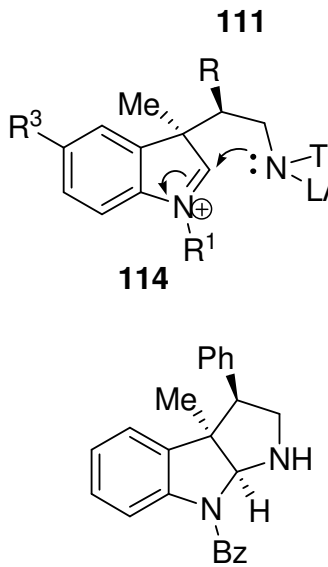

$(R, R, S)-112 \mathrm{c}$ yield: $87 \%$, ee: $99 \%$

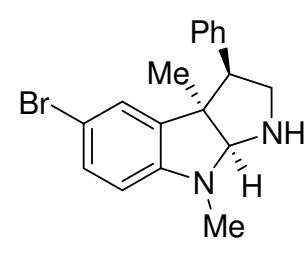

$(R, S, R)-\mathbf{1 1 2 d}$ yield: $89 \%$, ee: $98 \%$

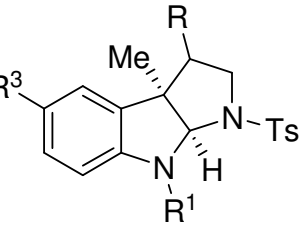

111

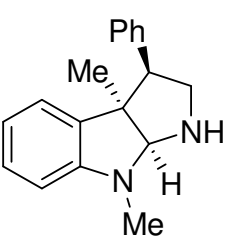

$(R, R, S)-112 a$ yield: $90 \%$, ee: $95 \%$ yield: $90 \%$, ee: $>99 \%$

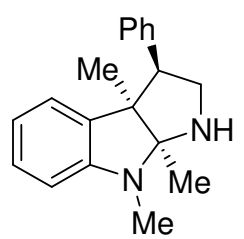

.

\section{Scheme 33}

Hirner and coworkers have demonstrated a palladium(0) and gold(I) Lewis acid dual-catalysis in rearrangement of vinyl aziridines $\mathbf{1 1 5}$ installing a $\mathrm{C}-\mathrm{C}$ bond and $\mathrm{C}-\mathrm{N}$ bond in one step to form pyrrolizidine and indolizidine products 116. ${ }^{72}$ According to proposed mechanism (Scheme 34), the gold complex (Lewis acid) attaches to aziridine nitrogen forming an aziridinium ion 117. The latter undergoes a Lewis acid-promoted oxidative addition by $\mathrm{Pd}(0)$ resulting into formation of a palladium(II) intermediate 118 . A syn aminometalation in intermediate 118 released the Lewis acid and formed a palladacyclic intermediate $\mathbf{1 1 9}$. A reductive elimination from the palladacycle led to the formation of observed product. A gold/palladium transmetalation occurred with complete retention of stereochemistry. A variety of substrates such as adamantyl (86\%), cyclohexyl (56\%), and cyclopentyl (51\%) were tolerated in this reaction. Methyl substitution at the internal position of the tethered alkene also afforded the corresponding indolizidine in $67 \%$ yield. Increasing the olefin tether length in diphenyl vinyl aziridine provided indolizidine in good yield (74\%) with an increased diastereomeric ratio (10:1). However, it was not efficient with gem-dimethyl group, probably due to a reduced rate of cyclization from a diminished Thorpe-Ingold effect. 


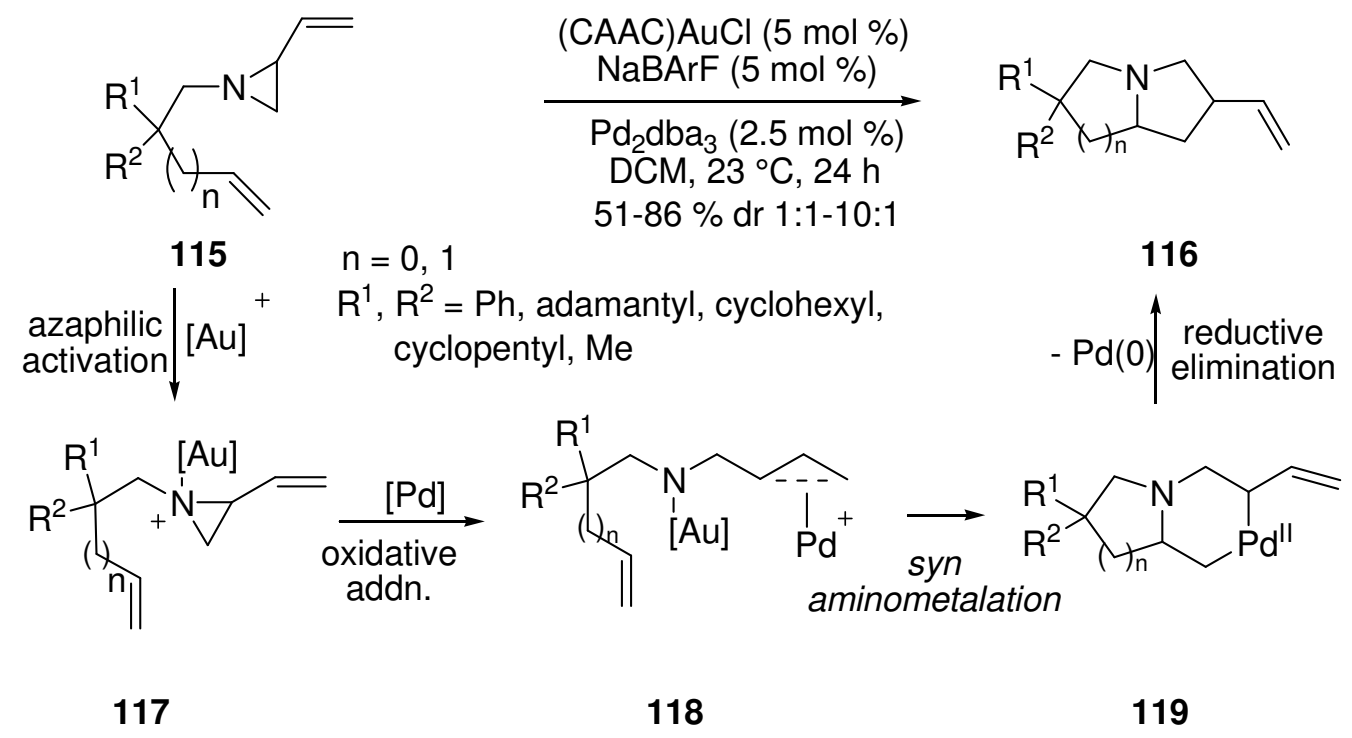

\section{Scheme 34}

Aziridines react with $\pi$-nucleophiles to give both bicyclic and monocyclic compounds under acidic conditions as governed by $N$-substitution. ${ }^{73}$ The $p$-nitrophenylsulfonyl ( $N$-Ns)-protected aziridine 120 gave 6azabicyclo[3.2.1] octane 121 in $95 \%$ yield in the presence of a Lewis acid $B\left(\mathrm{C}_{6} \mathrm{~F}_{5}\right)_{2}($ Scheme 35). The $N$ diphenylphosphinyl (Dpp)-protected aziridine furnished a mixture of aminomethyl-substituted cyclohexenes with Lewis acids; $\mathrm{BF}_{3} \mathrm{OEt}_{2}$ and $\mathrm{B}\left(\mathrm{C}_{6} \mathrm{~F}_{5}\right)_{2}$, respectively. The formation of product was explained via an initial attack of the Lewis acid on the olefinic linkage of the aziridine $\mathbf{1 2 0}$ leading to a carbocationic intermediate 122 that cyclized by nucleophilic attack of nitrogen on the carbocation. Azabicyclooctanes are found in natural products and pharmacologically active molecules. ${ }^{74}$ They are useful as antitumor agents. ${ }^{75}$ Azabicyclooctane based antagonists have been shown to decrease viability of breast cancer cells without affecting normal mammary epithelial cells as well as inhibiting tumor growth in a breast cancer xenograft model. ${ }^{75}$

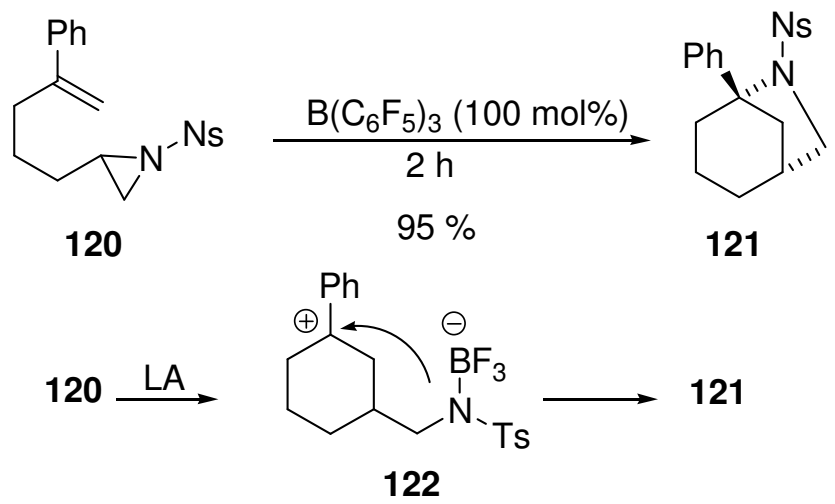

\section{Scheme 35}

A novel $\mathrm{N}$-bromosuccinimide-induced aminocyclization-aziridine ring-expansion cascade leading to the formation of functionalized pyrrolidines $124 \mathrm{a}$ as the major products is reported. ${ }^{76}$ The mechanism proposed by the authors involved addition of bromine on $\mathrm{C}=\mathrm{C}$ of aziridines $\mathbf{1 2 3}$ by the $\mathrm{NBS} / \mathrm{NsNH}_{2}$ protocol to produce an intermediate 125a. A subsequent reaction of aziridine in 125a with the bromonium ion led to the generation of another intermediate 125b, which then transformed to either pyrrolidines 124a or piperidines 124b 
depending on the $\mathrm{NsNH}_{2}$ attack on $\mathrm{C}-5$ or $\mathrm{C}-4$, respectively (Scheme 36). The substrates with electron-rich substituents afforded better regioselectivity. The best selectivity was observed in substrate bearing a tertbutylphenyl group. Compared to other substrates, ortho- $\mathrm{CH}_{3}$ phenyl system gave slightly lower yield. This was attributed to the steric repulsion.

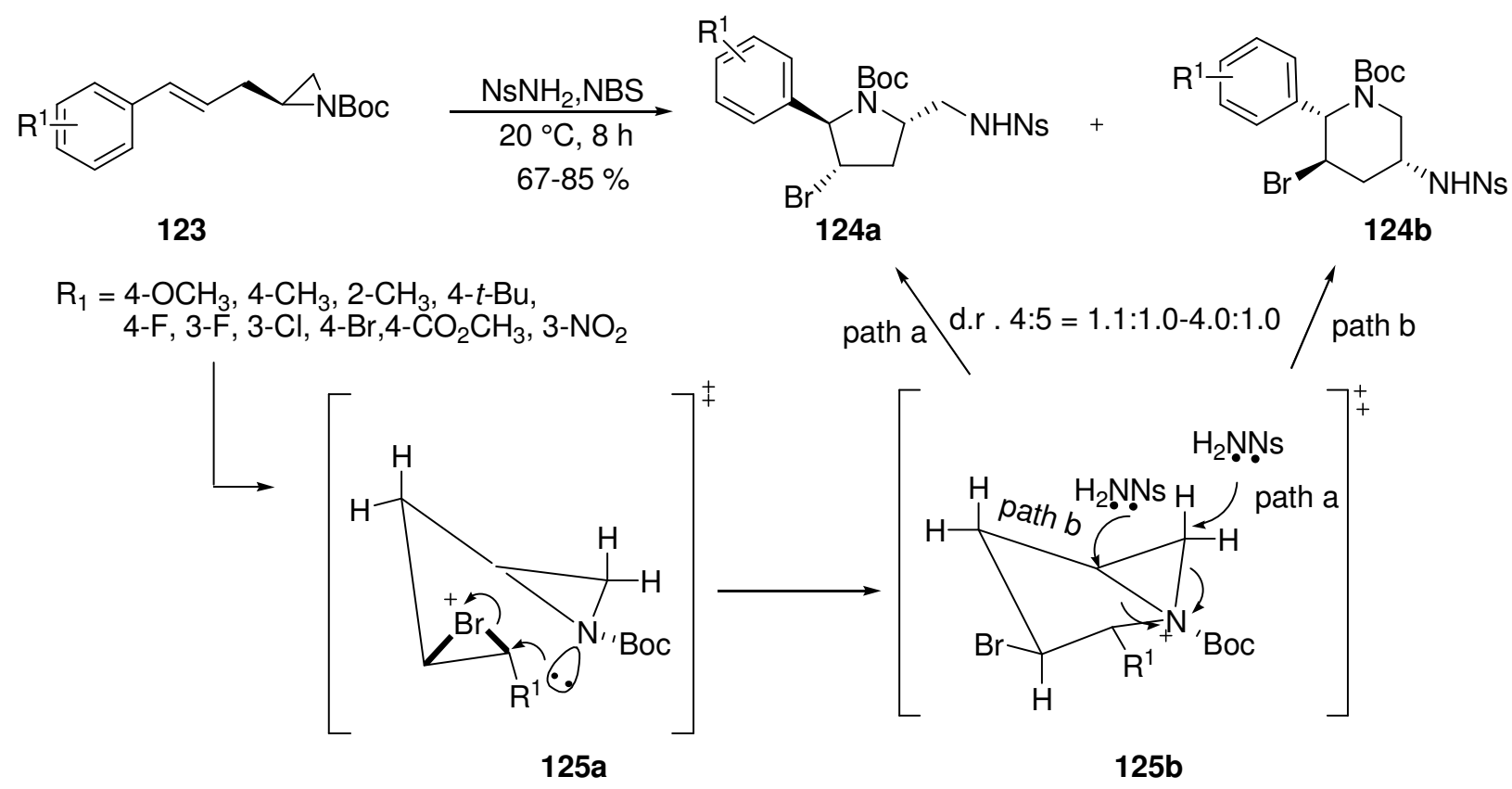

\section{Scheme 36}

Martinand-Lurin and coworkers have reported the Lewis acid-catalyzed ring-opening and cycloaddition of $\mathrm{N}$-sulfonylaziridines with methylenecycloalkanes such as methylenecyclobutane, methylenecyclopentane, and methylenecyclohexane to achieve the synthesis of spiro-fused pyrrolidine ring. For example, the reaction of $N$ arylsulfonylaziridines 126 with methylenecyclopentane 127 afforded pyrrolidines 128 (Scheme 37). ${ }^{31}$ The study revealed that the substituent on nitrogen had little influence on [3+2] cycloaddition reaction that was rationalized by theoretical studies. The DFT calculations revealed that the formation of 1,3-zwitterionic species was probably the rate-determining step.

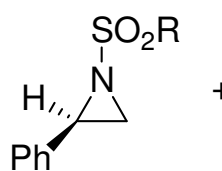

126<smiles>C=C1CCCC1</smiles>

127

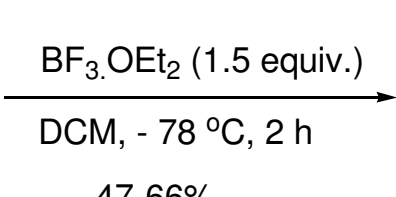

$47-66 \%$<smiles>O=S(=O)(O)N1CC(c2ccccc2)CC12CCCC2</smiles>

128

$$
\begin{aligned}
\mathrm{R}= & 4-\mathrm{MePh}, \mathrm{Ph}, 4-\mathrm{O}_{2} \mathrm{NPh}, \\
& 4-\mathrm{MeOPh}, \mathrm{OCH}_{2} \mathrm{CCl}_{3}, \\
& \mathrm{OCH}(\mathrm{Ph}) \mathrm{CCl}_{3}
\end{aligned}
$$

(6 examples)

\section{Scheme 37}

Dolfen and coworkers have reported synthesis of functionalized 2-(trifluoromethyl)pyrrolidines, from 1tosyl-2-(trifluoromethyl)aziridine 5 . $^{13}$ Error! Bookmark not defined. They have extended this study to the synthesis of 
piperidine and azepane as well. Deprotonation and subsequent alkylation of 1-tosyl-2(trifluoromethyl)aziridine 5 afforded the aziridines 129, which upon treatment with nucleophiles, triggered rearrangements of aziridines toward pyrrolidines 130 and piperidines 131 (Scheme 38). In this case, the $\mathrm{Cl}^{-}$ serves as a requisite leaving group for the ring-expansion process.

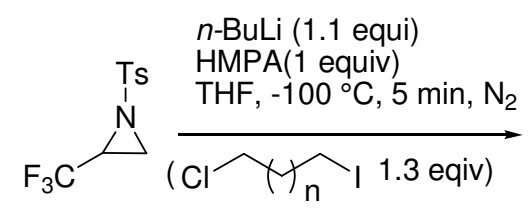

THF, $-100^{\circ} \mathrm{C}, 1 \mathrm{~h} \rightarrow 40^{\circ} \mathrm{C}, 3 \mathrm{~h}, \mathrm{~N}_{2}$

5

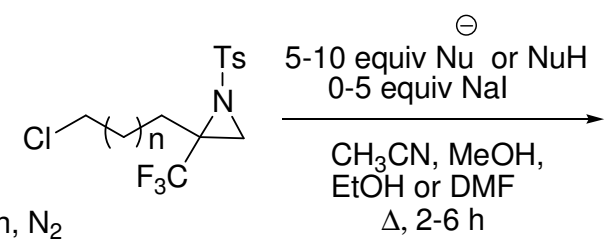

129

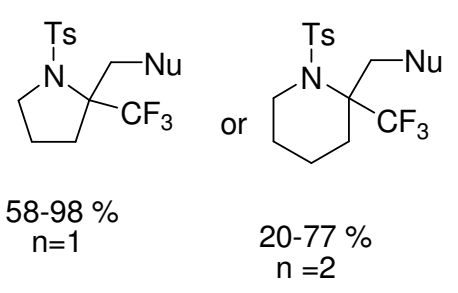

130

131

$\mathrm{Nu}=\mathrm{Cl}, i-\mathrm{PrNH}, i-\mathrm{BuNH}, \mathrm{CN}, \mathrm{SCN}, \mathrm{OMe}, \mathrm{OEt}$

\section{Scheme 38}

The mechanism proposed by the authors involved the ring cleavage of aziridines $\mathbf{1 2 9}$ under the action of the nucleophile to form the corresponding anions 132, followed by either direct ring-closure or protonation to amines 133 (in protic solvents) followed by ring-closure, thus affording pyrrolidines 130 or piperidines 131 (Scheme 39). Ring rearrangements towards piperidines occurred in the presence of a higher boiling solvent dimethylformamide. Treatment of aziridine $129(n=2)$ with equimolar amounts of $i-\mathrm{PrNH}_{2}$ and $\mathrm{Nal}$ afforded piperidines (see Section 5.1) while the treatment of $129(n=3)$ with 5 equiv of $i-\mathrm{PrNH}_{2}$ or $i$-BuNH $\mathrm{Bn}_{2}$ and $\mathrm{Nal}(1$ equiv) in acetonitrile afforded the 1-isoalkyl-3-tosylamino-3-(trifluoromethyl)azepanes (see Section 6.1) instead of piperidines. Addition of an equimolar amount of Nal appeared to be necessary to induce ringclosure in these cases.

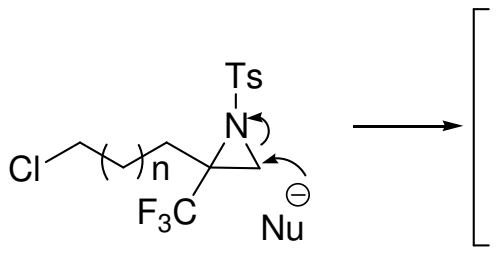

129

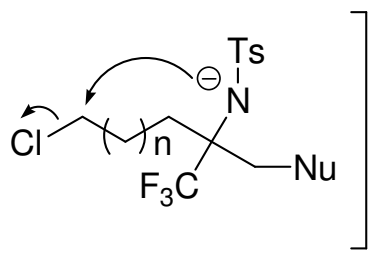

132

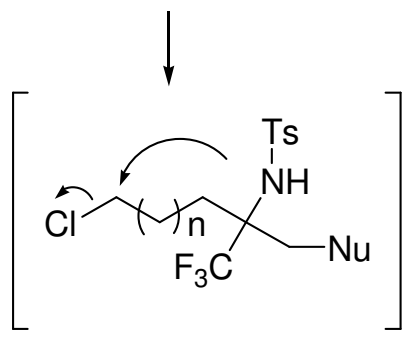

133

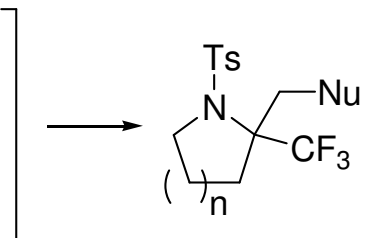

130: $\mathrm{n}=1$ 131: $n=2$

\section{Scheme 39}

Dolfen and coworkers have reported the Lewis acid-mediated regio- and stereoselective ring-opening of different 2-(2-cyanoethyl)aziridines 134 to pyrrolidines 137 either directly or via other aziridines 135 and 136 obtained by alkylation of side-chain in aziridines and 135, respectively (Scheme 40). ${ }^{77}$ The pyrrolidines were 
obtained through a ring-opening of the aziridine moiety at the more hindered carbon atom of intermediate 139 (Route a, Scheme 41), while 3-aryl-3-(2-cyanoethyl)aziridines 138 furnished 3-aminopiperidines 140 (see section 5.1) through a regioselective ring-opening at the benzylic position of the same intermediate due to the resonance stabilization of the developing benzylic carbenium ion at the C-3 position (route b, Scheme 42). The regioselectivity of ring opening process, according to the routes a and $b$, could be controlled by the selection of the substituents on the aziridine core.
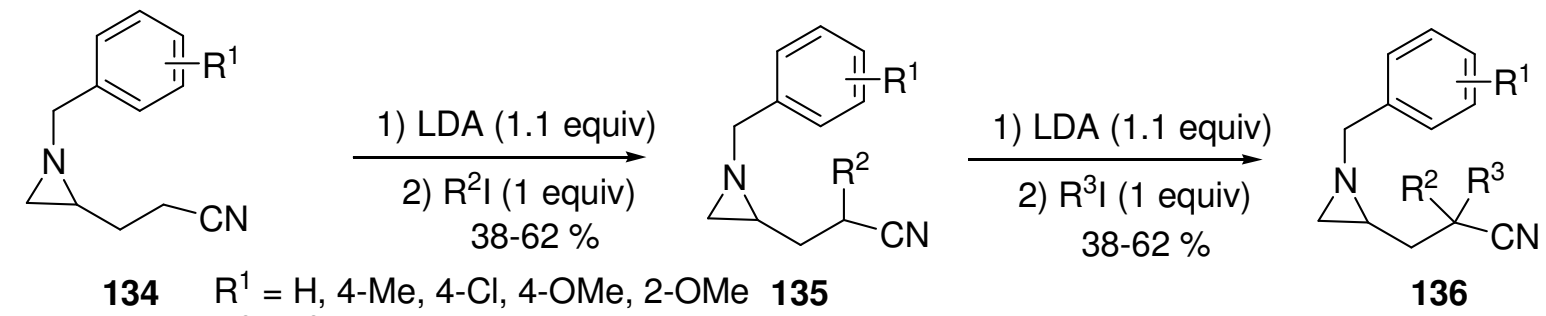

$134 \begin{aligned} & R^{1}=H, 4-M e, 4 \\ & R^{2}, R^{3}=M e, E t\end{aligned}$
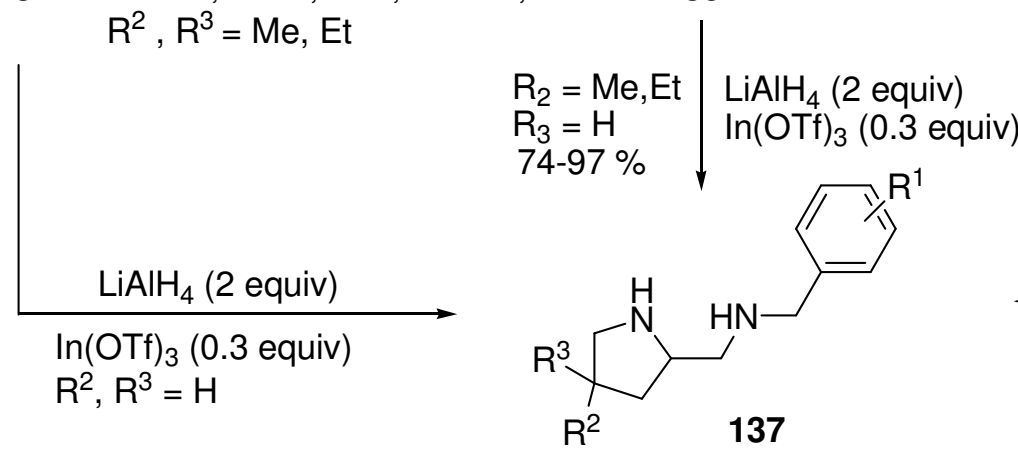

$\frac{\mathrm{LiAlH}_{4}(2 \text { equiv })}{\ln (\mathrm{OTf})_{3}(0.3 \text { equiv })}$

$\mathrm{R}_{2}, \mathrm{R}_{3}=\mathrm{Me}, \mathrm{Et}$

\section{Scheme 40}
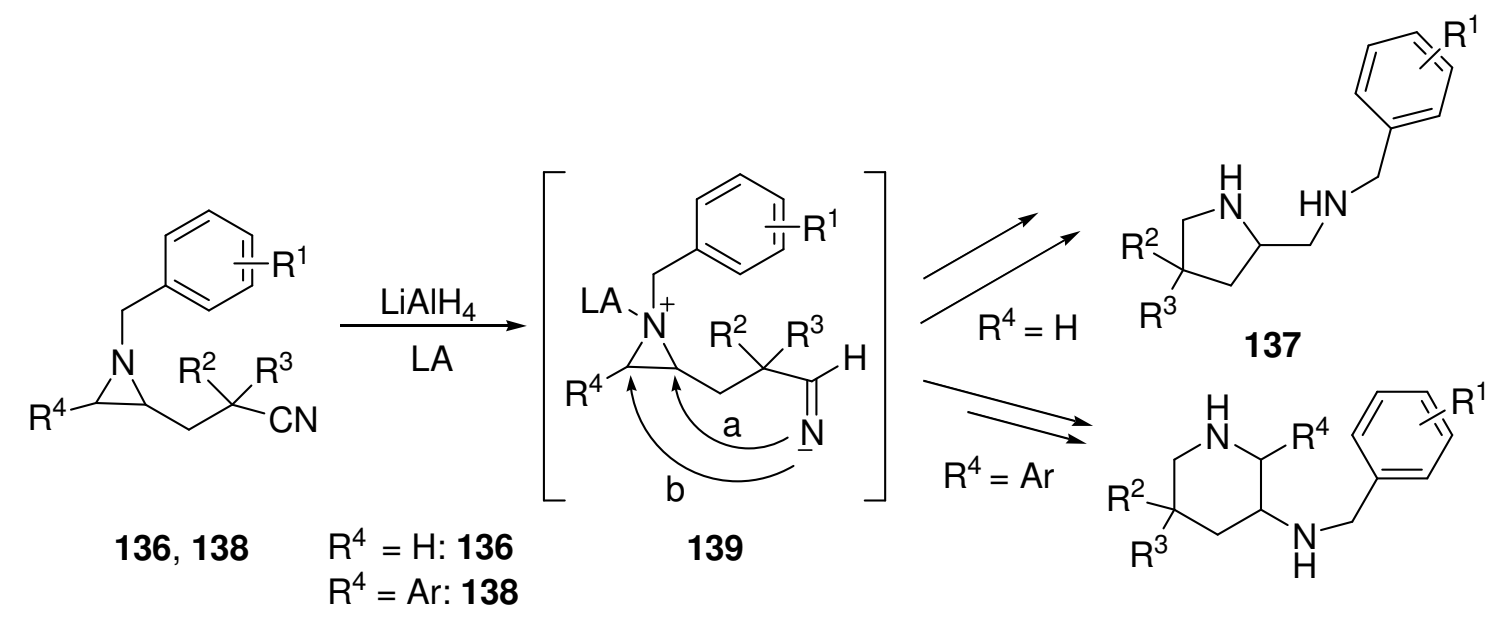

140

\section{Scheme 41}

\subsection{Synthesis of 2-pyrrolidinones}

The 2-pyrrolidinones or $\gamma$-lactam ring occurs in many secondary metabolites and is pharmacophore in many biologically important natural and synthetic compounds. ${ }^{78}$ It has also been used as a building block for the synthesis of naturally occurring compounds. Lee and coworkers have reported the synthesis of (-)-8-episwainsonine $\mathbf{1 4 4}$ that is an indolizidine derivative from a commercially available $1-(R)$ - $\alpha$-methylbenzylaziridine2-methanol 141. ${ }^{79}$ Aziridine-diol 142, obtained from the aziridine 141 in three steps, undergoes a 
regioselective ring-opening under influence of acetic acid in dichloromethane at room temperature. Heating the crude product mixture in toluene led to the formation of pyrrolidinone $\mathbf{1 4 3}$ (Scheme 42) bearing adjacent hydroxyl groups in cis-configuration. This compound was used for synthesizing (-)-8-epi-swainsonine 144 in a number of steps.

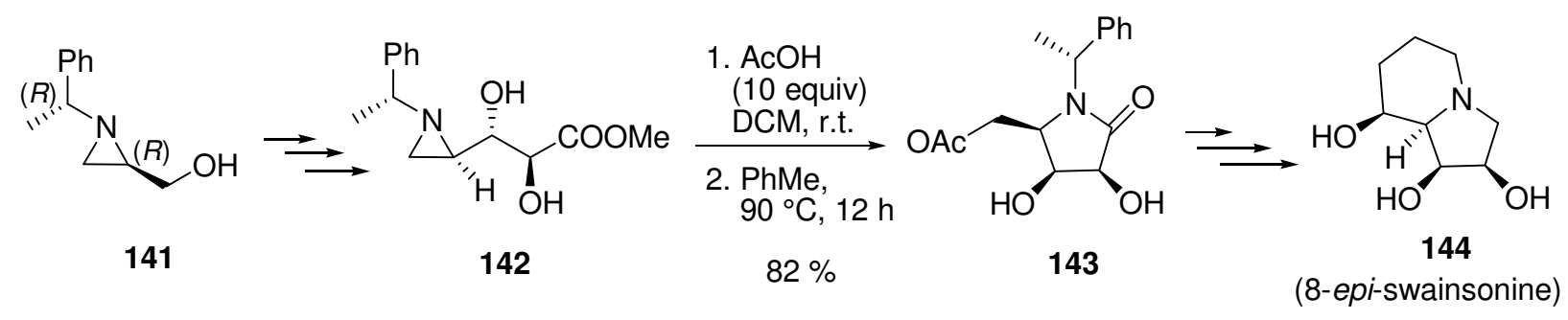

\section{Scheme 42}

The approaches for synthesis of $\gamma$-lactams using transition metals as catalysts in various reactions have made considerable progress in recent years. ${ }^{80}$ Ghorai and Tiwari have reported the synthesis of $\gamma$-lactams from $N$-tosyl, $N$-sulfonyl and $N$-nosylaziridines by transition metal catalysis (Scheme 43 ). ${ }^{81}$ The mono- and disubstituted aziridines 17 undergo an $\mathrm{S}_{\mathrm{N}}$ 2-type ring-opening under an influence of the Lewis acid in a highly enantio- and diastereoselective manner that is followed by cyclization with active methylene compounds $\mathbf{1 4 5}$ in domino fashion to afford the functionalized chiral $\gamma$-lactams $\mathbf{1 4 6}$ in good yields. It was observed that the electronic effect of the phenyl ring on $\mathrm{N}$-tosyl-2-phenylaziridine $\mathbf{1 7}$ had a vital role in determining the regioand diastereoselectivity. The authors have demonstrated the synthetic utility of such compounds by synthesizing pyrrolidinone-3-carboxylate 147 and $N$-tosylpyrrolidinone derivatives 149 by desulfonation and decarboxylation, respectively, of a pyrrolidinone 148 (Scheme 44).

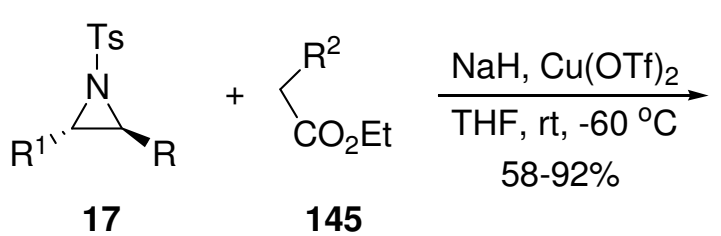

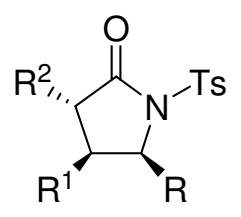

146

a. $\mathrm{R}=\mathrm{Et}, \mathrm{R}^{1}=\mathrm{Ph}, \mathrm{R}^{2}=\mathrm{CO}_{2} \mathrm{Et}$; b. $\mathrm{R}=n-\mathrm{Pr}, \mathrm{R}^{1}=\mathrm{Ph}, \mathrm{R}^{2}=\mathrm{CO}_{2} \mathrm{Et}$;

c. $R=$ vinyl, $R^{1}=P h, R^{2}=C_{2} E t ; d . R=$ allyl, $R^{1}=P h, R^{2}=\mathrm{CO}_{2} E t ;$

e. $R=E t, R^{1}=P h, R^{2}=C O M e$

\section{Scheme 43}

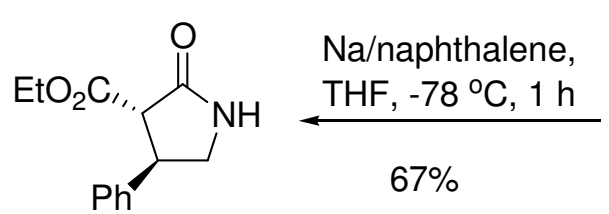

147

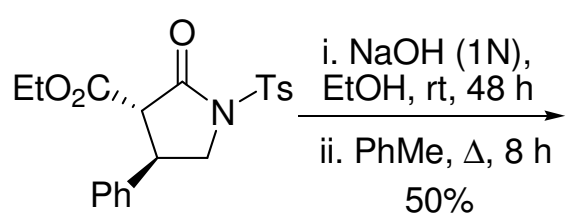

148<smiles>O=C1C[C@H](P)CN1[TeH]</smiles>

149

\section{Scheme 44}

A pyrrolidine-catalyzed [3+2] cycloaddition of substituted aziridines $\mathbf{1 5 0}$ with isocyanates, isoselenocyanates and carbon disulfide forming five-membered heterocycles $\mathbf{1 5 1}$ including pyrrolidinones is 
reported by Sengoden and coworkers (Scheme 45). ${ }^{82}$ This reaction goes through a urea-type intermediate $\mathbf{1 5 2}$, which on reaction with aziridine through an $\mathrm{S}_{\mathrm{N}} 2$ reaction afforded product 153. The intramolecular cyclization of the product 153 provided heterocycles 151 (Scheme 46). The same group also reported similar reactions of aziridines with heterocumulenes on water using iron(III) catalysis. ${ }^{83}$<smiles>[Y]C=[V][CH]</smiles>

a. $\mathrm{X}=\mathrm{NR}^{1}, \mathrm{Y}=\mathrm{S} ; \mathrm{R}^{2}=\mathrm{H}, \mathrm{R}^{3}=i-\mathrm{Pr} . \mathrm{R}^{1}=2-\mathrm{MeO}$, 3-F-Ph, 4-Et-Ph, $p-\mathrm{MeO}-\mathrm{Ph}$, 4-Me- $\mathrm{Ph}, 4-\mathrm{NO}_{2}, 2,4-\mathrm{Me}_{2}-\mathrm{Ph}, 3,4-\mathrm{Me}_{2}-\mathrm{Ph}, 3,5-\mathrm{Me}_{2}-\mathrm{Ph} \alpha$-methylbenzyl, 1-naphthyl

b. $\mathrm{X}=\mathrm{NR}^{1}, \mathrm{R}^{1}=$ 2-MeO-Ph, $\mathrm{Y}=\mathrm{S}, \mathrm{R}^{2}=\mathrm{H}, \mathrm{Br}, \mathrm{F}, \mathrm{MeO}, \mathrm{Me}, 2,4-\mathrm{Me}_{2}, \mathrm{R}^{3}=$ Allyl, $\mathrm{Bn}, n-\mathrm{Bu}$, $C$-hex, Tosyl, $i-\operatorname{Pr}$

c. $\mathrm{X}=\mathrm{NPh}, \mathrm{N}(2-\mathrm{MeO}-\mathrm{Ph}), \mathrm{N}(3-\mathrm{Me}-\mathrm{Ph}), \mathrm{N}(4-\mathrm{Cl}-\mathrm{Ph}), \mathrm{N}(p-\mathrm{MeO}-\mathrm{Ph}) \mathrm{Y}=\mathrm{Se}, \mathrm{R}^{2}=\mathrm{H} \cdot \mathrm{R}^{3}=i-\mathrm{Pr}$

d. $\mathrm{X}=\mathrm{S}, \mathrm{Y}=\mathrm{S}, \mathrm{R}^{2}=\mathrm{Br}, \mathrm{MeO}, \mathrm{Me}, \mathrm{R}^{3}=i-\mathrm{Pr}$

\section{Scheme 45}

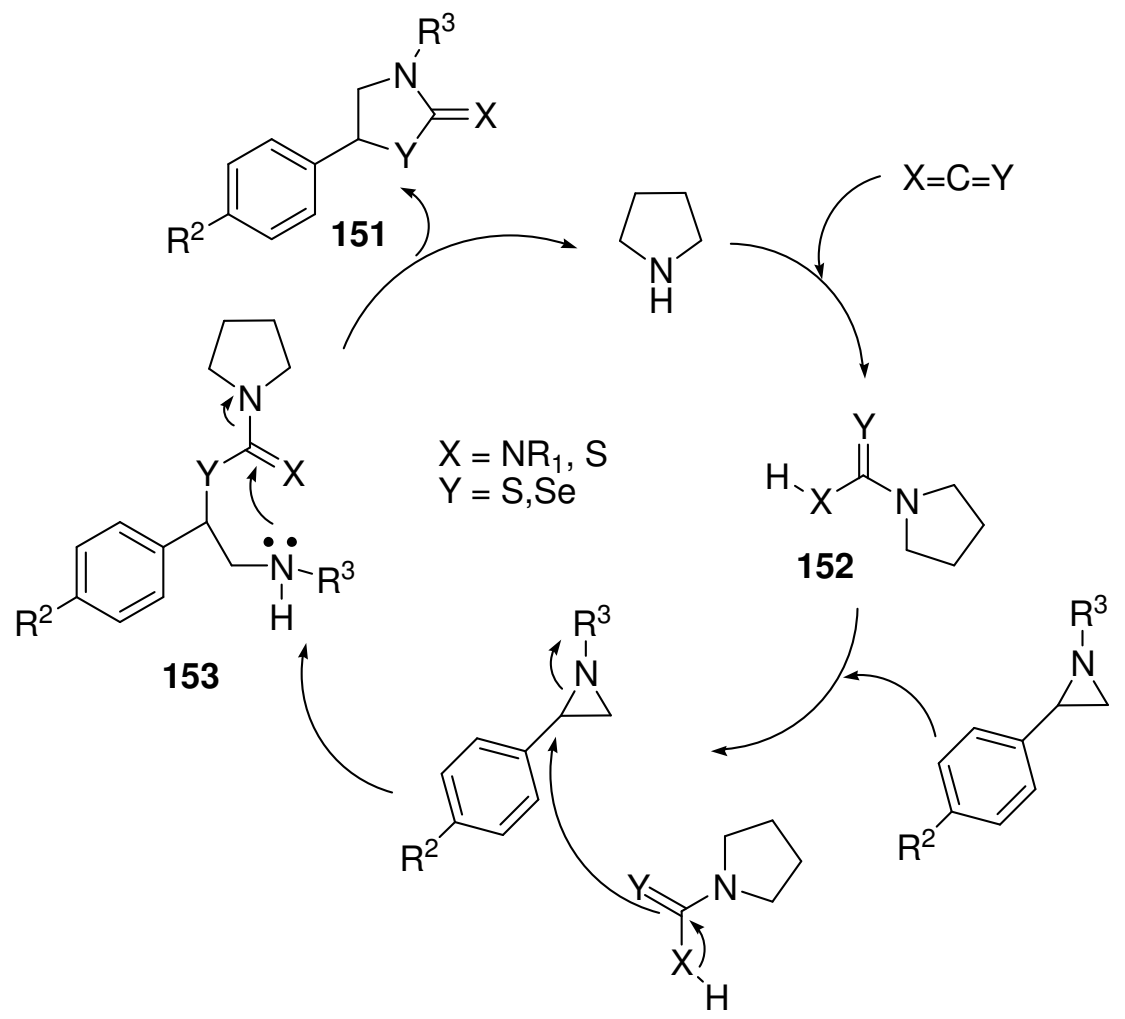

Scheme 46

\subsection{Synthesis of imidazoles}

The 2-chloro-2-imidoylaziridines 154, prepared via an aza-Darzens type reaction of 3,3-dichloro-1-azaallylic anions and $\mathrm{N}$-sulfonylaldimines, undergo a thermal rearrangement via $\mathrm{C}-\mathrm{C}$ bond cleavage to produce 4-chloro- 


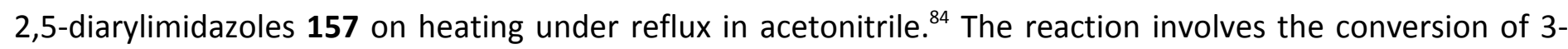
aryl-2-chloro-2-imidoylaziridines 154 to azomethine ylides 155 and their subsequent 1,5-dipolar electrocyclization to imidazolines 156 (Scheme 47). The latter products, after loss of benzenesulfonate, afforded imidazoles 157.

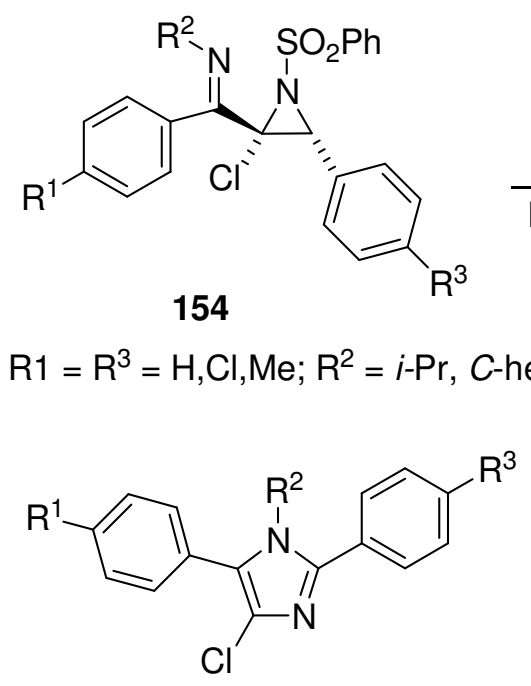

157

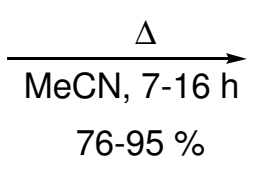

$76-95 \%$

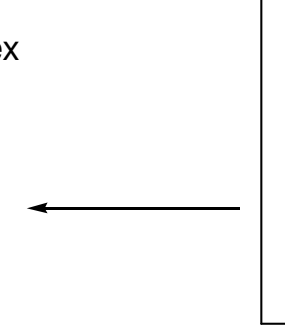

\llcorner

CI

\section{Scheme 47}

\subsection{Synthesis of imidazolines}

The reaction of imidoyl chlorides 159 with aziridine derivatives 158 in a single-pot Heine process have led to the synthesis of functionalized 2-imidazolines 161 (Scheme 48). ${ }^{85}$ The reaction is highly regio- and stereospecific. The imidoyl aziridine $\mathbf{1 6 0}$ is most likely activated by the Bronsted acid, 2,6-lutidine. $\mathrm{HCl}$. An $\mathrm{S}_{\mathrm{N}} 2$ attack of the chloride ion at the C-2-position of the imidoyl aziridines 160 may form intermediate 162 that can cyclize through a second $\mathrm{S}_{\mathrm{N}} 2$ reaction. Alternatively, the attack of the imidoyl carbon atom by the chloride ion to form product 163 and ring-expansion of the latter product by a 4-endo-tet ring-closure either by a $S_{N} i$ or stepwise process may lead to the formation of product (Scheme 49). There are evidences in support of both mechanisms.

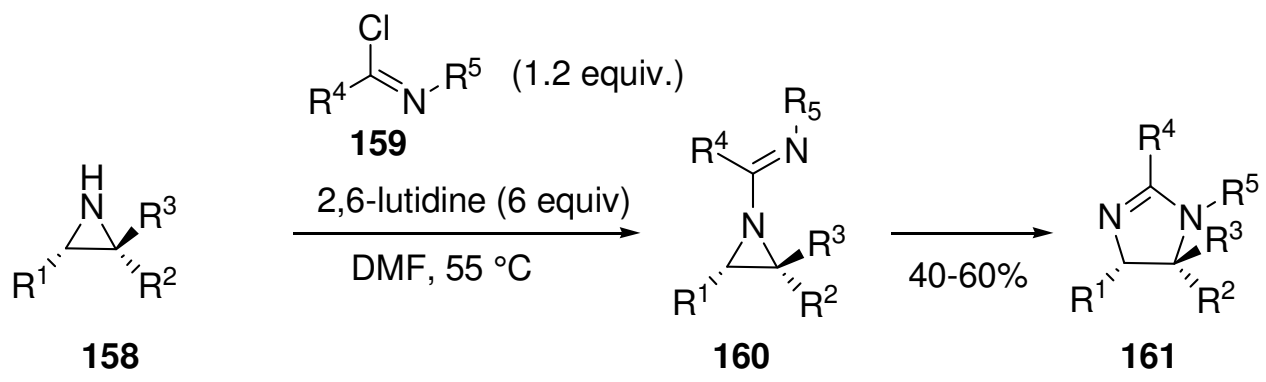

a. $\mathrm{R}^{1}=\mathrm{R}^{3}=\mathrm{Ph}, \mathrm{R}^{2}=\mathrm{H} ; \mathrm{R}^{4}=p-\mathrm{MeO}-\mathrm{Ph}, \mathrm{Ph}, p-\mathrm{F}-\mathrm{Ph}, p-\mathrm{NO}_{2}-\mathrm{Ph}, \mathrm{C}$-hex, $\mathrm{Me}$; $\mathrm{R}^{5}=\mathrm{CH}_{2} \mathrm{Ph}, \mathrm{Me}$, $p$-MeO-Ph, $C$-hex

b. $\mathrm{R}^{1}=p-\mathrm{MeO}-\mathrm{Ph}, \mathrm{Ph}, p-\mathrm{NO}_{2}-\mathrm{Ph}, \mathrm{PhCH}=\mathrm{CH}, n-\mathrm{C}_{6} \mathrm{H}_{13} ; \mathrm{R}^{2}=\mathrm{H}, \mathrm{Me}, \mathrm{CH}_{2} \mathrm{Ph}$; $\mathrm{R}^{3}=\mathrm{CO}_{2} \mathrm{Et}$, COPh, $\mathrm{H} ; \mathrm{R}^{4}=\mathrm{Ph} ; \mathrm{R}^{5}=\mathrm{CH}_{2} \mathrm{Ph}$

\section{Scheme 48}




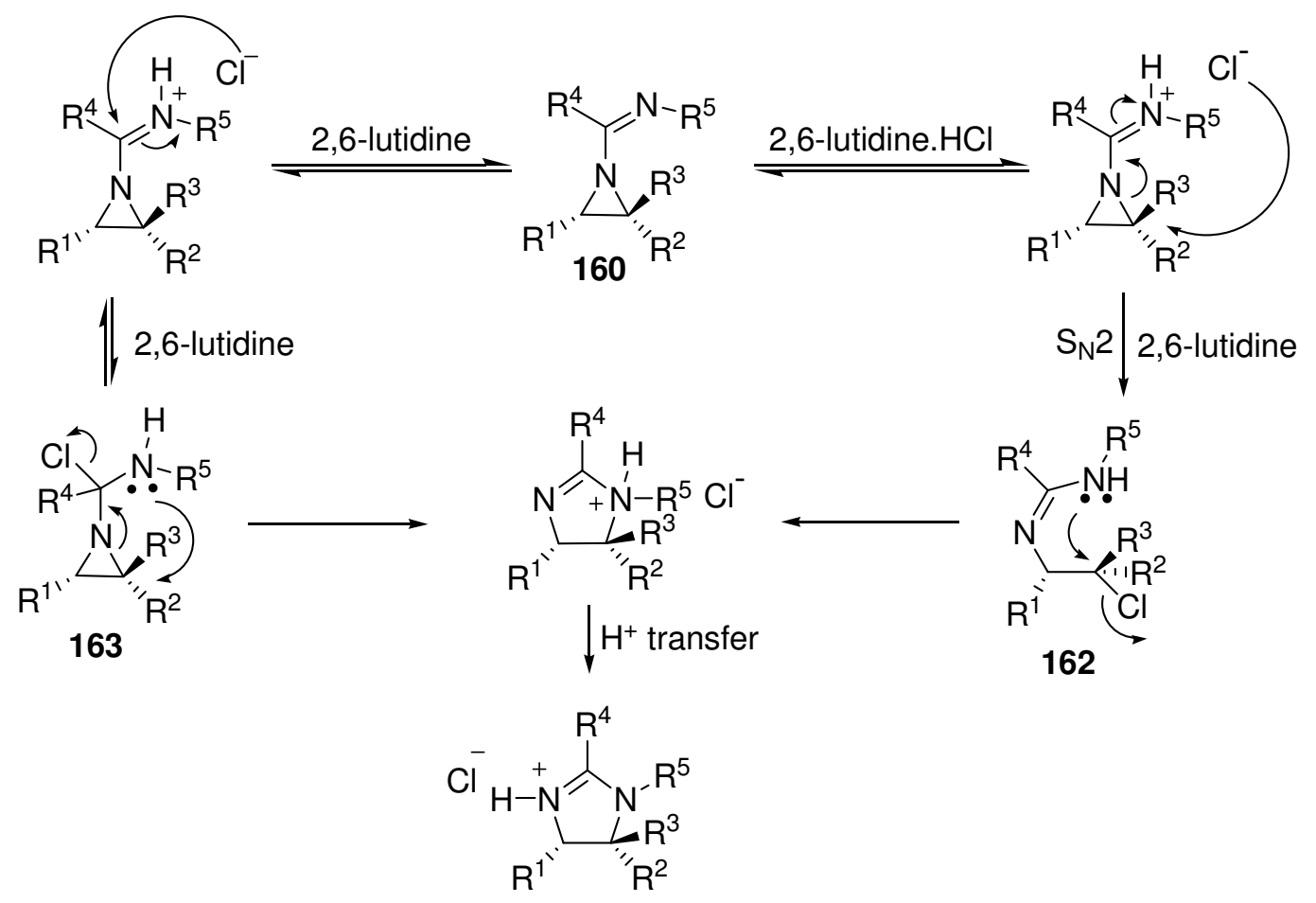

\section{Scheme 49}

\subsection{Synthesis of imidazolidines}

Sengoden and coworkers have reported a stereospecific copper-catalyzed domino ring-opening of activated aziridines and their $s p^{3} \mathrm{C}-\mathrm{H}$ functionalization with $\mathrm{N}$-alkylanilines resulting into the formation of functionalized imidazolidines. ${ }^{86}$ Anilines with bulky group on nitrogen such as $N$-benzylaniline and $N$-isopropylaniline failed to react with 2-phenyl-1-sulfonylaziridine due to steric hindrance. The reaction of an optically active aziridine 110a with a series of $N$-methylanilines 164 afforded imidazolidines 165 with excellent optical purity (ee >99\%) (Scheme 50). The plausible mechanism for the formation of products involves coordination of $\mathrm{Cu}(\mathrm{OTf})_{2}$ with the nitrogen lone pair of aziridine and its subsequent ring-opening leading to the formation of intermediate 166. Another intermediate 167 may be formed by single electron transfer reduction of $\mathrm{Cu}(\mathrm{OTf})_{2}$ using the nitrogen lone pair of $\mathbf{1 6 6}$. Homolysis of $\mathrm{N}$-methyl $\mathrm{C}-\mathrm{H}$ bond by tert-butoxy radical is suggested to form imine 168 that may cyclize to give the observed products. 


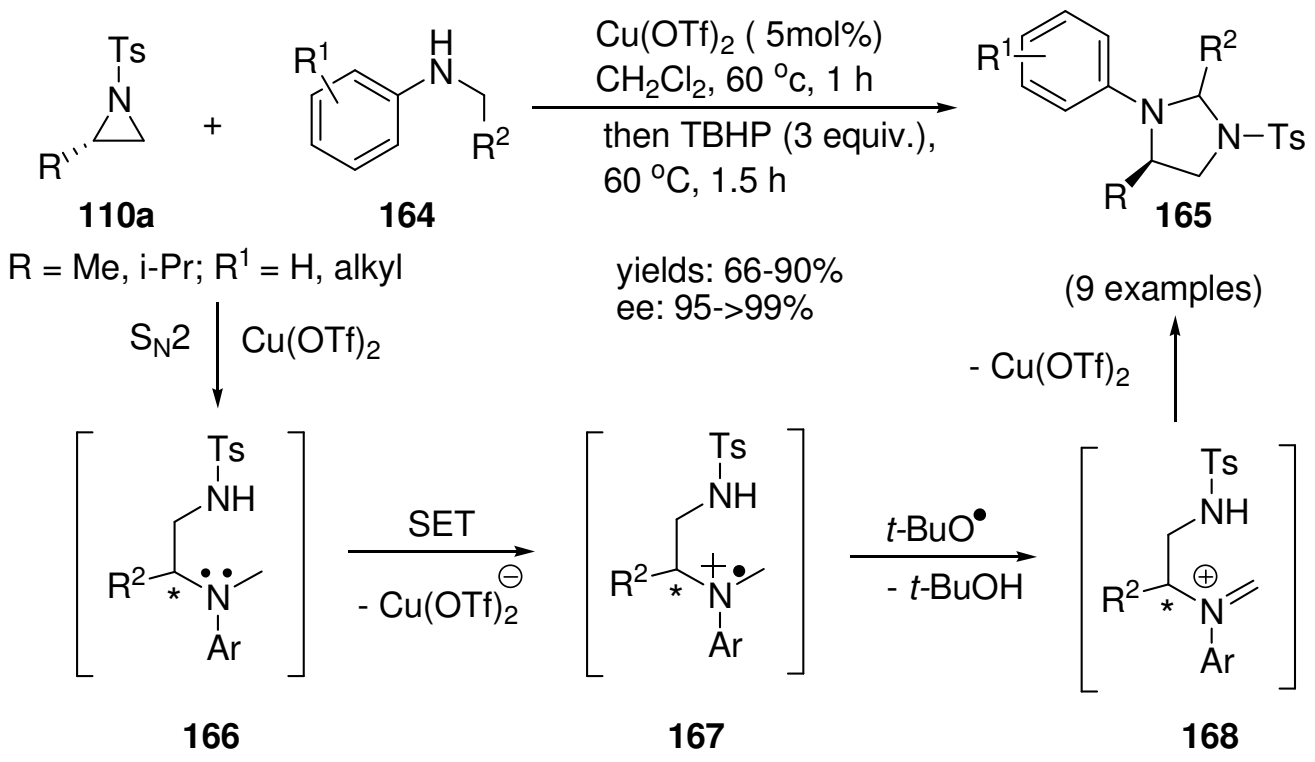

\section{Scheme 50}

\subsection{Synthesis of imidazolidin-2-ones, imidazolidine-2-thiones, and 2-iminoimidazolidines}

Takeda group has employed Lewis base for the ring-expansion of aziridinofullerenes with aryl isothiocyanates forming imidazolidinone-fused fullerenes. ${ }^{87} \mathrm{~A}$ ring-expansion of trans-aziridine-2-carboxylates with isocyanates results into formation of imidazolidin-2-ones. ${ }^{88} \mathrm{~A}$ similar reaction of trans-aziridine-2-carboxylates 169 with isothiocyanates leads to the formation of trans-imidazolidine-2-thiones $\mathbf{1 7 0}$ in regioselective and stereoselective manners (Scheme 51). ${ }^{89}$ The steric and electronic effects in substrates play a role resulting into epimerization of starting aziridines in some cases and/or formation of imidazolidin-4-ones. The formation of trans-imidazolidine-2-thiones is suggested via a zwitterionic key intermediate 171, generated by a nucleophilic attack of lone pair on aziridine nitrogen onto the electrophilic carbon of isothiocyanates. The zwitterionic intermediate $\mathbf{1 7 1}$ undergoes a regiospecific $\mathrm{C}-\mathrm{N}$ bond cleavage to give a linear zwitterionic intermediate $\mathbf{1 7 2}$ that cyclizes to form the final product. The formation of 2-iminoimidazolidines is reported by a Lewis acidcatalyzed [3+2]-cycloaddition of carbodiimides with 2-substituted $N$-sulfonylaziridines and 2phenylaziridines. ${ }^{90}$ The reaction, catalyzed by zinc bromide, occurs in dichloromethane at room temperature.

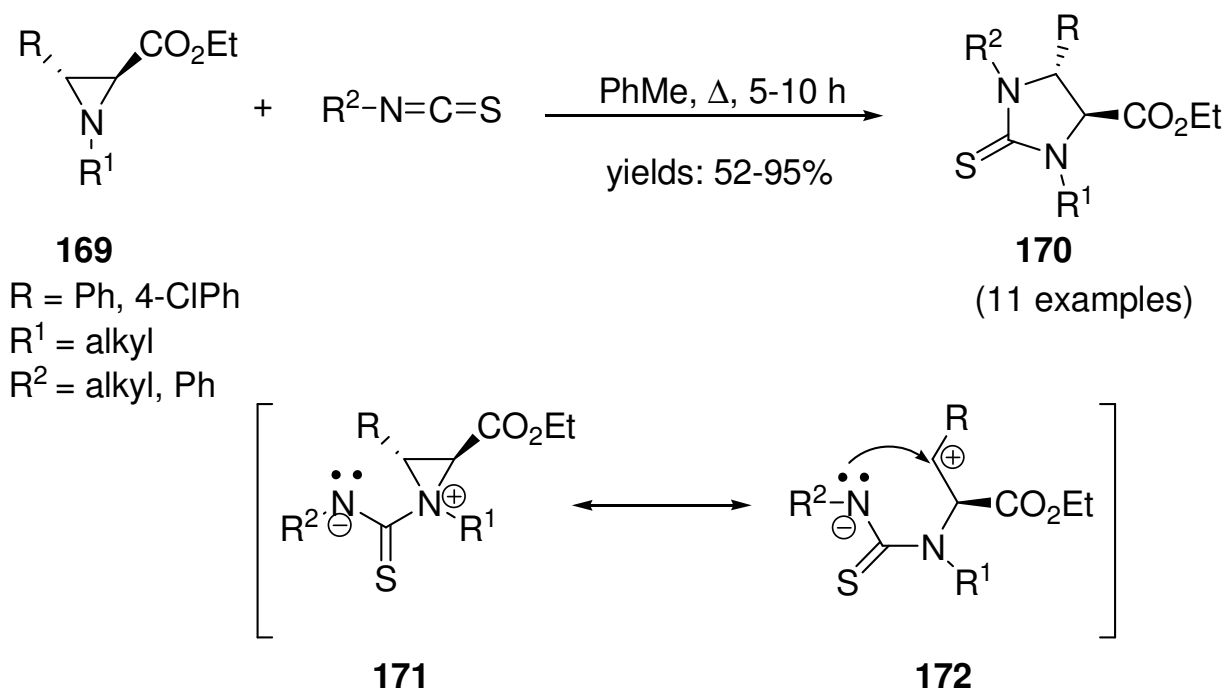

\section{Scheme 51}




\subsection{Synthesis of oxazoles}

It was very recently demonstrated that $\mathrm{N}-\mathrm{H}$ ketoaziridines 62 a could be rearranged to 2,5-diaryloxazoles 174 via an in situ formation of $\mathrm{N}$-bromoketoaziridines 173 in the presence of $\mathrm{N}$-bromosuccinimide. ${ }^{91}$ Under thermal conditions, $\mathrm{N}$-bromo substituted ketoaziridines $\mathbf{1 7 3}$ are converted into an azomethine ylide 175 via C$\mathrm{C}$ bond cleavage that is followed by the ring-closure of the latter leading to a cyclized intermediate 176, which then undergoes thermal elimination of hydrogen bromide to produce oxazoles 174 (Scheme 52). The authors have also reported that the presence of electron-withdrawing $R^{1}$ groups and electron-donating $R^{2}$ groups favored the formation of azomethine ylide. It was also observed that the bromine group on the aziridine nitrogen had a stabilizing effect on the formation of azomethine ylide and was crucial for the thermal C-C bond cleavage of the ketoaziridine ring.

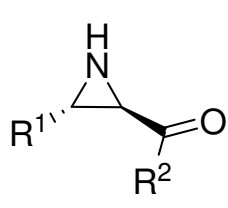

$62 a$

$$
\begin{aligned}
\mathrm{R}^{1}= & \mathrm{Ph}, 2-\mathrm{Cl}-\mathrm{Ph}, 2,4-\mathrm{Cl}-\mathrm{Ph}, 4-\mathrm{Cl}-\mathrm{Ph}, \\
& \text { 3-MeO-Ph, 3-Cl-Ph, 4- } \mathrm{NO}_{2}-\mathrm{Ph}, \\
& \text { 3- } \mathrm{NO}_{2}-\mathrm{Ph} \\
\mathrm{R}^{2}= & \mathrm{Ph}, 3-\mathrm{NO}_{2}-\mathrm{Ph}, 4-\mathrm{Br}-\mathrm{Ph}, 4-\mathrm{Cl}-\mathrm{Ph}, \\
& p-\mathrm{MeO}-\mathrm{Ph}
\end{aligned}
$$

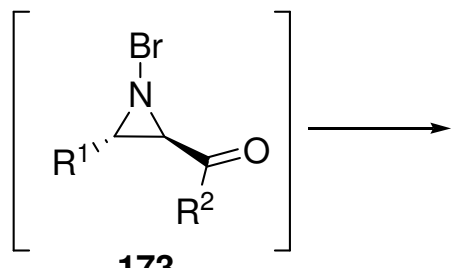

173<smiles>[3H]C</smiles>

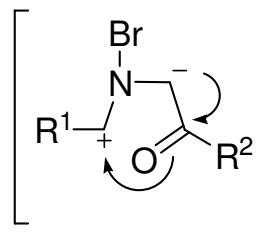

175<smiles>[R]c1cnc([R])o1</smiles>

174

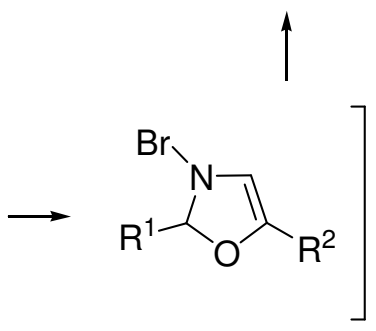

176

\section{Scheme 52}

\subsection{Synthesis of oxazolidines}

A tandem ring opening/cyclization of aziridines leads to the formation of oxazolidine derivatives. ${ }^{92} \mathrm{~A}$ silver triflate, AgOTf-catalyzed ring-opening of $\mathbf{N}$-tosyl-2-arylaziridines $\mathbf{1 1 0}$ with water and subsequent reaction of the ring-opened product with another molecule of aziridine gives the product 177 (Scheme 53). 2-(2Chlorophenyl)/alkyl-1-tosylaziridines failed to afford the desired oxazolidine products. The ring opens by a nucleophilic attack of water at the benzylic ring carbon (C-2). The resulting 1-aryl-2-aminoethanol 178 reacts with aziridine again by a nucleophilic attack of its hydroxyl group on benzylic carbon of the aziridine generating a bis-aminoether 179. The latter compound, in the presence of AgOTf, gives another intermediate 180 that is stabilized to intermediate 181 by neighboring group participation of aromatic ring. A 1,2-phenyl migration in intermediate $\mathbf{1 8 1}$ forming another intermediate $\mathbf{1 8 2}$ followed by cyclization forms the final product. 


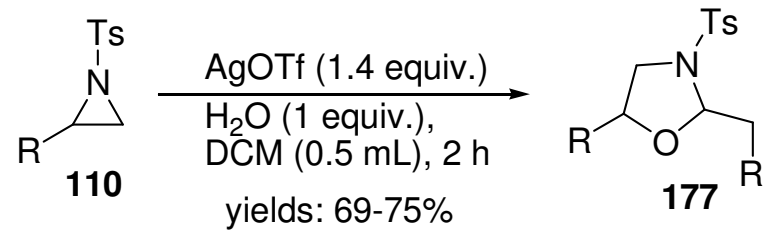

$\mathrm{R}=\mathrm{Ph}, 4-\mathrm{CIPh}, 2-\mathrm{CIPh}, 4-\mathrm{BrPh}, \mathrm{n}-\mathrm{hex}, \mathrm{BrCH}_{2}, \mathrm{HOCH}_{2} \mathrm{CH}_{2}$

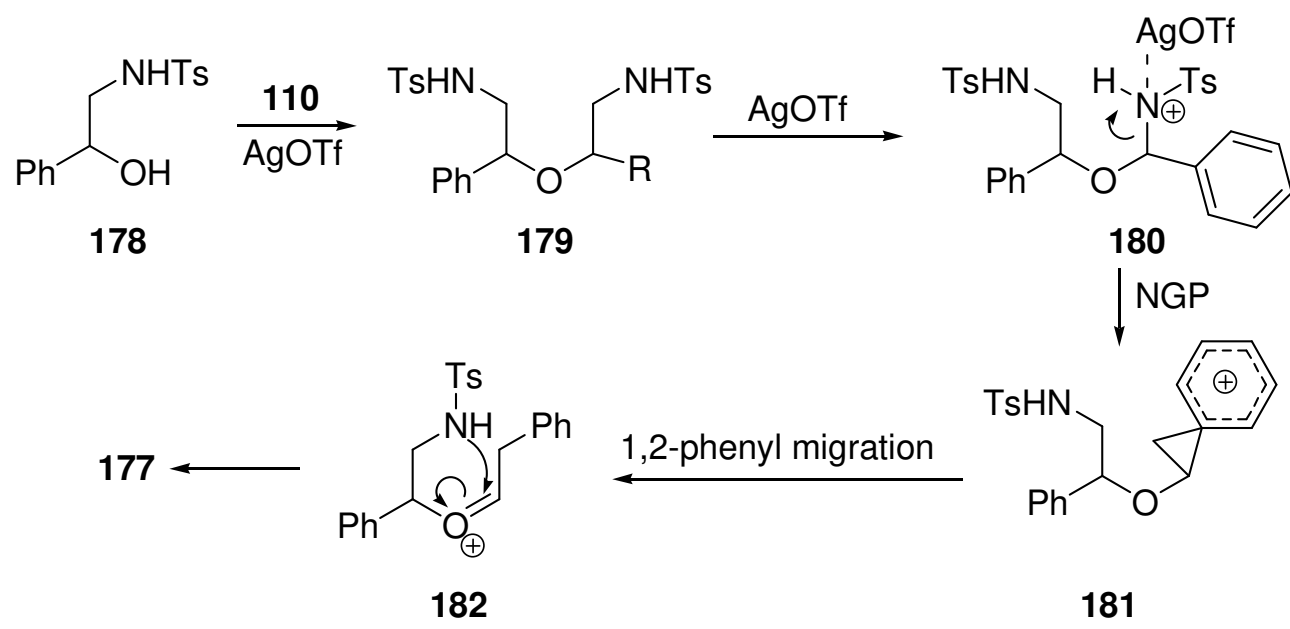

\section{Scheme 53}

The Lewis acid-catalyzed [3+2]-cycloaddition of carbonyl compounds to aziridines has been investigated by many researchers recently. Wu and coworkers demonstrated an efficient [3+2]-cycloaddition of aldehydes and azomethine ylides, obtained from a Lewis acid catalyzed $\mathrm{C}-\mathrm{C}$ bond cleavage of $\mathrm{N}$-tosylaziridines 98 under mild conditions, providing highly substituted 1,3-oxazolidines 183 with high diastereo- and regioselectivity (Scheme 54). ${ }^{93}$ It is worthy to note that moderate enantioselectivity (60\% ee) is achieved by the use of Pybox as a chiral ligand. In yet another recent report, Yang and coworkers have reported the $\mathrm{BF}_{3}-\mathrm{OEt}_{2}$-Catalyzed cycloaddition of $\mathrm{N}$-sulfonylaziridinofullerenes with various aromatic-, heteroaromatic-, and aliphatic aldehydes, and some ketones forming fullerooxazolidines. ${ }^{94}$ The reaction of ethyl formate, however, led to elimination of ethoxy group in an unprecedented manner forming fullerooxazole bearing no substituent at C-2 position of oxazole ring.

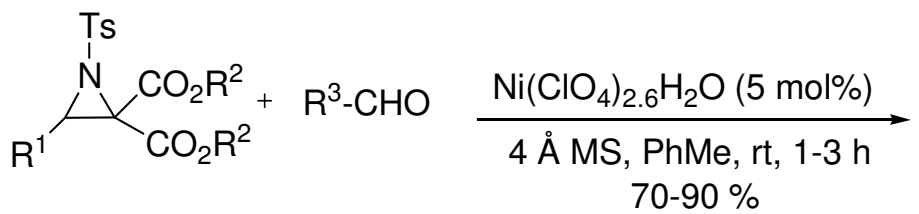

98<smiles>[R2]OC(=O)C1(C([R2])=O)C([R])OC([R7])N1[3H]</smiles>

183

$\mathrm{R}^{1}=4-\mathrm{NO}_{2}-\mathrm{Ph}, 4-\mathrm{Cl}-\mathrm{Ph}, 4-\mathrm{Br}-\mathrm{Ph}, 4-\mathrm{Me}-\mathrm{Ph}$ 4-i-Pr-Ph, 3-Me-Ph, 2-Br-Ph, $\mathrm{Ph}$

$\mathrm{R}^{2}=\mathrm{Me}, \mathrm{Et}, i-\mathrm{Pr}$

$\mathrm{R}^{3}=\mathrm{Ph}, 3-\mathrm{Me}-\mathrm{Ph}, 4-\mathrm{MeO}-\mathrm{Ph}, 4-\mathrm{Cl}-\mathrm{Ph}$,

\section{Scheme 54}




\subsection{Synthesis of oxazolidin-2-ones and oxazolidine-2-thiones}

Oxazolidinones are useful as protected vicinal amino alcohols and as Evans auxiliaries. ${ }^{95}$ They have been reported to exhibit biological activity, especially optically active oxazolidinones. ${ }^{96}$ Some oxazolidinones inhibit bacterial protein synthesis by preventing binding of the aminoacyl-tRNA to the A site of the ribosome. ${ }^{97}$ For example, Linezolid (LZD) (Zyvox) has gained wide use clinically for treating infections caused by gram-positive pathogens. ${ }^{98}$ In that regard, many protocols for synthesizing oxazolidinones have been developed, including the use of aziridines.

$N$-Boc-protected aziridines undergo an intramolecular Lewis acid-catalyzed reaction to give oxazolidinones. ${ }^{99}$ The reaction involves reduction of the aziridine aldehydes 184 with sodium borohydride followed by treatment with $\mathrm{HCl}$ in dioxane to furnish a single regioisomer of oxazolidinones 185 (Scheme 55). ${ }^{16}$ The products were obtained in good yields with high enantiomeric excess with retention of configuration.

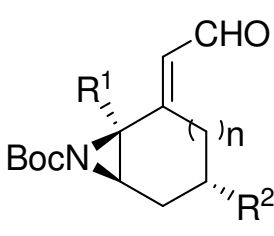

184
1. $\mathrm{NaBH}_{4}, \mathrm{MeOH}$

2. $\mathrm{HCl}$ in dioxane

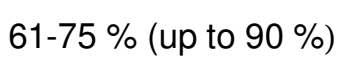

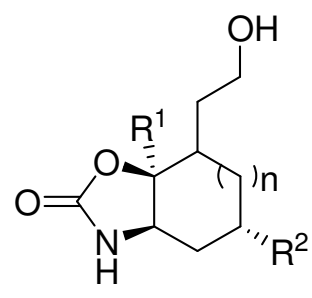

185

$\mathrm{R}^{1}=$ pentyl, Me

$\mathrm{R}^{2}=\mathrm{H}, \mathrm{s}^{\mathrm{s}} \pi$

$$
\mathrm{n}=0,1
$$

\section{Scheme 55}

Hamada group has also synthesized an oxazolidinone 189 from an N-boc-protected aziridine 186 (Scheme 56). ${ }^{15 E r r o r ! ~ B o o k m a r k ~ n o t ~ d e f i n e d . ~ T h e ~ o x a z o l i d i n o n e ~ w a s ~ t h e n ~ u t i l i z e d ~ t o ~ a c c e s s ~ a ~ k e y ~ i n t e r m e d i a t e ~ r e q u i r e d ~ f o r ~ t h e ~}$ synthesis of (-)-allosamizoline, an aglycon unit of the potent chitinase inhibitor allosamidin. The aziridine ringopening with acetic acid leading to formation of cyclopentane $\mathbf{1 8 7}$ followed by creation of an olefinic system 188 in the cyclopentane ring, and cyclization led to an entry into an oxazolidinone ring system.

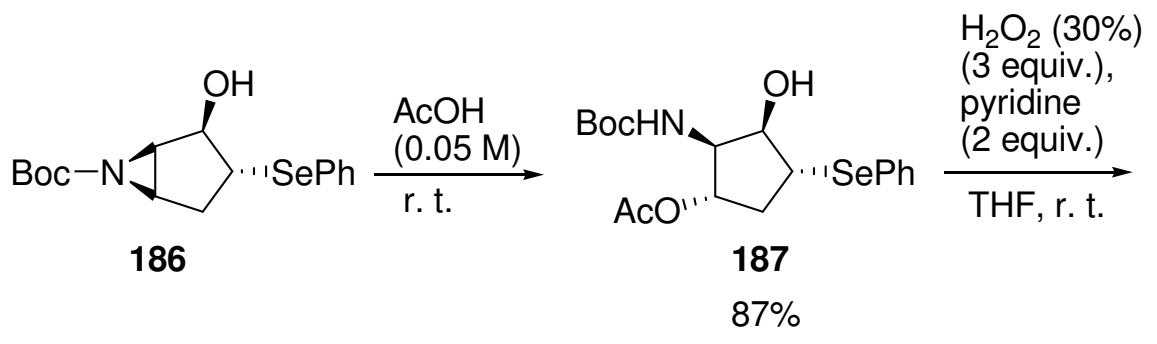

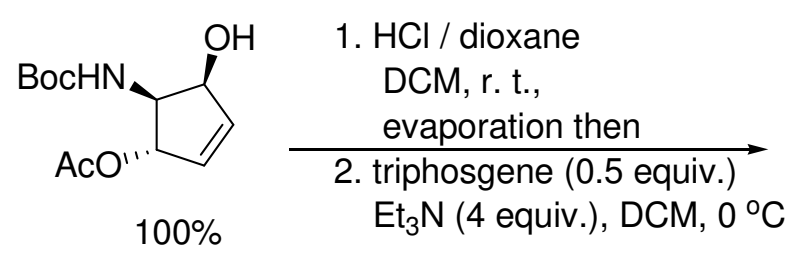

188

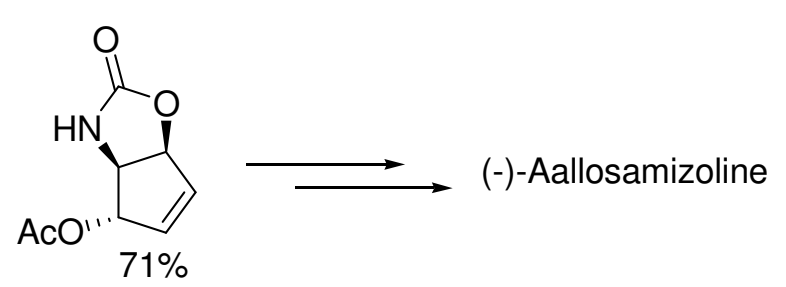

189

\section{Scheme 56}


Very recently Kaabi and coworkers reported the regio- and stereoselective transformation of trans- $N$ alkylaziridine-2-carboxylates 169 to the corresponding trans-1,3-oxazolidin-2-ones 191 in good yields (Scheme 57). ${ }^{100}$ It is noteworthy to mention that the reaction conditions and $N$-substituent had little influence on the course of the reaction. Upon reaction with methylchloroformate 190, a regioselective nucleophilic ringopening by the attack of in situ liberated chloride anion on the benzylic carbon of the electrophilic aziridinium ion 192 formed the chloride intermediates 193. This compound could be cyclized to trans- $N$-alkyl-1,3oxazolidin-2-ones 191 through an intramolecular nucleophilic attack of the carbonyl oxygen atom and subsequent displacement of chloride ion.

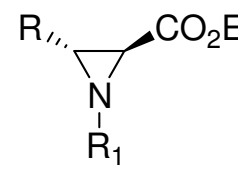

169

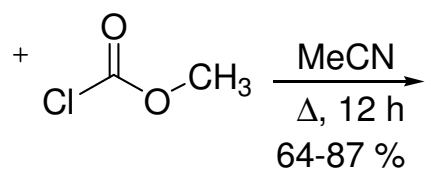

190

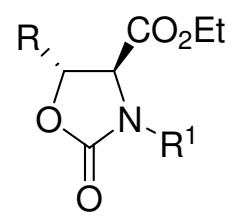

191

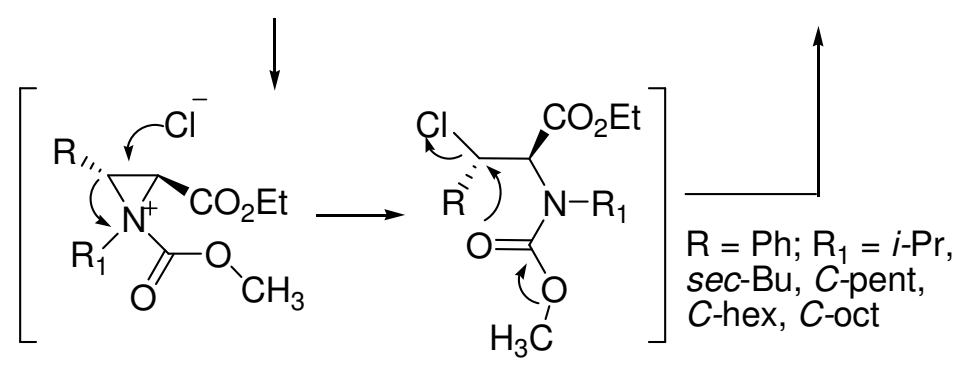

192

193

\section{Scheme 57}

A commercial approach that is very efficient as well to construct oxazolidinone ring from aziridine is the insertion of $\mathrm{CO}_{2}$ molecule in aziridine ring. A number of catalysts are known in literature to ease the reaction. Some of these involve quaternary ammonium bromide-functionalized polyethylene glycol, ${ }^{101}$ zirconyl chloride, ${ }^{102}$ alkali metal halide, ${ }^{103}$ Lewis basic ionic liquids, ${ }^{104}$ protic onium salt, ${ }^{105}$ polyethylene glycolfunctionalized phosphonium salts, ${ }^{106} \mathrm{DBN},{ }^{107}$ polyethylene glycol functionalized ionic liquids, ${ }^{108} 2,2^{\prime}, 2^{\prime \prime}-$ terpyridine, ${ }^{109}$ and mesoporous zirconium phosphonates. ${ }^{110}$ A very few selected examples are described in succeeding paragraphs.

An insertion of $\mathrm{CO}_{2}$ in aziridine ring of $\mathrm{NH}$-aziridine or 1-alkyl-2-arylaziridines 105 in the presence of polymer-supported diol-functionalized ionic liquids (PS-DFILXs) as catalysts gives 4- and 5-aryl-2oxazolidinones 194 and 195 (Scheme 58). ${ }^{111}$ The reaction offers high conversions with excellent regioselectivities under mild solvent-free conditions. The yield of the major product 194 increases with an increase in size of alkyl chain on nitrogen atom of aziridine. On the contrary, the increase in bulkiness of the $N$ substitution ( $t$-butyl, $C$-hex) tends to lower yields. However, the problem of steric hindrance could be overcome by increasing the temperature of reaction. 


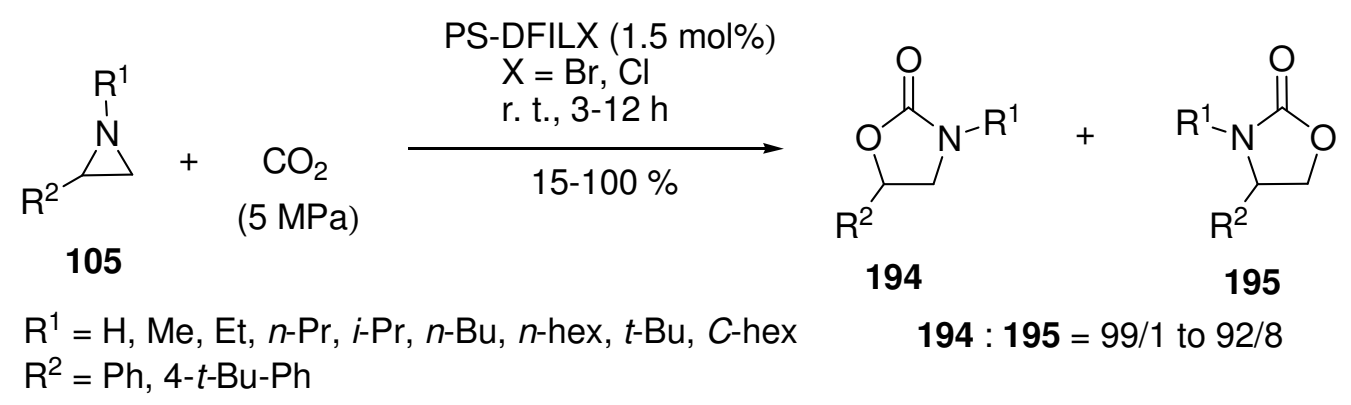

\section{Scheme 58}

The reaction is believed to be initiated by activation of the aziridine ring through hydrogen bonding between the hydroxyl groups of the polymer-supported diol-functionalized ionic liquid 196 and the $N$ - atom of aziridines 105 to form an intermediate 197. This tends to polarize the $\mathrm{C}-\mathrm{N}$ bond of aziridines, resulting in ringopening via two pathways, a or b to give intermediates 198 and 199, respectively. A subsequent cyclization leads to the formation of 2-oxazolidinones 194 and 195 and regeneration of the catalyst. The major product 194 could originate from ring- opening of the aziridine at the most hindered carbon, path $a$, ${ }^{112}$ whereas the minor product $\mathbf{1 9 5}$ may be formed from the less hindered position, path $b$. The hydroxyl groups on vicinal carbon atom of the ionic liquid do not only initiate activation of the aziridine, but also stabilize intermediates 200 and 201 during the reaction (Scheme 59).

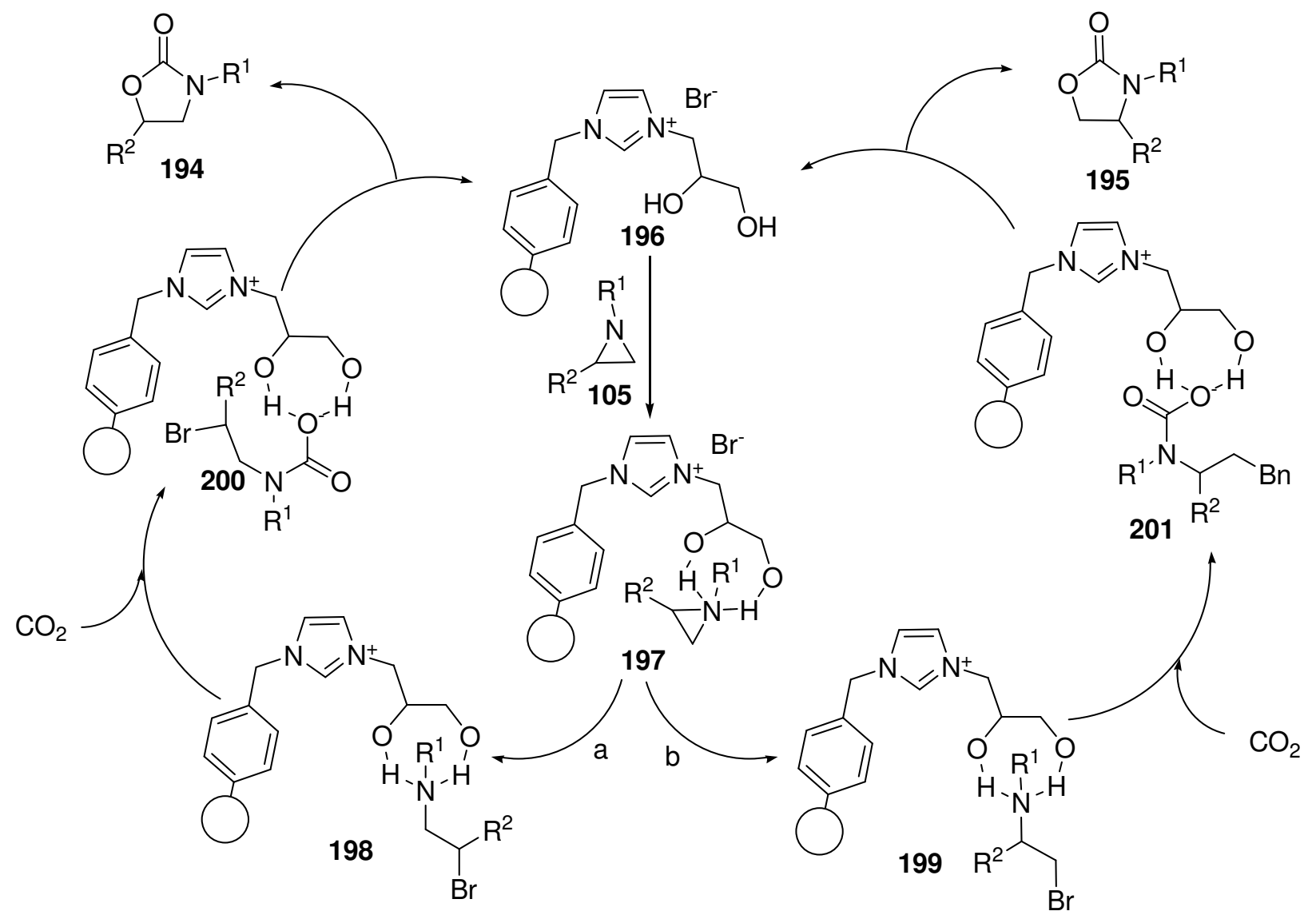

\section{Scheme 59}


A similar carbonylation reaction of unactivated aziridines 105 was reported by Gao et al whereby polystyrene-supported Lewis acid Fe(III) ionic liquid catalyst was used. ${ }^{113}$ Oxazolidinones 194 and 195 were selectively formed in good to excellent yields as well as high regioselectivities (Scheme 60).
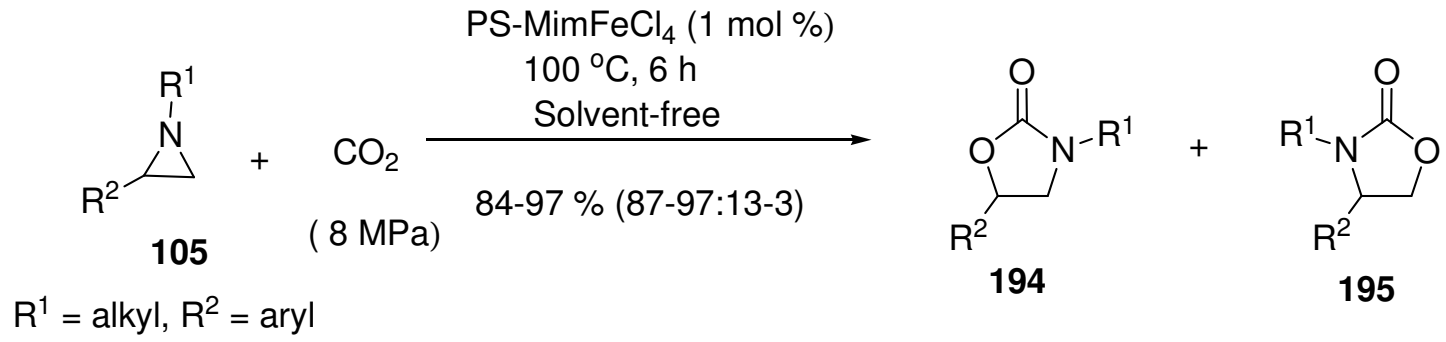

(5 aziridines)

\section{Scheme 60}

2-Vinyl aziridines 202 react with carbon dioxide (1 bar) in the presence of triphenylphosphine $\left(\mathrm{PPh}_{3}\right)$ and palladium catalyst to furnish 5-vinyloxazolidinones 203 and 204 with no erosion in enantio-purity (Scheme 61). ${ }^{114}$ Tetrabutylammonium difluorotriphenylsilicate adduct (TBAT) was required to hinder ion-pairing between the amide ion and the cationic Pd, thus increasing the yields of the products 203 and 204 . The process is both regio- and stereoselective. Both the electron-donating and electron-withdrawing para substituents on the trans-aziridine core were tolerated. However, alkyl groups on the vinyl moiety resulted in lower yields.

$\mathrm{R}^{2}=\mathrm{H}$, aryl, Me, TMS

(14 aziridines)

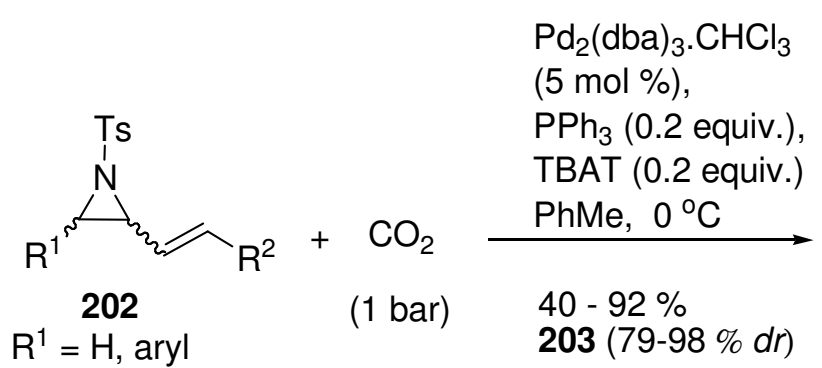

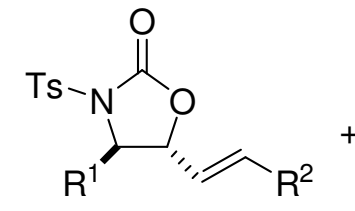

203

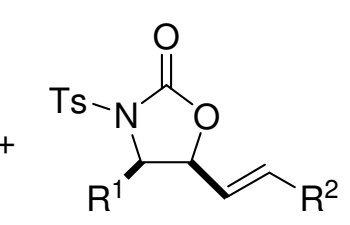

204

\section{Scheme 61}

The mechanism involves the reaction of $\mathrm{Pd}(0)$ complex with trans-E-vinylaziridines 46 or cis- $E$ vinylaziridines $\mathbf{2 0 5}$ to form a $\pi$-allyl palladium intermediate $\mathbf{2 0 6}$ which then isomerizes to another complex 207. The intermediates $\mathbf{2 0 6}$ and $\mathbf{2 0 7}$ are then captured by carbon dioxide to afford the intermediates 208 and 209, respectively, which cyclize to the corresponding 5-vinyloxazolidinones 203 and 204 (Scheme 62). ${ }^{114}$ 

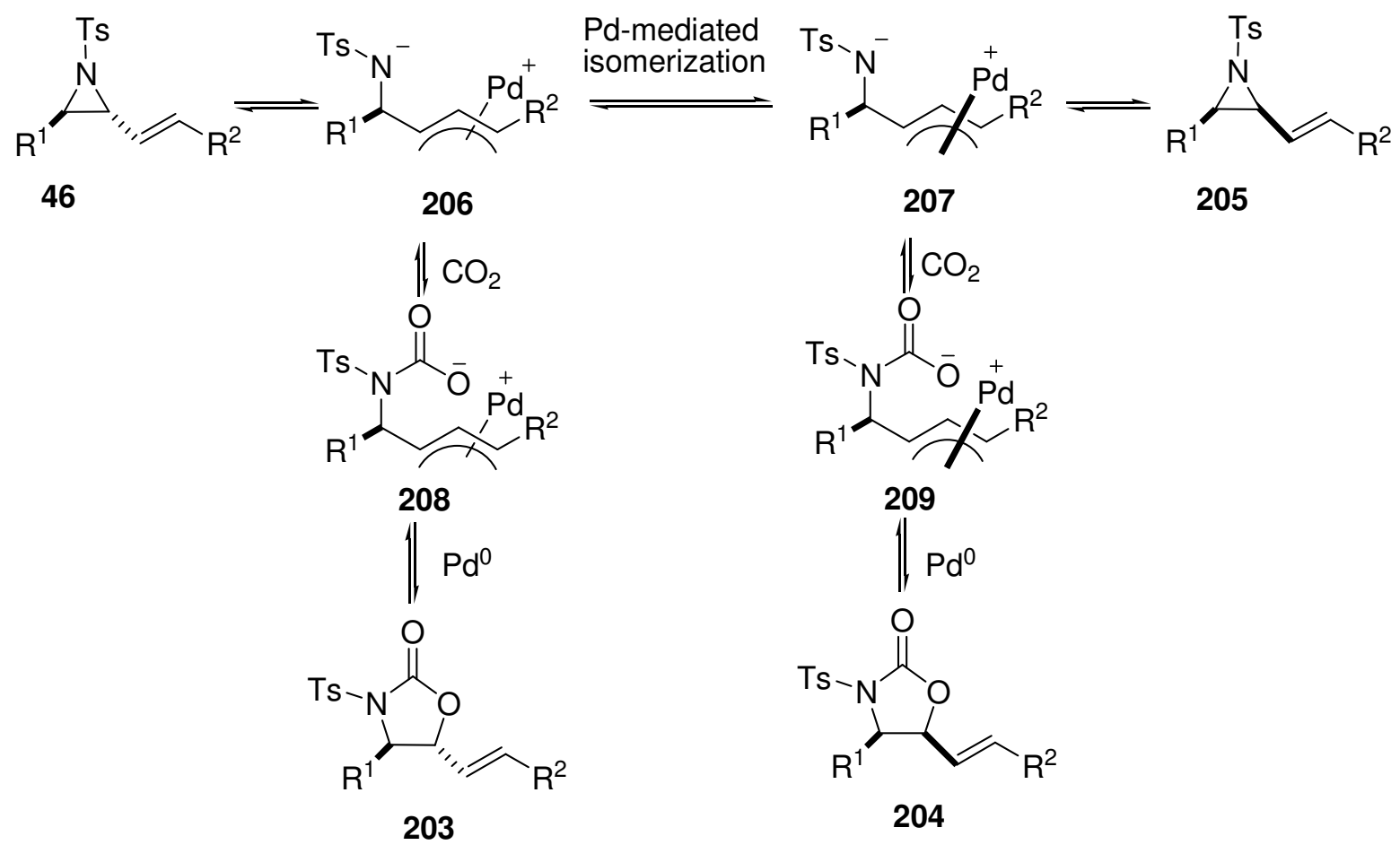

\section{Scheme 62}

Although the Lewis acid-catalyzed 1,3-dipolar cycloadditions are more common Takeda and coworkers have reported a Lewis base-catalyzed fixation of carbon dioxide with $\mathrm{N}$-arylsulfonyl-substituted aziridinofullerenes to synthesize oxazolidinone-fused fullerenes. ${ }^{87}$ This group has used 10 mol\% of tricyclohexylphosphine as a catalyst. The presence of phenylsulfonyl group gave $85 \%$ yield of the product. Introducing a nitro group at C-4 of phenyl ring drastically reduced the yield to $23 \%$ whereas a 4 -methoxy group on same position yielded $70 \%$ of the product. The $\mathrm{N}$-methylsulfonyl-substituted aziridinofullerene also afforded the product in $70 \%$ yield.

The reaction of $\mathrm{N}$-alkyl-3-arylaziridine-2-carboxylates 169 with phenylisocyanate $\mathbf{2 1 0}$ occurs without any catalyst leading to the formation of trans-oxazolidin-2-imines $211 .^{88}$ The reaction proceeds by nucleophilic attack of aziridine ring nitrogen on carbonyl carbon of the isocyanate to form an intermediate $\mathbf{2 1 2}$ that cleaves at $\mathrm{N}-\mathrm{C} 3$ bond of the aziridine ring forming another intermediate 213. An intramolecular nucleophilic attack by oxygen atom lone pair on enolate leads to cyclization forming the final product (Scheme 63).

The first stereo- and regioselective conversion of keto-aziridines $\mathbf{2 1 4}$ to 2-iminooxazolidines 215 using phenylisocyanate $\mathbf{2 1 0}$ in the presence of potassium iodide is reported (Scheme 64). ${ }^{115}$ For the reaction in presence of potassium iodide, authors have proposed that the presence of an aryl moiety on C-3 and a carbamoyl moiety on ring-nitrogen develops a partial positive charge on C-3 making it an appropriate site for nucleophilic attack by iodide ion for ring cleavage. The ring cleavage is followed by an attack of oxygen to the iodide bearing carbon to give the oxazolidine. 


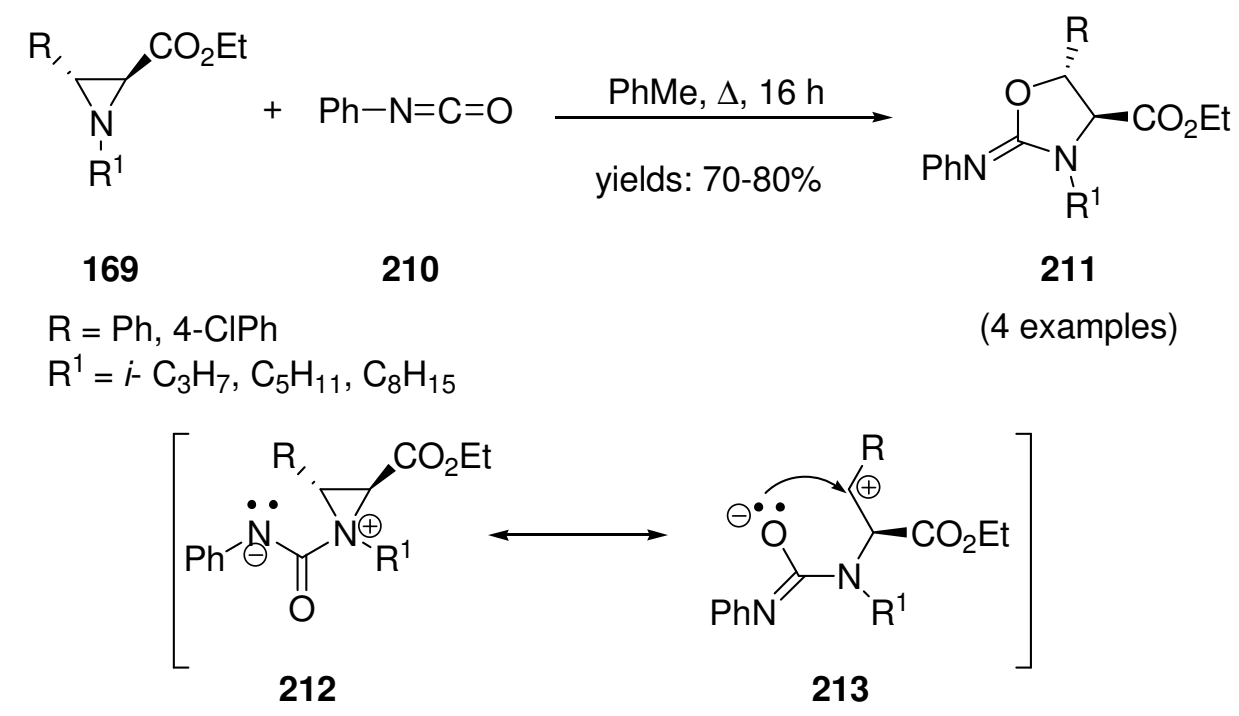

\section{Scheme 63}

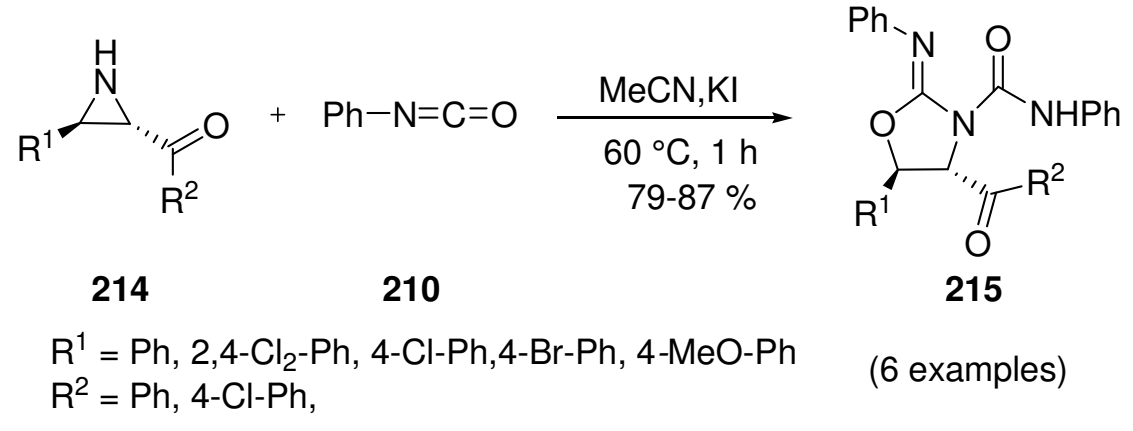

\section{Scheme 64}

\subsection{Synthesis of isoxazolidinones}

A simple and efficient synthesis of 4-alkylamino isoxazolidin-3-ones is reported by the ring-opening of $\mathrm{N}$ alkylaziridine-2-carboxylates by $\mathrm{N}$-hydroxylamine anions. ${ }^{116}$ The $\mathrm{N}$-alkylhydroxylamine salts 216 can act as $\mathrm{N}, \mathrm{O}$ binucleophile towards ethyl $\mathrm{N}$-alkylaziridine-2-carboxylates 169 to form the isoxazolidin-3-ones 217 (Scheme 65). This reaction involved the regio- and stereo-specific nucleophilic ring-opening at the benzylic position by the oxygen atom of the hydroxylamine anion ( $\left.\mathrm{R}-\mathrm{NH}^{-} \mathrm{O}\right)$ as the first nucleophilic center, accompanied with an inversion of configuration. Then the $O$-alkylated hydroxylamine intermediate formed underwent a spontaneous intramolecular cyclization with the nitrogen atom as the second nucleophilic center, to give functionalized isoxazolidin-3-ones. The reactions of $\mathrm{N}$-isopropylaziridine failed with hydroxylamine bearing a benzyl or tert-butyl group did not yield the product. 


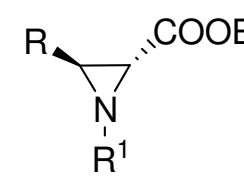

169<smiles>[R]NO</smiles>

216<smiles>[R]N[C@H]1C(=O)N([R2])OC1[R]</smiles>

217

$\mathrm{R}=\mathrm{Ph}, 4-\mathrm{CIPh} ; \mathrm{R}^{2}=\mathrm{Me}, \mathrm{Bn}, t-\mathrm{Bu}$

$\mathrm{R}^{1}=i-\mathrm{Pr}, \mathrm{CH}-\left(\mathrm{CH}_{3}\right) \mathrm{C}_{6} \mathrm{H}_{5}, C$-pent, $C$-oct

\section{Scheme 65}

\subsection{Synthesis of 2-iminothiazolidines}

Craig II and coworkers, in 2014, reported alkyl and aryl isothiocyanates as effective substrates for [3+2]cycloaddition with 2-substituted $\mathrm{N}$-sulfonylaziridines and 2-phenylaziridine for the synthesis of 2iminothiazolidines. ${ }^{90}$ The reaction occurred in chemo-, regio-, and diastereoselective manners. The authors proposed the formation of products through an intimate ion-pair mechanism. The removal of sulfonyl group from the product opens up avenue for their further functionalization. In 2016, two exciting papers have appeared on application of aziridines in synthesis of 2-imonothiazolidines. First, Ghorai and coworkers reported the formation of thiazolidines from activated aziridines by a Lewis-acid catalyzed domino ringopening and cyclization with aryl- and alkylisothiocyanates ${ }^{117}$ and then Punniyamurthy group reported an aluminum-catalyzed enantiospecific [3+2]-cycloaddition of unactivated aziridines 105 with isothiocyanates 218 leading to the formation of 2-iminothiazolidines 219 (Scheme 66). ${ }^{118}$ Ghorai and coworkers have studied the reaction of aziridines with different sulfonylaryl groups on nitrogen with alkyl and aryl isothiocyanates in the presence of $\mathrm{BF}_{3} . \mathrm{OEt}_{2}$ to get the products in excellent yields (up to 99\%). The reaction with enantiomerically pure disubstituted aziridines yielded the single diastereomer of the corresponding iminothiazolidines with ee up to $99 \%$ (Scheme 67). They have proposed similar mechanism as suggested earlier ${ }^{61,71}$ that is activation of aziridines by Lewis acid and $\mathrm{S}_{\mathrm{N}}$ 2-type ring-opening followed by 5-exo-dig cyclization with isothiocyanates. Punniyamurthy et al. have employed unactivated aziridines using aluminum salen as a catalyst. In this study as well, a stereospecific $\mathrm{S}_{\mathrm{N}}$ 2-type ring-opening followed by 5-exo-dig cyclization is proposed. In both studies, it was observed that the nucleophilic attack took place at benzylic carbon atom of the aziridine ring.

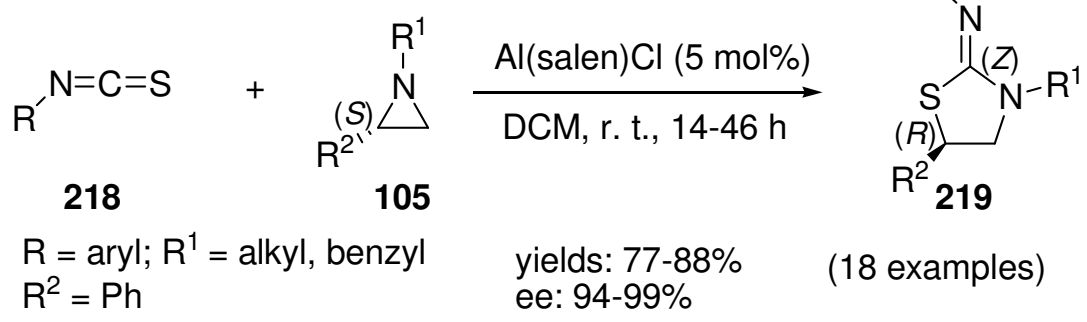

\section{Scheme 66}




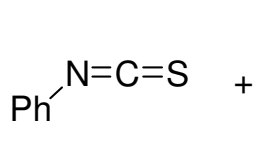

218a

$\mathrm{R}=\mathrm{Ph}, 4-\mathrm{FC}_{6} \mathrm{H}_{4}, 4-\mathrm{O}_{2} \mathrm{NC}_{6} \mathrm{H}_{4}$, 4- $t-\mathrm{BuC}_{6} \mathrm{H}_{4}, 2,4,6-\mathrm{Me}_{3} \mathrm{C}_{6} \mathrm{H}_{2}$ $\underset{\text { TBAHS (1 equiv.) }}{\stackrel{\mathrm{BF}_{3} \mathrm{OEt}_{2}(20 \text { mol\%) }}{\longrightarrow}}$

$-30^{\circ} \mathrm{C}, 30-45 \mathrm{~min}$

yields: $94-98 \%$

ee: $76->99 \%$

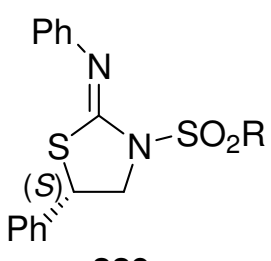

220

(5 examples)

\section{Scheme 67}

\section{Synthesis of Six-membered Heterocycles}

\subsection{Synthesis of piperidines and tetrahydroisoquinolines}

The formation of piperidines from 2-chloroalkyl-2-trifluoromethylaziridines and from 2-cyanoaziridines has been described earlier in section on pyrrolidines. ${ }^{13,77}$ The 2-aryl-3-(2-cyanoethyl)aziridines 221 furnish 3aminopiperidines $\mathbf{2 2 2} \mathbf{a}$ and $\mathbf{2 2 2} \mathbf{b}$ through a regioselective ring-opening at the benzylic position due to the resonance stabilization of the developing benzylic carbenium ion at the C-2 position (Scheme 68). ${ }^{77}$

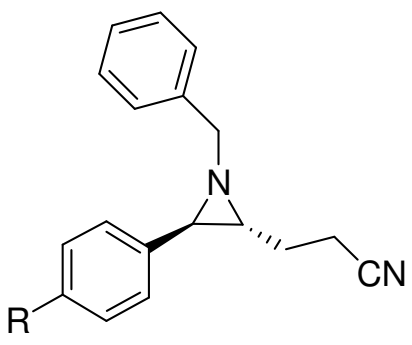

221

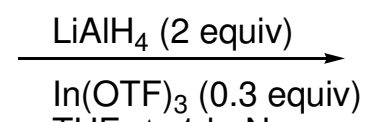

THF, $\Delta, 1 \mathrm{~h}, \mathrm{~N}_{2}$ $56-84 \%$

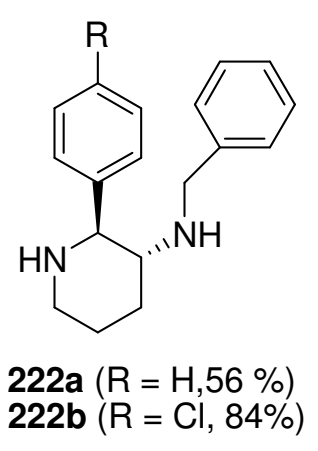

\section{Scheme 68}

Recently, Tummanapalli reported the first example of an intramolecular ring-expansion of $N$-benzylsubstituted 2-arylaziridines 223 using scandium(III) as a Lewis acid. ${ }^{119}$ In this reaction, 4-substituted tetrahydroisoquinolines $\mathbf{2 2 7}$ are obtained by cyclization of carbenium ion 224, which was generated in situ by treatment of $\mathbf{N}$-benzyl aziridines $\mathbf{2 2 3}$ with scandium(III) triflate, through intermediates $\mathbf{2 2 5}$ and 226 (Scheme 69). It should be noted that meta-alkoxy substitution is essential for the cyclization to occur. It also facilitates the efficient trapping of the carbenium ion leading to the formation of the tetrahydroisoquinoline. The employment of aziridines with other groups afforded 2-aminoalcohols. More recently, Xing and coworkers have reported a Lewis acid $\left(\mathrm{BF}_{3}\right.$. OEt $\mathrm{OEt}_{2}$-catalyzed three-component reaction of arenes, aldehydes, and $\mathrm{N}$-tosylsubstituted 2-arylaziridines forming cis-1,4-disubstituted tetrahydroisoquinolines in moderate yields. ${ }^{120}$ The reaction proceeds through an iminium ion, generated from the reaction of aldehydes with amines $\left[\mathrm{ArCH}(\mathrm{Ar}) \mathrm{CH}_{2} \mathrm{NHTs}\right]$ that formed after the Lewis-acid catalyzed ring-opening of aziridines. 


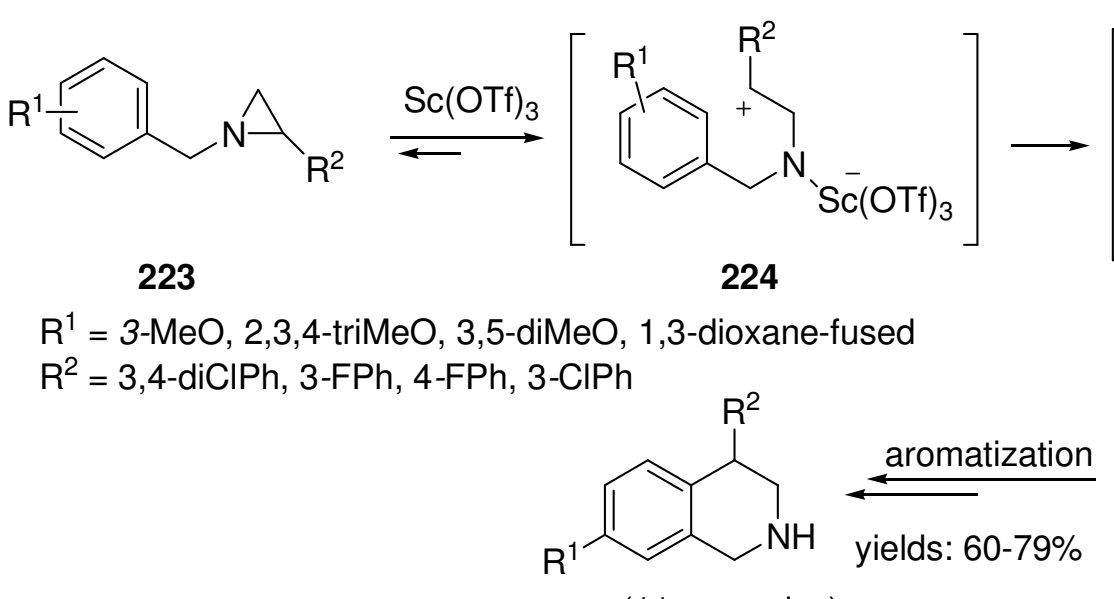

(11 examples)

227<smiles>[R7]C[As]CN(Cc1cccc([R1])c1)[Si][Ge]</smiles>

225

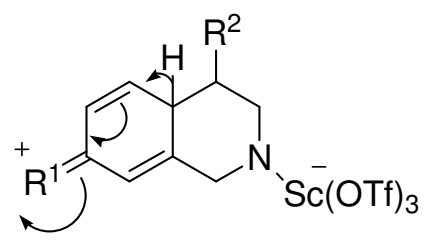

226

\section{Scheme 69}

\subsection{Synthesis of dihydropyridin-2-ones}

Fontana group has reported that the silyl-substituted aziridines, trans-3-phenyl-2-(2'trimethylsilyl)vinylaziridine $\mathbf{4 6}$ underwent palladium-catalyzed carbonylation at 1 bar CO pressure leading to the exclusive formation $\delta$-lactam 228 (Scheme 70). ${ }^{44}$ The formation of this product has been explained through an unsymmetrical $\pi$-allyl-Pd complex 229. The preference for carbonylation occurring adjacent to Si may result due to the shorter C-Pd bond length in $229,{ }^{121}$ leading to the formation of the acyl palladium species 230. The latter complex may undergo cyclization at a faster rate after photodesilylation. The reaction was observed to depend on the $\mathrm{CO}$ concentration which influenced the equilibrium concentration of the acyl palladium species 230. At higher pressure of $\mathrm{CO}$ (50 bar), $\beta$-lactam was still the major product (three diastereomers in overall yield of $43 \%$ ) while the $\delta$-lactam 228 was obtained in only $20 \%$ yield.

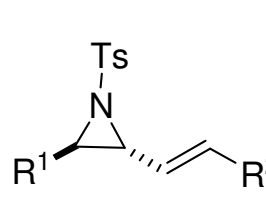

46

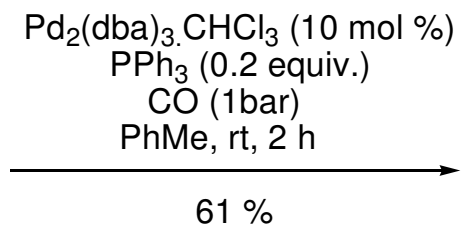

$\mathrm{R}^{1}=\mathrm{Ph}$ $\mathrm{R}^{2}=\mathrm{SiMe}_{3}$<smiles>[R7]C1C=CCC(=O)N1[AsH2-]</smiles>

228<smiles>[18O]C(=C[SiH3])C=C(N[As])c1ccccc1</smiles>

229

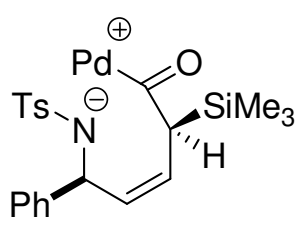

230

\section{Scheme 70}




\subsection{Synthesis of piperazines}

Samanta and coworkers have reported a $\mathrm{BF}_{3} . \mathrm{OEt}_{2}$-mediated highly regioselective ring-opening of less reactive $\mathrm{N}$-Ts chiral aziridines $\mathbf{1 1 0 b}$ to synthesize piperazines $235 .{ }^{122}$ The $\mathrm{N}$-Ts chiral aziridines, derived from $\alpha$-amino acids, underwent a ring-opening reaction with S-phenylalanine methyl ester hydrochlorides 231 to form secondary amines 232, which were then protected using mesyl chloride. The mesyl protected 233 were treated with $\mathrm{LiBH}_{4}$ to afford carbinols 234. Finally, the Mitsunobu cyclization of 234 with diethylazodicarboxylate (DEAD) furnished cis-2,5-disubstituted chiral piperazines 235 (Scheme 71). This reaction sequence was exploited for the preparation of piperazine core framework of natural product $(+)$ piperazinomycin.
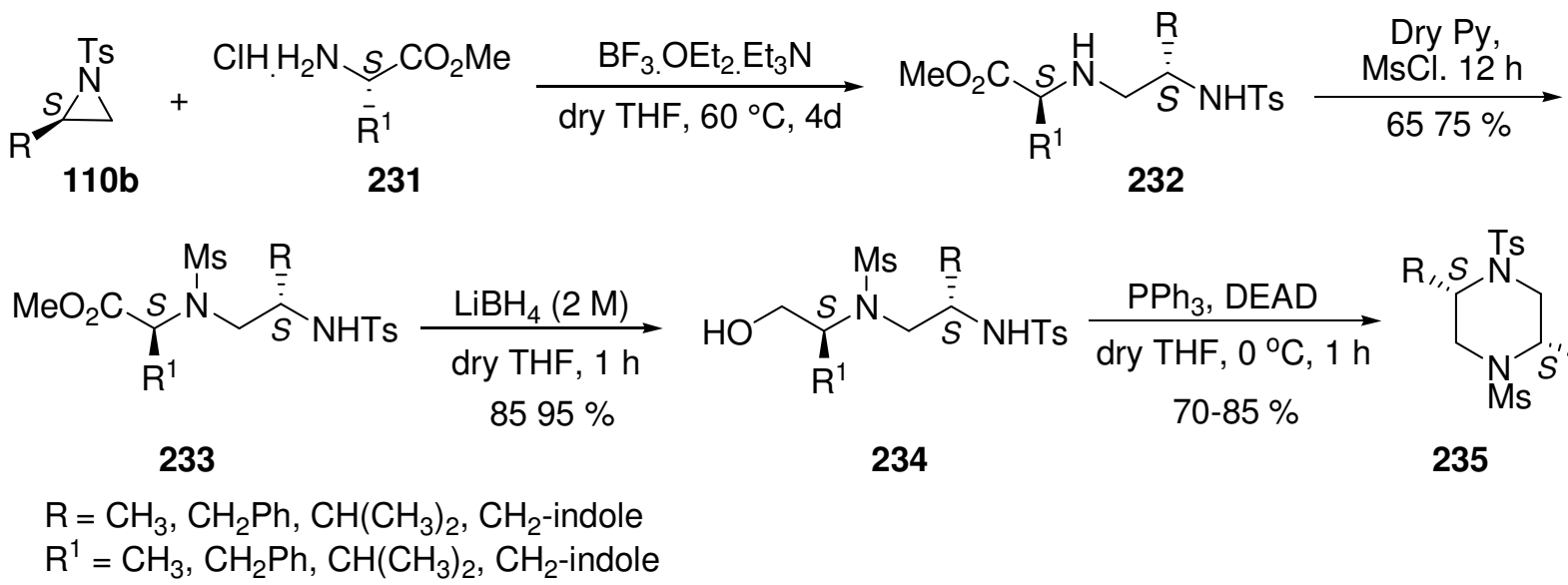

234

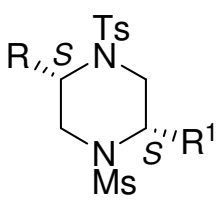

235

\section{Scheme 71}

Treatment of $\mathrm{N}$-alkyl arylaziridines 105 with a catalytic amount of a Lewis acid, magnesium bromide furnished corresponding 2,5-disubstituted $N, N$-dialkylpiperazines 236 as a 1 : 1 mixtures of two easily separable diastereoisomers together with the meso-product 237 (Scheme 72). ${ }^{123}$ Enantioselective version (er $>98: 2$; yield $40 \%)$ of this transformation was also developed, chiral aziridines $(S)$ and $(R)$ gave the chiral $(S, S)$ and $(R, R)$ piperazines, respectively, together with meso-compounds.

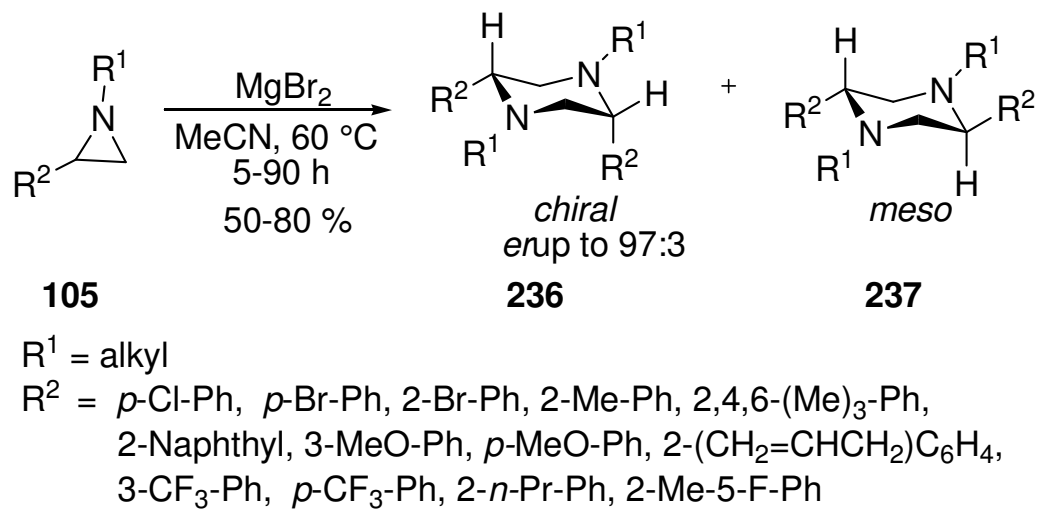

\section{Scheme 72}




\subsection{Synthesis of pyrimidines}

Zheng and Wu have reported a base-promoted tandem reaction of 2-(2-alkynylphenyl)aziridines 238 with 2isocyanoacetates 239 in the presence of copper(II) triflate (Scheme 73). ${ }^{124}$ This reaction led to an entry into tetrahydro-3H-indeno[2,1-d]pyrimidine ring system 240 in moderate to good yields. When a 2-(2alkynylphenyl)aziridines with a tert-butyl group attached to the carbon-carbon triple bond was used, the product was obtained in trace amount.<smiles>[R]C#CC1=CC=C[R]C=C1C1C([R9])N1[AsH3-]</smiles>

238<smiles>[R]OC(=O)C[18O]</smiles>

239

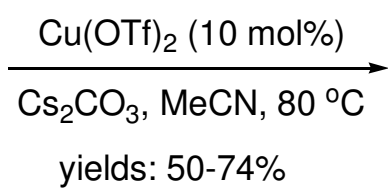

yields: $50-74 \%$

$\mathrm{R}^{1}=\mathrm{H}, \mathrm{Me}, \mathrm{Cl}, \mathrm{F}, \mathrm{OR} ; \mathrm{R}^{2}=\mathrm{Ph}, 4-\mathrm{ClPh}$, 4-MePh, 4-MeOPh; $\mathrm{R}^{3}=\mathrm{H}, \mathrm{Me}$, Et, $n$-Pr; $\mathrm{R}^{4}=\mathrm{Et}, t-\mathrm{Bu}$<smiles>[R2]C=C1c2ccc([R7])cc2[C@H]2C([R3])N([3H])C=N[C@]12C=[R20]</smiles>

240

(15 examples)

\section{Scheme 73}

Wang and coworkers have reported a catalytic enantioselective ring-opening followed by formal [3+3]cycloaddition reaction of 3-isothiocyanato-2-oxindoles 241 with $\mathbf{N}$-(2-picolinoyl)aziridines 242 leading to the formation of pyrimidine ring spiro-fused to 2-oxindole ring $244 .{ }^{125}$ The authors have employed a magnesium catalyst generated in situ using (R)-3,3'-fluorous-BINOL 243 as a chiral ligand to synthesize a series of enantioenriched pyrimidines (Scheme 74). The authors have reported that variation of the ring systems on aziridine was well tolerated as the products were obtained in moderate to good yields but with excellent diastereo- and enantioselectivity.<smiles>[R7]N1C(=O)C(N=C=S)c2cc[Y]([H])cc21</smiles>

241<smiles>[R9]C1C([2H])N1C(=O)c1ccccn1</smiles>

242
1. $\mathrm{Bu}_{2} \mathrm{Mg}, 243, \mathrm{PhMe}$ $0^{\circ} \mathrm{C}$ - r. t.,

2. $t$-BuOK, Mel, THF, $0^{\circ} \mathrm{C}, 10 \mathrm{~min}$ yields: up to $92 \%$ $\mathrm{dr}:>20 / 1$ ee: up to $>99 \%$

$$
\begin{aligned}
\mathrm{R}^{1}= & \mathrm{H}, 5-\mathrm{Me} ; \mathrm{R}^{2}=\mathrm{Me}, \mathrm{Bn}, n-\mathrm{Pr} ; \\
\mathrm{R}^{3}= & C \text {-hex, } C \text {-pent, } C \text {-hexene, } \\
& \text { tetrahydronaphthale, } \\
& \text { Me, Et, } \mathrm{Ph}
\end{aligned}
$$<smiles>Oc1c(F)cc2ccccc2c1-c1c(O)c(F)cc2ccccc12</smiles><smiles>[R]c1ccc2c(c1)[C@@]1(N=C(C)N(C(=O)c3ccccn3)C([R3])[C@H]1[R3])C(=O)N2[R]</smiles>

(14 examples)

244

\section{Scheme 74}




\subsection{Synthesis of dihydroxazines}

Oxazines are heterocycles with diverse properties useful in material and medicinal chemistry. Some fluorescent dyes such as Nile red and Nile blue possess the aromatic benzphenoxazine structural motif. ${ }^{126}$ The 1,3-oxazines possess biological properties such as antifungal, ${ }^{127,128}$ antibacterial, ${ }^{129,130}$ antitumor, ${ }^{131}$ antimalarial $^{132}$ and anti-HIV agents. ${ }^{133}$ They are also used as monomers for polymer formation and photochromic agents. ${ }^{134}$

The chiral $N$-tosylaziridines 245 undergo a tandem ring-opening/ closing reaction with propargyl alcohols 246 in the presence of potassium tert-butoxide in dimethylsulfoxide at $40{ }^{\circ} \mathrm{C}$ furnishing 3,4-dihydro- $2 \mathrm{H}-1,4-$ oxazines 247 in reasonable yields (Scheme 75). ${ }^{135}$ Various chiral mono $N$-tosylaziridines bearing substituents with different electronic and steric effects were tolerated with the exception of unsubstituted and benzyl substituted $N$-tosylaziridines. Substituent on the aryl propargyl alcohols had no effect on the yield. The most plausible mechanism involves formation of an oxygen nucleophile by deprotonation of aryl propargyl alcohols 246 by potassium tert-butoxide. The oxygen nucleophile reacts with the $N$-tosylaziridine 245 to furnish nucleophilic intermediate 248. Isomerization of intermediate $\mathbf{2 4 8}$ leads to generation of an allene intermediate $\mathbf{2 4 9}$ which then undergoes intramolecular nucleophilic ring-closing reaction to aryl dihydroxazine 247. ${ }^{135}$
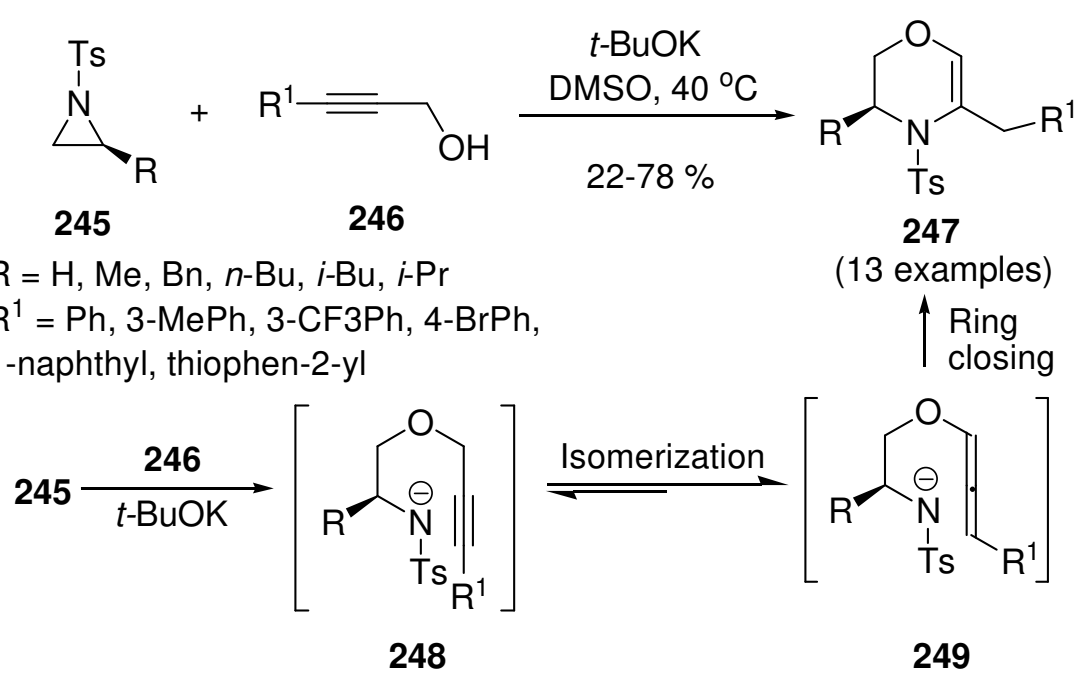

\section{Scheme 75}

A gold(I)-catalyzed tandem ring-opening and 6-exo dig cyclization/isomerization of aziridines 17 with propargylic alcohols $\mathbf{2 5 0}$ is reported as an efficient entry to functionalized 3,4-dihydro-2H-1,4-oxazine ring system 251. ${ }^{136}$ The latter compounds could be easily reduced to corresponding morpholines. The $N$ tosylaziridines with different electronic environments on C-2 and C-3 positions undergo an easy nucleophilic ring-opening by $S_{N} 1$ mechanism followed by cyclization/isomerization cascade (Scheme 76). The gold(I) catalyst serves as both $\pi$ acid and $\sigma$ acid, to activate both the substrates in the reaction. The $N$ benzoylaziridines did not react under these conditions. The symmetric bicyclic aziridines used in study led to the synthesis of corresponding fused-oxazines in reasonable yields at $55^{\circ} \mathrm{C}$. 


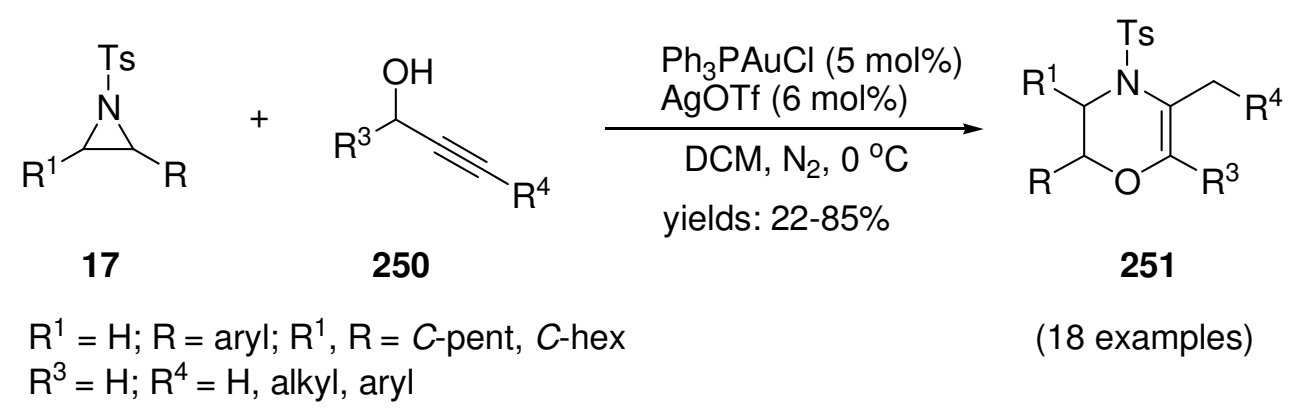

\section{Scheme 76}

\subsection{Synthesis of dihydrobenzoxazines and dihydrobenzothiazines}

Bhadra and coworkers have reported the synthesis of a series of diversely functionalized 1,4-benzoxazines $\mathbf{2 5 3}$ by $\mathrm{Al}_{2} \mathrm{O}_{3}$-supported $\mathrm{Cu}(\mathrm{II}$ )-catalyzed domino aziridine ring-opening of $\mathrm{N}$-tosylaziridines $\mathbf{1 1 0}$ with 2-iodophenols 252 followed by cyclization (Scheme 77). ${ }^{137}$ The catalytic system was prepared by stirring an aqueous solution of $\mathrm{CuSO}_{4}-5 \mathrm{H}_{2} \mathrm{O}$ with basic alumina for $2 \mathrm{~h}$ at room temperature. ${ }^{138}$ The 2,3-dialkylaziridines and cycloalkanefused aziridines were also employed successfully. The nucelophilic attack occurred regioselectively at benzylic carbon leading to the cleavage of $\mathrm{C} 2-\mathrm{N} 1$ bond only when the catalyst was used. The catalyst could be recovered and reused for seven times without any loss of efficiency. Ghorai and coworkers have reported the synthesis of chiral dihydrobenzothiazines 255 through regio- and stereoselective $\mathrm{S}_{\mathrm{N}} 2$-type ring-opening of activated aziridines 17 with 2-halothiophenols 254 followed by copper powder-mediated C-N bond cyclization (Scheme 78). ${ }^{52}$

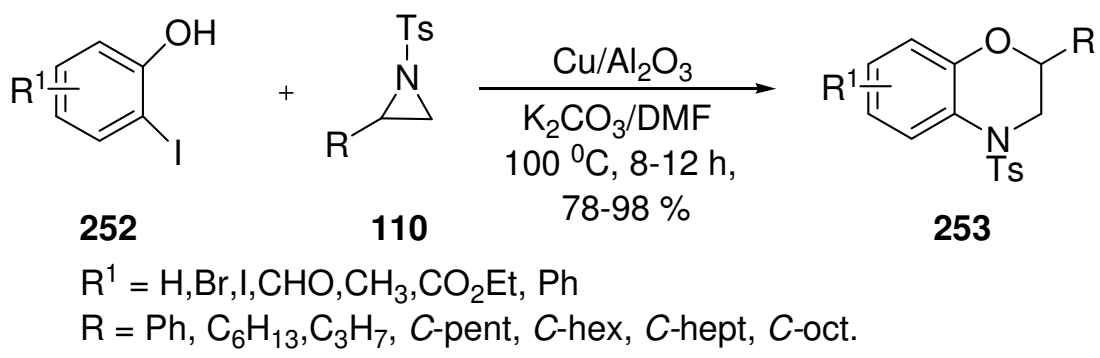

\section{Scheme 77}

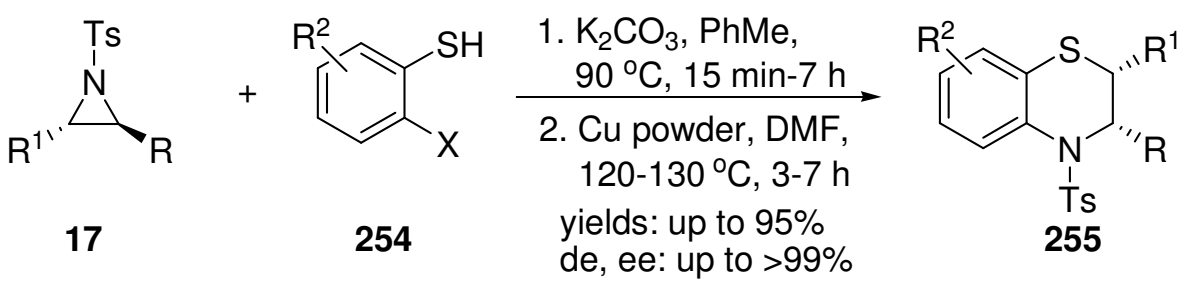

$\mathrm{X}=\mathrm{Cl}, \mathrm{Br} ; \mathrm{R}^{2}=\mathrm{Me}, \mathrm{F}, \mathrm{Cl}$

$\mathrm{R}^{1}=\mathrm{Ph}, 2-\mathrm{CIPh}$, 3-CIPh, 4-CIPh, 2-BrPh, 4- $t-\mathrm{BuPh}$

$\mathrm{R}=\mathrm{H}, \mathrm{Me}, \mathrm{n}-\mathrm{Pr}, n-\mathrm{Bu}, i-\mathrm{Pr}, i-\mathrm{Bu}, t-\mathrm{Bu}$

\section{Scheme 78}


De Kimpe and coworkers have reported the synthesis of dihydrobenzoxazines, dihydrobenzothiazines, dihydrobenzodioxines, dihydrobenzodithiines, and dihydrobenzoxathiines 256 and 257 from cis-1-tosyl-2tosyloxymethyl-3-(trifluoromethyl)aziridine 43 (Scheme 79). ${ }^{38} \mathrm{~A}$ regioselective ring-opening occurs either directly forming intermediate $\mathbf{2 5 9}$ or through another aziridine $\mathbf{2 5 8}$ depending on the nucleophile used. The sulfur-nucleophile led to nucleophilic substitution on aziridine followed by ring-opening whereas the oxygen nucleophile led to ring-opening first.

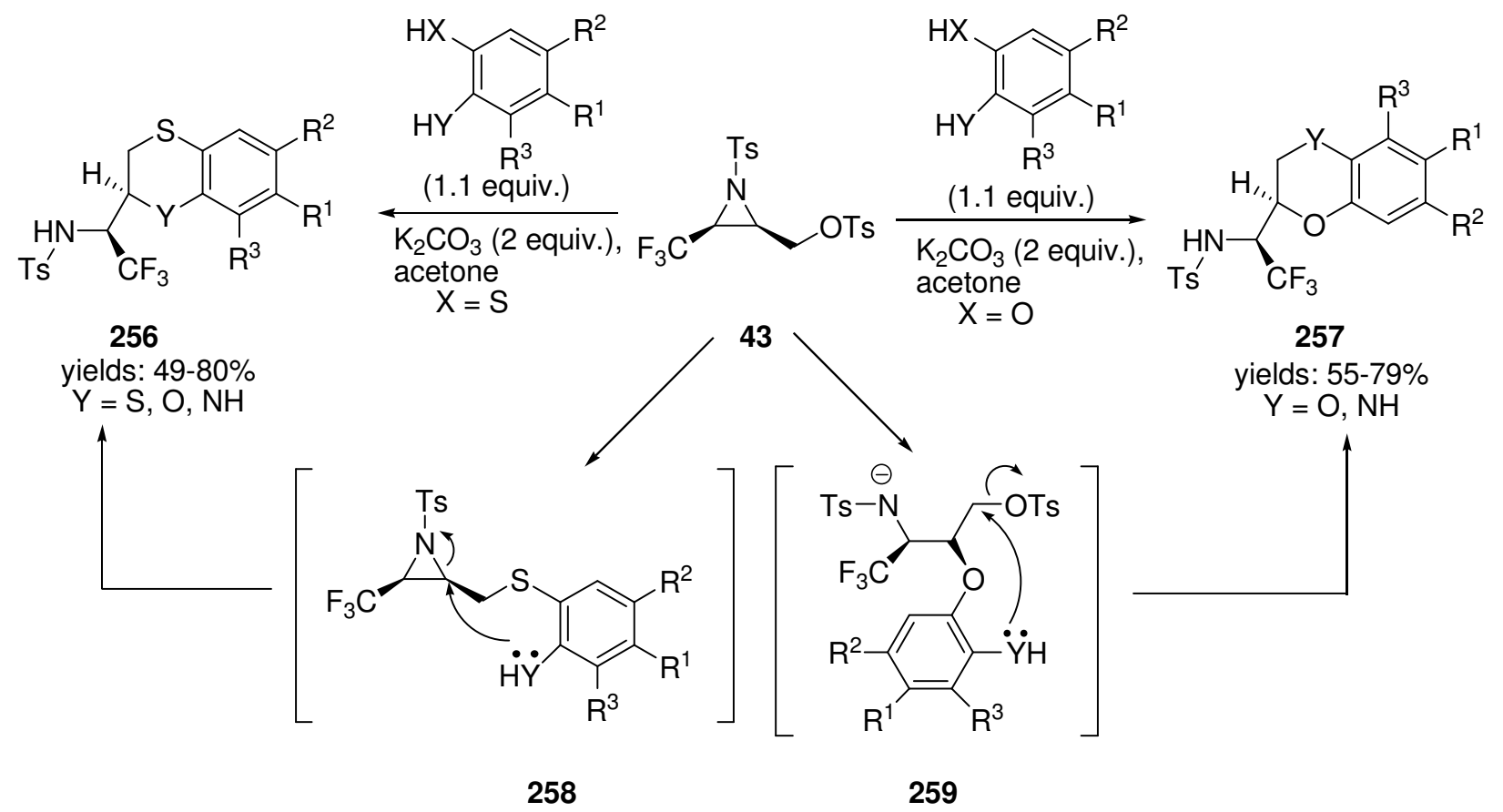

\section{Scheme 79}

\subsection{Synthesis of morpholines and thiomorpholines}

The ring-opening of aziridines with different nucleophiles followed by cyclization has been reported to form morpholine derivatives by different group. In 2010, Bornholdt developed a method to access 3-substituted morpholines 264 from N-2-benzothiazolesulfonyl (Bts)-activated aziridine 260 (Scheme 80). ${ }^{139}$ The reaction involved the $\mathrm{Cu}$-catalyzed ring-opening of aziridine with Grignard reagents forming aminoethers 261 that were converted to alcohols 262. A subsequent ring-annulation reaction with a vinylsulfonium salt forming morpholines $\mathbf{2 6 3}$ followed by the deprotection of $\mathrm{N}$-Bts group under very mild conditions led to the formation of final products. 


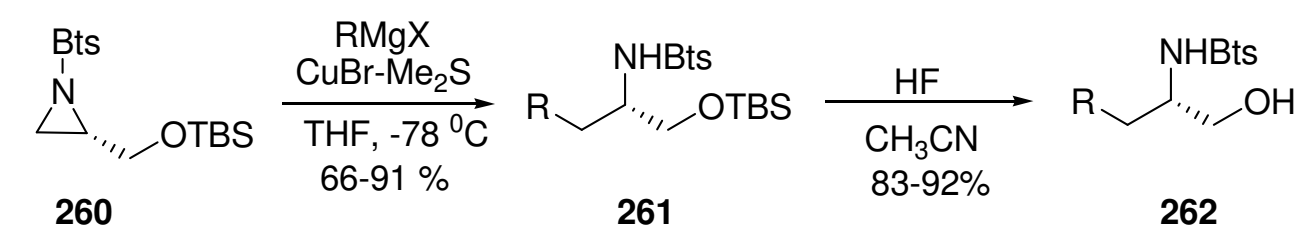

$$
\mathrm{R}=\mathrm{Me} \text {, Et, vinyl, } C \text {-prop, } \mathrm{Ph}, \mathrm{p}-\mathrm{MeO}-\mathrm{Ph}
$$<smiles>[2H]C[C@H]1COCCN1</smiles>

264

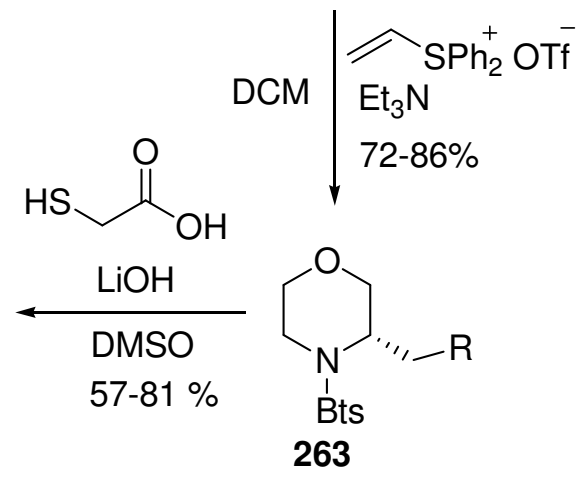

\section{Scheme 80}

Ghorai and coworkers have published several papers on Lewis acid-catalyzed ring-opening reaction of activated aziridines. ${ }^{140,141} \mathrm{~A} \mathrm{Cu}(\mathrm{OTf})_{2}$-catalyzed highly regioselective $\mathrm{S}_{\mathrm{N}}$ 2-type ring-opening of chiral aziridines 126 with 2-chloroethanol 265 followed by cyclization furnishing morpholines $\mathbf{2 6 6}$ is reported (Scheme 81). ${ }^{142}$ The partial racemization of the starting aziridine was prevented by using quaternary ammonium salts to get the product with high enantioselectivity (up to 99\%) and diastereoselectivity (up to 99\%). The highest enantioselectivity of $90 \%$ was observed with $N$-tosyl-2-phenylaziridine when the reaction was carried out at $50{ }^{\circ} \mathrm{C}$ for 6 hours.

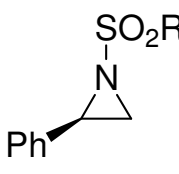

126<smiles>[C+]CCO</smiles>

265
1. $\mathrm{Cu}(\mathrm{OTf})_{2}$, TBAHS

$\mathrm{DCM}, 0--50^{\circ} \mathrm{C}$

2. $\mathrm{KOH}, \mathrm{THF}, \mathrm{r} . \mathrm{t}$. 20 min- $6 \mathrm{~h}$ yields: $56-62 \%$ ee: $82-90 \%$<smiles>O=S(=O)(O)N1CCO[C@H](c2ccccc2)C1</smiles>

266

$\mathrm{R}=\mathrm{Ph}, 4-\mathrm{MeOPh}, 4-\mathrm{FPh}$

\section{Scheme 81}

McGhee has described the synthesis of 2,5-disubstituted and 2,3,5-trisubstituted morpholines 270 from carbamate-protected aziridines $\mathbf{2 6 7}$ in either a two-step sequence (Scheme 82), or a one-pot domino reaction sequence. ${ }^{143}$ In the two-step sequence, Lewis acid catalyzed selective attack of allyl alcohol $\mathbf{2 6 8}$ at the more substituted carbon atom of aziridines afforded aminoalkenes 269 , which underwent hydroamination in the presence of palladium catalyst $\mathbf{2 7 1}$ to afford substituted morpholines $\mathbf{2 7 0}$. They also showed a one-pot ring opening-hydroamination eliminating the need to isolate the amioalkene intermediate procedure using $\mathrm{AgBF}_{4}$ as the latter can also act as a mild Lewis acid. 


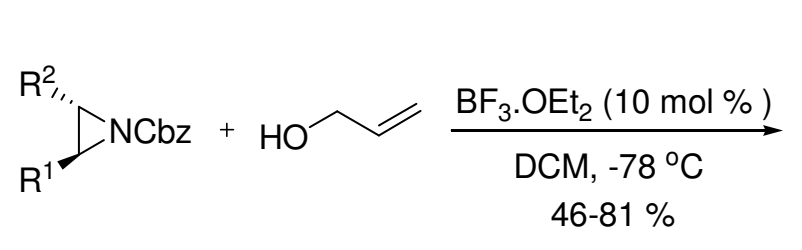

267
268

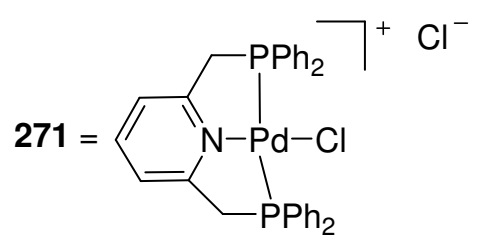<smiles>[R]C(=O)NC([R])C([R7])OCC=C</smiles>

269

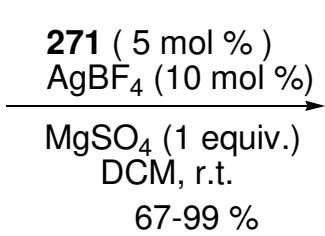

$67-99 \%$

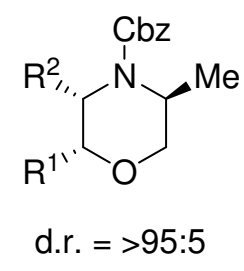

270

$\mathrm{R}^{1}=\mathrm{H}$, Me, Et, $n$-Bu, $C$-hex, $t$-Bu, $\mathrm{CH}_{2} \mathrm{Ph}, \mathrm{Ph}$

$\mathrm{R}^{2}=\mathrm{H}, \mathrm{Me}$

\section{Scheme 82}

Xia and coworkers have reported a metal-free one-pot synthesis of 2-substituted and 2,3-disubstituted morpholines from $\mathrm{N}$-tosyl-substituted 2-arylaziridines. ${ }^{144}$ This group has used a simple and inexpensive reagent ammonium persulfate as an oxidant for aziridine ring-opening with 2-haloethanols. Use of optically pure aziridines in reactions led to the synthesis of chiral morpholines in 95-99\% ee but in low to moderate yields. It is assumed that aziridine participates in single electron transfer (SET) with the persulfate anion to generate the radical cation 273 (Scheme 83). A concerted ring-opening and nucleophilic addition gives an amino radical intermediate 274. This radical is converted to a haloamine alkoxy intermediate $\mathbf{2 7 5}$ by abstraction of a hydrogen atom from alcohol. Finally, the cyclization in presence of a base gives morpholines.

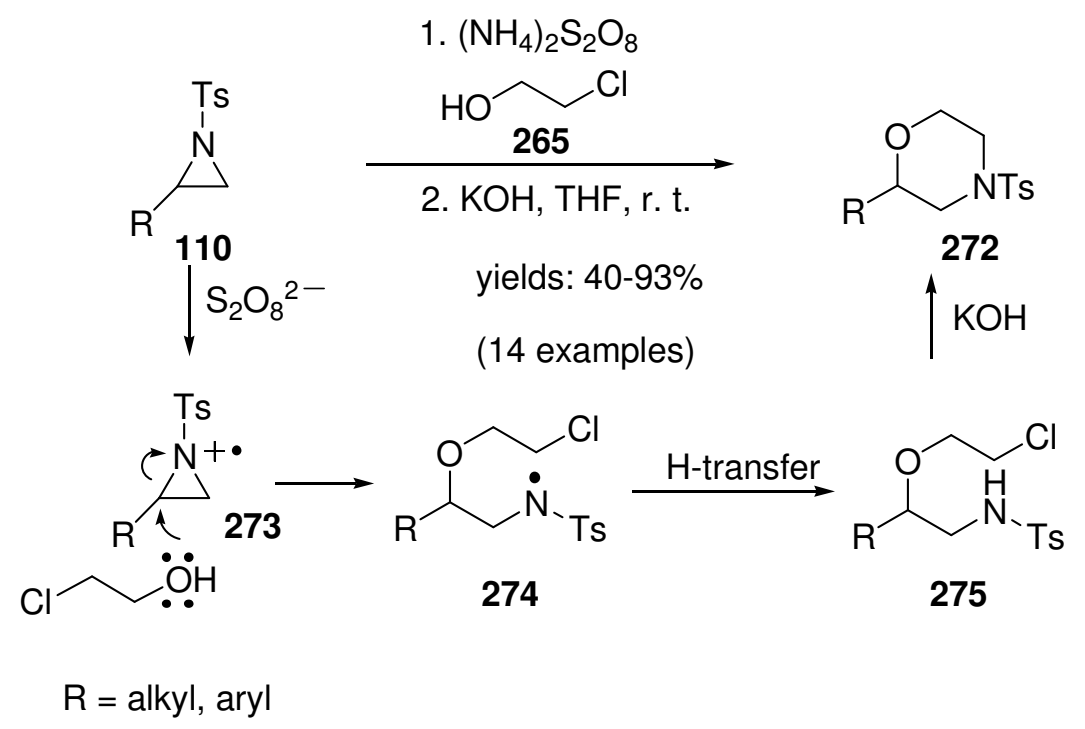

\section{Scheme 83}

Samzadeh-Kirmani has reported a single-pot reaction of 2-substituted aziridines, nitromethane, and isothiocyanates forming 1,4-thiomorpholine. ${ }^{145}$ The reaction gave the best yield when potassium carbonate was used as base in THF. The reaction occurs at $60^{\circ} \mathrm{C}$ in eight hours.

Pathipati and coworkers have reported the expansion of aziridine ring to a six-membered heterocyclic series with three heteroatoms, one oxygen and two nitrogen atoms, in the ring. ${ }^{146} A$ series of $1,2,4-$ oxadiazinanes $\mathbf{2 7 8}$ have been synthesized by reactions of aziridines $\mathbf{2 7 6}$ with nitrones $\mathbf{2 7 7}$ in the presence of 
indium(III) chloride as a Lewis acid catalyst (Scheme 84). The $\mathrm{N}$-benzylaziridines reacted even without catalyst but furnished low yields. The $\mathrm{N}$-ethylaziridine, however, did not react in the absence of a catalyst. Also, $\mathrm{N}$ tosylaziridine did not undergo annulation probably due to weak Lewis acid activation or less nucleophilicity of the $N$-tosyl group.<smiles>[R]C1C([R7])N1[18O]</smiles><smiles>[R7]C1ON([R])C([R7])N([R])C1[R]</smiles><smiles>CN1O[C@@H](c2ccccc2)CN(Cc2ccccc2)C1c1ccccc1</smiles>

$87 \%$<smiles>CCN1CC(c2ccccc2)ON(C)C1c1ccccc1</smiles>

$51 \%$<smiles>CN1O[C@@H]2CCCC[C@H]2N(Cc2ccccc2)C1c1ccccc1</smiles>

$90 \%$
278<smiles>COc1ccc(C2N(Cc3ccccc3)O[C@H]3CCCC[C@H]3N2Cc2ccccc2)cc1</smiles>

\section{Scheme 84}

Wulff and coworkers have reported the formation of morpholine-2,3,6-triones $\mathbf{2 8 0}$ from the reaction of cis1-benzhydryl-3-arylaziridine-2-carboxylic acids 279 with oxalyl chloride (Scheme 85). ${ }^{45}$ The authors have suggested two possible mechanisms for the formation of products. The first possibility is an initial ring-opening of the aziridine $\mathbf{2 8 1}$ to give the $\beta$-chloramine $\mathbf{2 8 2}$ which may cyclize to morpholine-2,3,6-triones. Alternatively, a nucleophilic addition of the aziridine nitrogen to acyl chloride unit may form an aziridinium ion 283 which can be opened by chloride ion.

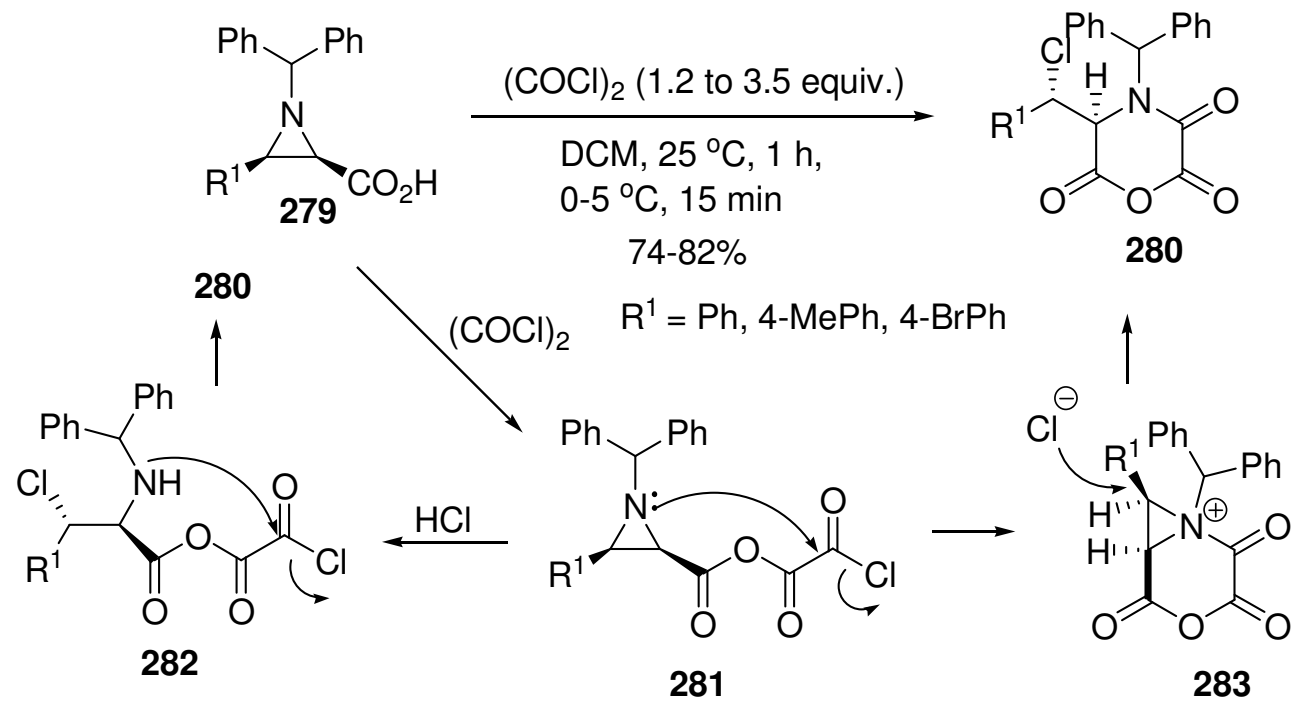

\section{Scheme 85}




\section{Synthesis of Seven-membered Heterocycles}

\subsection{Synthesis of azepanes}

Azepane motif is present in a number of important heterocyclic compounds and bioactive alkaloids. ${ }^{147}$ The functionalized azepanes have flexible ring structures and this conformational diversity is important for their bioactivity. The structural flexibility of azepanes offers potent inhibition against various enzymes. ${ }^{148}$

The ring-expansion of aziridines to seven-membered heterocyclic systems is a difficult to achieve goal. De Kimpe and coworkers reported the formation of azepanes through piperidines, obtained in turn, by a ringexpansion of 2-(2-cyano-2-phenylethyl)aziridine. ${ }^{149}$ Later on, this group has described the ring-expansion of 2(4-chlorobutyl)-1-tosyl-2-(trifluoromethyl)aziridine to azepanes (Scheme 86). ${ }^{13}$ Of the two possible mechanisms, the first involved an initial cleavage of aziridine ring by alkyl amines at C-3 position followed by substitution of chloride with iodide leading to the formation of an intermediate $\mathbf{2 8 4}$ (path a). The intermediate $\mathbf{2 8 4}$ may cyclize to azepanes $\mathbf{2 8 6}$ via an intermediate 287. Another possible mechanism involved an initial substitution at alkyl halide side-chain of aziridines by amines furnishing another aziridines 285 which underwent an intramolecular ring-opening (path b).

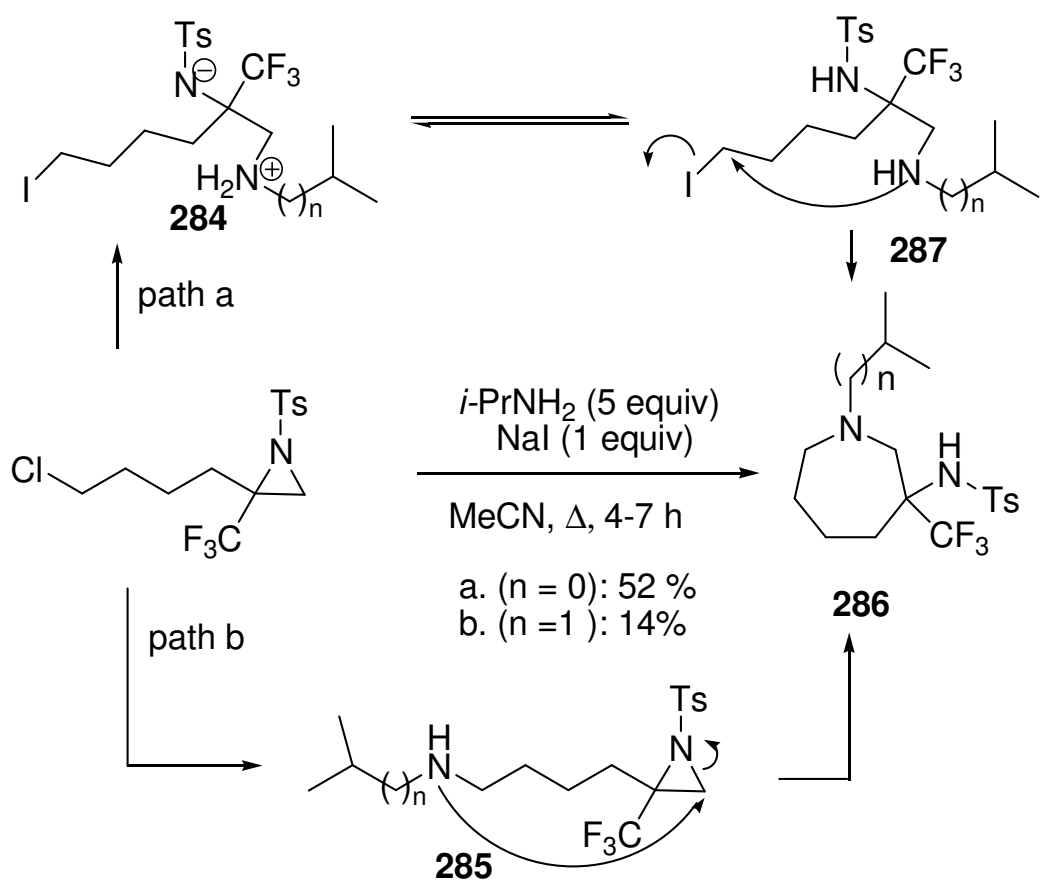

\section{Scheme 86}

\subsection{Synthesis of diazepinones}

Saito and coworkers have reported a [5+2]-cycloaddition reaction of 1-benzyl-2-vinylaziridines 288 with sulfonyl isocyanates $\mathbf{2 8 9}$ under mild conditions forming cyclic ureas, diazepinones $\mathbf{2 9 1}$ in good yields (Scheme 87). ${ }^{150}$ It is worth mentioning that the reaction did not require any catalyst. The reaction was, however, extremely sensitive to solvents. The seven-membered heterocyclic products were obtained in dichloromethane. The change of solvent from dichloromethane to DMF led to the formation of imidazolidin-2ones. The reaction may proceed through an aziridinium ion $\mathbf{2 9 0}$, generated by nucleophilic attack of aziridine nitrogen atom on the electrophilic carbon atom of the isocyanate. 


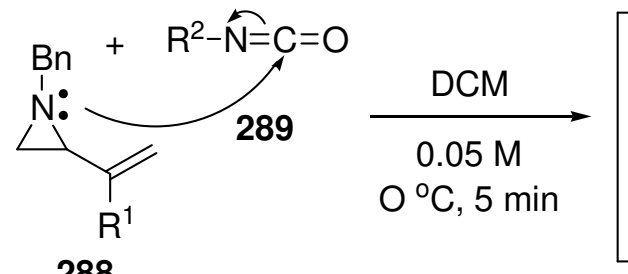

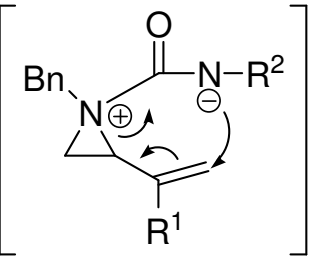

290

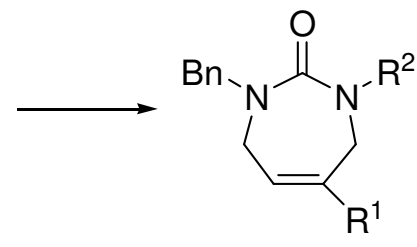

291

$R^{1}=$ Me, $R^{2}=$ Ts: $82 \% ; R^{1}=$ Me, $R^{2}=M s: 89 \%$;

$R^{1}=P h, R^{2}=T s: 90 \% ; R^{1}=P h, R^{2}=M s: 52 \%$;

$R^{1}=$ OTBS, $R^{2}=T s: 59 \% ; R^{1}=$ OTBS, $R^{2}=M s: 48 \%$;

\section{Scheme 87}

\subsection{Synthesis of benzodiazepines, benzoxazepines and benzothiazepines}

Ghorai and coworkers have reported a simple and stereospecific method for the synthesis of 2,3,4,5tetrahydrobenzodiazepines 293 from aziridines 82 (Scheme 88). ${ }^{151}$ An $\mathrm{S}_{\mathrm{N}} 2$-type ring-opening of $\mathrm{N}$-activated aziridines with 2-bromobenzylamine $\mathbf{2 9 2}$ followed by an intramolecular cyclization through copper-mediated $\mathrm{C}-\mathrm{N}$ bond formation led to the formation of products. The scope of the reaction is quite wide as a diverse array of aziridines could be employed successfully to furnish the products in excellent yields (up to $94 \%$ yield) with very high enantioselectivity (up to $99 \%$ ee).

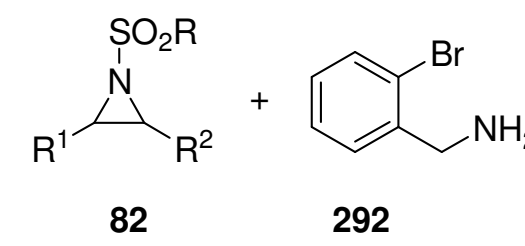

$\operatorname{Ar}=\operatorname{aryl} ; R^{1}=\operatorname{Ar} ; R^{2}=H, R^{1} R^{2}=C$-hex
1. $\mathrm{LiClO}_{4}(30 \mathrm{~mol} \%)$ $\mathrm{MeCN}, \mathrm{D}, 3.5-15 \mathrm{~h}$

2. Cu-powder (1 equiv.) DMSO, $120^{\circ} \mathrm{C}, 1-7 \mathrm{~h}$ yields: up to $94 \%$ ee up to: $99 \%$<smiles>[R]C1NCc2ccccc2N(S(=O)(=O)O)C1[R]</smiles>

293

(14 examples)

\section{Scheme 88}

Ghorai group has also reported similar ring-opening of $\mathrm{N}$-activated aziridines 110 with 2bromobenzylalcohol 294, and 2-bromobenzylthiol 297 forming ring-opened products 295 and 298, respectively. The copper-catalyzed cyclization of these products led to synthesis of corresponding tetrahydrobenzoxazepines 296 (Scheme 89) and tetrahydrobenzothiazepines 299 (Scheme 90). ${ }^{152}$

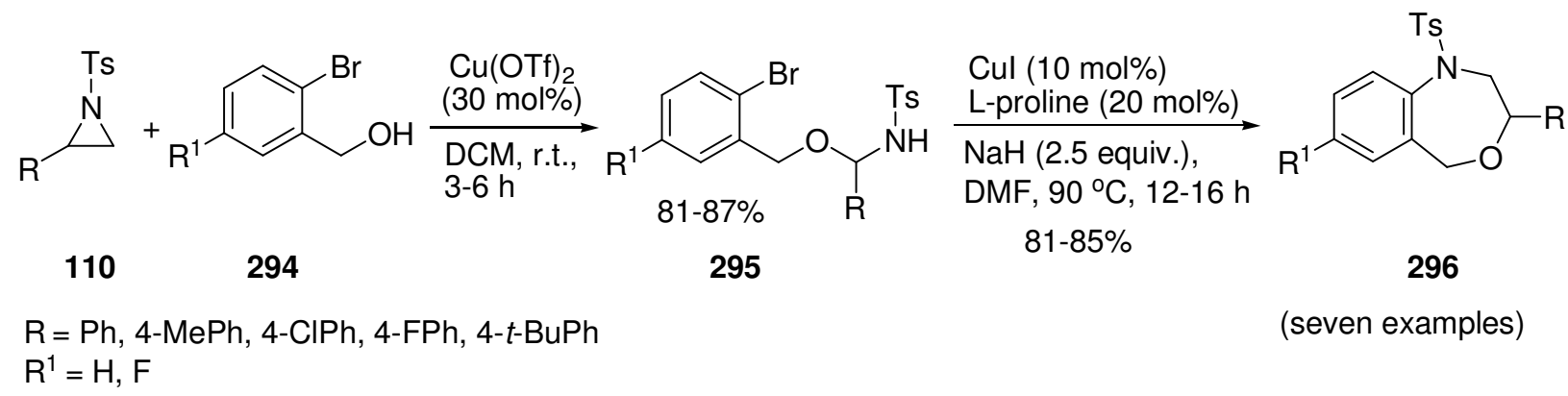

\section{Scheme 89}




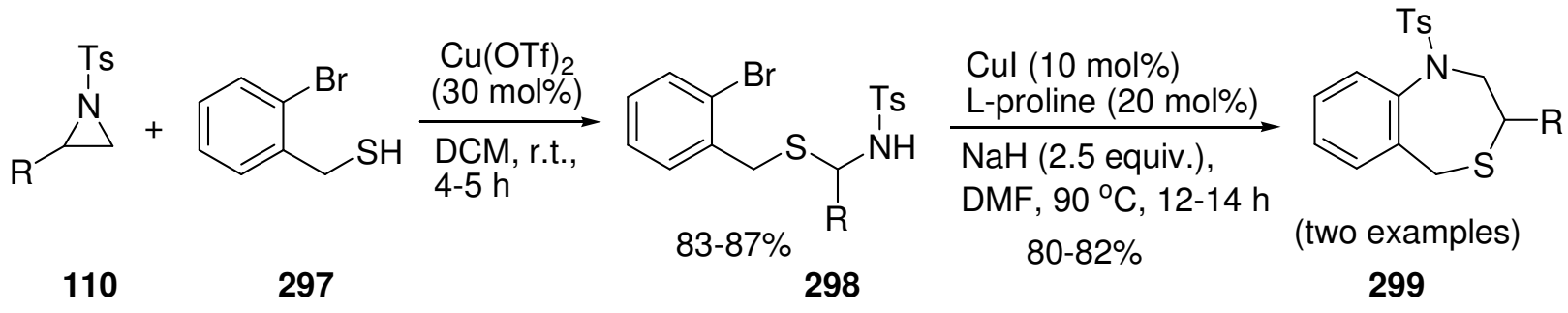
$\mathrm{R}=\mathrm{Ph}, 4-\mathrm{CIPh}$

\section{Scheme 90}

The aziridine ring opening with hydroxyphenyl acrylates and aminophenyl acrylates followed by intramolecular $\mathrm{C}-\mathrm{N}$ bond formation through the palladium-catalyzed aza-Michael reaction is reported recently as a straightforward approach for the synthesis of 2,3,4,5-tetrahydrobenzoxazepines 302 (Scheme 91) and 2,3,4,5-tetrahydrobenzodiazepine 305, respectively (Scheme 92). The products are obtained in high yields (up to $82 \%$ ) with an excellent enantioselectivity (ee up to $94 \%$ ). ${ }^{153}$ The relative stereochemistry at 2,5-positions was observed as cis. The reaction is quite general as a number of activated aziridines with various aryl groups at C-2 position and different arylsulfonyl groups on ring nitrogen have been employed. According to proposed mechanism, the $S_{N}$ 2-type reaction of acrylates occurs at the benzylic carbon of the aziridines leading to ring opening. The ring-opened products 301 and $\mathbf{3 0 4}$ undergo a Wacker-type reaction involving addition of $N$ sulfonylaryl group to the palladium-coordinated olefinic moiety generating the intermediates 306 and 307 . The intermediate $\mathbf{3 0 7}$, on reductive elimination affords the desired product and the catalyst $\mathrm{Pd}(0)$ is regenerated.

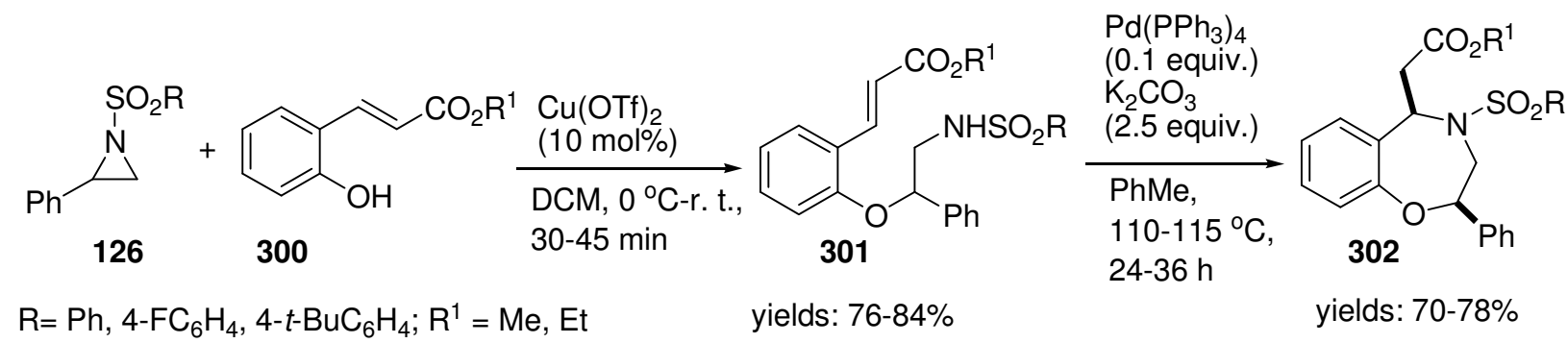

(5 examples)

\section{Scheme 91}




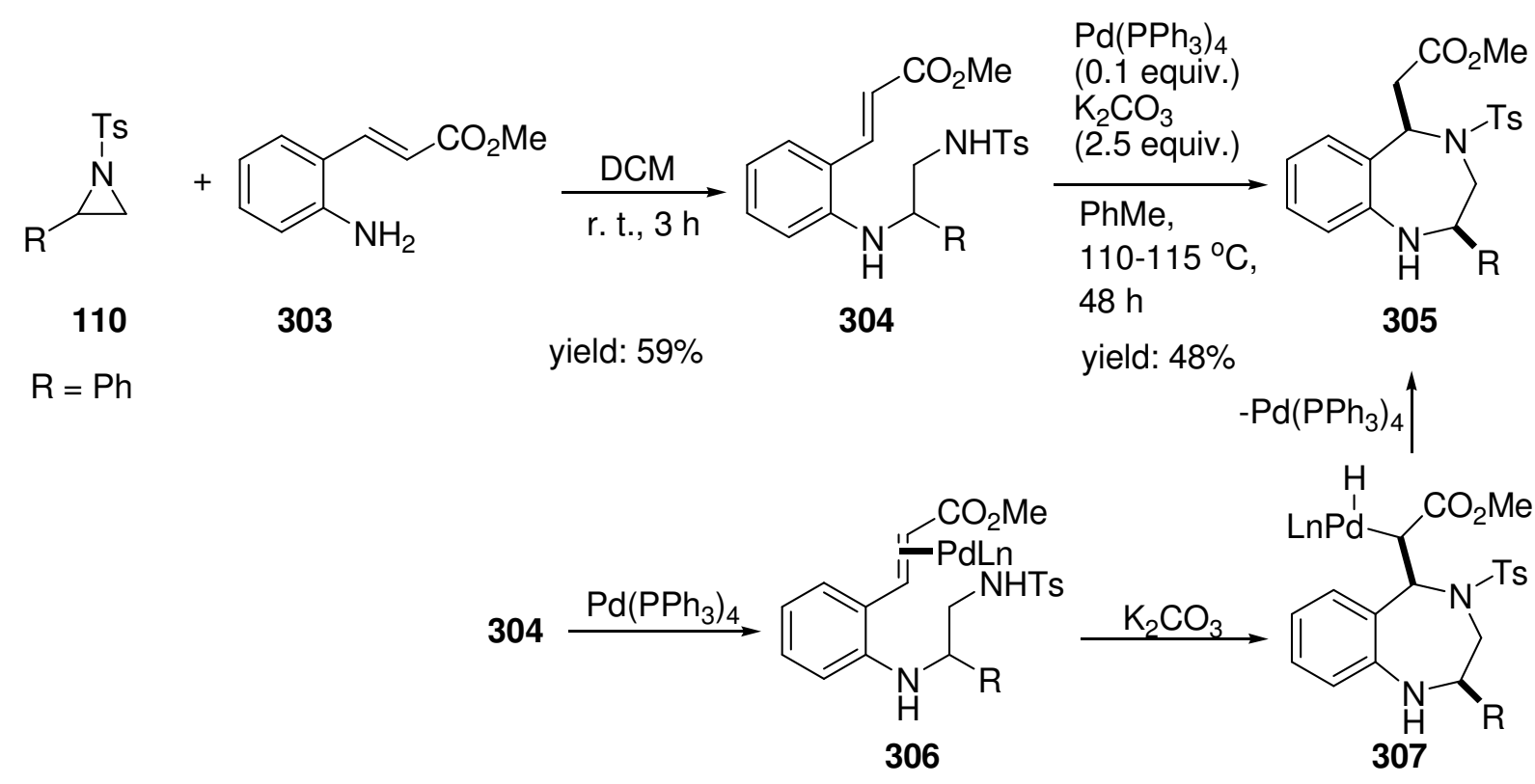

\section{Scheme 92}

\section{Concluding Remarks}

Aziridine ring is undoubtedly a powerful building block for synthesis of diverse types of heterocyclic compounds. Different types of aziridines are easily prepared in laboratory using well-known methods. The investigation on reactivity of aziridine ring with focus on application in synthesis of other heterocyclic compounds has seen resurgence of interest in recent years. Although $\mathrm{N}$-sulfonylaziridines and 2-vinylaziridnes appear to be of great interest $N$-alky/aryl-substituted aziridines have also been thoroughly investigated. The review of literature revealed the application of aziridines in synthesis of four- to seven-membered heterocyclic compounds containing one or more heteroatoms in the ring. Many of these heterocyclic motifs are of immense biological importance. The nucleophilic ring-opening of aziridines has led to the synthesis of azetidines. The synthesis of $\beta$-lactams is reported by a Pd-catalyzed carbonylation reaction of aziridines, and by reaction of aziridines with oxalyl chloride. The Lewis acid catalyzed nucleophilic ring-opening with different types of nucleophiles followed by [3+2]-cycloaddition with a range of dipolarophiles constitutes a general approach for the synthesis of five-membered heterocycles pyrrolidines, oxazolidines, and thiazolidines. These reactions occur in both intra- and intermolecular fashions. The ring-opening of appropriate C-2 chloroalkylsubstituted aziridines followed by cyclization is known to form four- to seven-membered heterocyclic compounds. The fixation of carbon dioxide by aziridines using a number of catalysts is an important method for the preparation of oxazolidinones. Although the Lewis acid-catalyzed cycloadditions are more common a Lewis base-catalyzed fixation of carbon dioxide with $\mathrm{N}$-arylsulfonyl-substituted aziridinofullerenes has been developed to synthesize oxazolidinone-fused fullerenes. Asymmetric synthesis of some five-membered heterocycles is reported as well. The ring-expansion of 2-(2-cyanoethyl)aziridines using $\mathrm{LiAlH}_{4}$, palladiumcatalyzed ring-expansion of 2-vinylaziridines, and magnesium bromide-initiated ring-expansion of aziridines serve as useful methods for the syntheses of piperidines, dihydropyridin-2-ones, and piperazines, respectively. A [3+3]-cycloaddition reaction of 3-isothiocyanato-2-oxindoles with $\mathrm{N}$-(2-picolinoyl)aziridines leading to the formation of pyrimidine ring spiro-fused to 2-oxindole ring is described. A copper-catalyzed aziridine ring- 
opening with various nucleophiles followed by cyclization constitutes an important method for a convenient entry into the five- to seven-membered aza-, oxaza-, and thiazaheterocycles. A bulk of literature in a short span of time indicates continuing interest in the area and more interesting outcome.

\section{Acknowledgements}

Authors are grateful to the Chemistry Department, University of Botswana, Gaborone, Botswana, for providing the necessary facilities.

\section{References}

1. Singh, G. S. Mini-Rev. Med. Chem. 2016, 16, 892 and references therein. https://doi.org/10.2174/1389557515666150709122244

2. Padwa, A.; Murphree, S. S. Arkivoc 2006, iii, 6. http://dx.doi.org/10.3998/ark.5550190.0007.302

3. Padwa, A. In Aziridines and azirines: monocyclic in Comprehensive Heterocyclic Chemistry-III, Katritzky, A.; Ramsden, C.; Scriven, E.; Taylor, R. Eds; Elsevier: UK, 2008; Vol. 1; p 2.

4. Zwanenburg, B.; ten Holte, P. Top. Curr. Chem. 2001, 216, 93. https://doi.org/10.1007/3-540-44726-1 3

5. Singh, G. S.; D’hooghe, M.; De Kimpe, N. Chem. Rev. 2007, 107, 2080. https://doi.org/10.1021/cr0680033

6. Tehrani, K. A.; De Kimpe, N. Curr. Org. Chem. 2009, 13, 854. https://doi.org/10.2174/138527209788167169

7. Heo, Y. M.; Paek, S. M. Molecules 2013, 18, 9650.

https://doi.org/10.3390/molecules18089650

8. Ohno, H. Chem. Rev. 2014, 114, 7784. https://doi.org/10.1021/cr400543u

9. Pellissier, H. Adv. Synth. Catal. 2014, 356, 1899. https://doi.org/10.1002/adsc.201400312

10. Pellissier, H. Tetrahedron 2010, 66, 1509. https://doi.org/10.1016/i.tet.2009.11.089

11. Zhou, S.; Tian, C.; Li, C.; Guo, Y.; Wang, X.; Liu, J.; Zhang, Z. Molecules 2012, 17, 5604. https://doi.org/10.3390/molecules17055604

12. Katagiri, T.; Katayama, M.; Taeda, T.; Ohshima, T.; Iguchi, N.; Uneyama, K. J. Org. Chem. 2011, 76, 9305. https://doi.org/10.1021/jo201554g

13. Dolfen, J.; Kenis, S.; Van Hecke, K.; De Kimpe, N.; D’hooghe, M. Chem. Eur. J. 2014, 20, 10650. https://doi.org/10.1002/chem.201304759

14. Menjo, Y.; Hamajima, A.; Sasaki, N.; Hamada, Y. Org. Lett. 2011, 13, 5744. https://doi.org/10.1021/ol2023054

15. Nemoto, T.; Muramoto, R.; Ruengsatra, T.; Hamada, Y. Tetrahedron 2016, 72, 1991. https://doi.org/10.1016/j.tet.2016.02.067

16. Halskov, K. S.; Naicker, T.; Jensen, M. E.; Jørgensen, K. A. Chem. Commun. 2013, 49, 6382. 
https://doi.org/10.1039/c3cc43506g

17. Liang, L.; Lv, H.; Yu, Y.; Wang, P.; Zhang, J. L. Dalton Trans. 2012, 41, 1457. https://doi.org/10.1039/C2DT11995A

18. Zhu, B. H.; Zheng, J. C.; Yu, C. B.; Sun, X. L.; Zhou,Y. G.; Shen, Q.; Tang Y. Org. Lett. 2010, 12, 504. https://doi.org/10.1021/ol9027072

19. Illa, O.; Arshad, M.; Ros, A.; McGarrigle, E. M.; Aggarwal, V. K. J. Am. Chem. Soc. 2010, 132, 1828. https://doi.org/10.1021/ja9100276

20. Sola, T. M.; Churcher, I.; Lewis, W.; Stockman, R. A. Org. Biomol. Chem. 2011, 9, 5034. https://doi.org/10.1039/c1ob05561e

21. Larson, S. E.; Li, G.; Rowland, G. B.; Junge, D.; Huang, R. H.; Woodcock, H. L.; Antilla, J. C. Org Lett. 2011, 13, 2188.

https://doi.org/10.1021/ol200407r

22. Khoumeri, O.; Spitz, C.; Terme, T.; Vanelle, P. Molecules 2013, 18, 7364. https://doi.org/10.3390/molecules18077364

23. Mukherjee, M.; Gupta, A. K.; Lu, Z.; Zhang, Y.; Wulff, W. D. J. Org. Chem. 2010, 75, 5643. https://doi.org/10.1021/jo101160c

24. Lu, Z.; Zhang, Y.; Wulff, W. D. J. Am. Chem. Soc. 2007, 129, 7185. https://doi.org/10.1021/ja069371r

25. Huang, L.; Wulff, W. D. J. Am. Chem. Soc. 2011, 133, 8892. https://doi.org/10.1021/ja203754p

26. Deng, Y.; Lee, Y. R.; Newman, C. A.; Wulff, W. D. Eur. J. Org. Chem. 2007, 2068. https://doi.org/10.1002/ejoc.200601126

27. Ren, H.; Wulff, W. D. Org. Lett. 2010, 12, 4908. https://doi.org/10.1021/ol102064b

28. Zeng, X.; Xu, Z.; Lu, M.; Zhong, G. Org. Lett. 2009, 11, 3036. https://doi.org/10.1021/ol901047w

29. Desai, A. A.; Wulff, W. D. J. Am. Chem. Soc. 2010, 132, 13100. https://doi.org/10.1021/ja1038648

30. Vetticatt, M. J.; Desai, A. A.; Wulff, W. D. J. Am. Chem. Soc. 2010, 132, 13104. https://doi.org/10.1021/ja103863j

31. Martinand-Lurin, E.; Gruber, R.; Retailleau, P.; Fleurat-Lessard, P.; Dauban, P. J. Org. Chem. 2015, 80, 1414.

https://doi.org/10.1021/j0502333j

32. Stanković, S.; D’hooghe, M.; Catak, S.; Eum, H.; Waroquier, M.; Van Speybroeck, V.; De Kimpe, N.; Ha, H. J. Chem. Soc. Rev. 2012, 41, 643. https://doi.org/10.1039/C1CS15140A

33. Lu, P. Tetrahedron, 2010, 66, 2549. https://doi.org/10.1016/i.tet.2010.01.077

34. Paasche, A.; Arnone, M.; Fink, R. F.; Schirmeister, M.; Engels, B. J. Org. Chem. 2009, 74, 5244. https://doi.org/10.1021/jo900505q

35. Singh, G. S.; D’hooghe, M.; De Kimpe, N. In Azetidines, azetes and azetidinones: monocyclic in Comprehensive Heterocyclic Chemistry-III, Katritzky, A.; Ramsden, C.; Scriven, E.; Taylor, R. Eds; Elsevier: UK, 2008; Vol. 2; p 1. 
36. Stankovic, S.; Catak, S.; D’hooghe, M.; Goossens, H.; Tehrani, A. K.; Bogaert, P.; Waroquier, M.;

Speybroeck, V. V.; De Kimpe, N. J. Org. Chem. 2011, 76, 2157.

https://doi.org/10.1021/jo102555r

37. Stankovic, S.; Goossens, H.; Catak, S.; Tezcan, M.; Waroquier, M.; Speybroeck, V. V.; D’hooghe, M.; De Kimpe, N. J. Org. Chem. 2012, 77, 3181.

https://doi.org/10.1021/jo202637a

38. Kenis, S.; D’hooghe, M.; Verniest, G.; Reybroeck, M.; Thi, T. A. D.; Thi, C. P.; Pham, T. T.; TÖrnroos, K. W.; Tuyen, N. V.; De Kimpe, N. Chem. Eur. J. 2013, 19, 5966.

https://doi.org/10.1002/chem.201204485

39. Žukauskaite, A.; Mangelinckx, S.; Sackus, A.; De Kimpe, N. Heterocycles 2014, 88, 731. https://doi.org/10.3987/COM-13-S(S)35

40. Elander, R. P. Appl. Microbiol. Biotechnol. 2003, 61, 385. https://doi.org/10.1007/s00253-003-1274-y

41. Kahan, J. S.; Kahan F. M.; Goegelman, R.; Currie, S. A.; Jackson, M.; Stapley, E. O; Miller, T. W.; Miller, A. K.; Hendlin, D.; Mochales, S.; Hernandez, S.; Woodruff, H. B. Birnbaum, J. J. Antibiot. 1979, 32, 1. https://doi.org/10.7164/antibiotics.32.1

42. Bulychev, A.; Bellettini, J. R.; O’Brien, M.; Crocker, P. J.; Samama, J. P.; Miller, M. J.; Mobashery, S. Tetrahedron 2000, 56, 5719.

https://doi.org/10.1016/S0040-4020(00)00427-0

43. Rosenblum, S. B.; Huynh, T.; Afonso, A.; Davies Jr., H. R. J. Med. Chem. 1998, 41, 973. https://doi.org/10.1021/jm970701f

44. Fontana, F.; Tron, G. C.; Barbero, N.; Ferrini, S.; Thomas, S. P.; Aggarwal, V. K. Chem. Commun. 2010, 46, 267.

https://doi.org/10.1039/B920564K

45. Huang, L.; Zhao, W.; Staples, R. J.; Wulff, W. D. J. Chem. Sci. 2013, 4, 622.

https://doi.org/10.1039/C2SC21240D

46. Decamps, S.; Sevaille, L.; Ongeri, S.; Crousse, B. Org. Biomol. Chem. 2014, 12, 6345. https://doi.org/10.1039/C4OB01262C

47. Anzenbacher, P., Jr.; Nishiyabu, R.; Palacios, M. A. Coord. Chem. Rev. 2006, 250, 2929. https://doi.org/10.1016/i.ccr.2006.09.001

48. Yoshida, M.; Easmin, S.; Al-Amin, M.; Hirai, Y.; Shishido, K. Tetrahedron 2011, 67, 3194. https://doi.org/10.1016/i.tet.2011.03.015

49. Yoshida, M.; Maeyama, Y.; Al-Amin, M.; Shishido, K. J. Org. Chem. 2011, 76, 5813. https://doi.org/10.1021/jo201000f

50. Wang, S.; Zhu, X.; Chai, Z.; Wang, S. Org. Biomol. Chem. 2014, 12, 1351. https://doi.org/10.1039/C30B42324G

51. Sayyad, M.; Nanaji, Y.; Ghorai, M. K. J. Org. Chem., 2015, 80, 12659. https://doi.org/10.1021/acs.joc.5b02251

52. Ghorai, M. K.; Sayyad, M.; Nanaji, Y.; Jana, S. Chem. Asian J. 2015, 7, 1480. https://doi.org/10.1002/asia.201500153

53. Castellano, S.; Fiji, H. D. G.; Kinderman, S. S.; Watanabe, M.; de Leon, P.; Tamanoi, F.; Kwon, O. J. Am. Chem. Soc. 2007, 129, 5843. https://doi.org/10.1021/ja070274n

54. Kern, N.; Blanc, A.; Weibel, J. M.; Pale, P. Chem. Commun. 2011, 47, 6665. 
https://doi.org/10.1039/c1cc11351h

55. Brichacek, M.; Lee, D. E.; Njardarson. J. T. Org. Lett. 2008, 10, 5023.

https://doi.org/10.1021/ol802123e

56. Brichacek, M.; Villalobos, M. N.; Plichta, A.; Njardarson J. T. Org. Lett. 2011, 13, 1110. https://doi.org/10.1021/ol200263g

57. Mack, D. J.; Njardarson, J. T. J. Chem. Sci. 2012, 3, 3321.

https://doi.org/10.1039/c2sc21007j

58. Laia, F. M. R.; Cardoso, A. L.; Beja, A. M.; e Melo, T. M. V. D. P. Tetrahedron 2010, 66, 8815. https://doi.org/10.1016/j.tet.2010.09.081

59. Cardoso, A. L.; Nunes, R. M. D.; Arnaut, L. G.; e Melo, T. M. V. D. P. Synthesis 2011, 43, 3516.

60. Laia, F. M. R.; e Melo, T. M. V. D. P. Synthesis 2015, 47, 2781.

https://doi.org/10.1055/s-0034-1378717

61. Ghorai, M. K.; Tiwari D. P. J. Org. Chem. 2013, 78, 2617. https://doi.org/10.1021/jo302815m

62. Beşev, M. 2002. Radical cyclizatios to pyrrolidines. Comprehensive summaries of Uppsala dissertations from Faculty of Science and Technology 702, p 2.

63. http://en.wikipedia.org/wiki/Pyrrolidine. Wikipedia, the free encyclopedia. Date accessed 09/12/2013.

64. List, B. Tetrahedron 2002, 58, 5573. https://doi.org/10.1016/S0040-4020(02)00516-1

65. Lowe, M. A.; Ostovar, M.; Ferrini, S.; Chen, C.C.; Lawrence, P.G.; Fontana, F.; Calabrese, A. A.; Aggarwal, V. K. Angew. Chem., Int. Ed. 2011, 50, 6370.

https://doi.org/10.1002/anie.201101389

66. Arena, G.; Chen, C. C.; Leonori, D.; Aggarwal, V. K. Org. Lett. 2013, 15, 4250. https://doi.org/10.1021/ol4020333

67. Sengoden, M.; Punniyamurthy, T. Angew. Chem. 2013, 125, 600. https://doi.org/10.1002/ange.201207746

68. Li, L.; Wu, X.; Zhang, J. Chem. Commun. 2011, 47, 5049. https://doi.org/10.1039/c1cc10926j

69. Chawla, R.; Singh, A. K.; Yadav, L. D. S. RSC Adv., 2013, 3, 11385. https://doi.org/10.1039/c3ra00175j

70. Rai, A.; Yadav, L. D. S. Tetrahedron Lett., 2013, 54, 3127. https://doi.org/10.1016/j.tetlet.2013.04.013

71. Mal, A.; Sayyad, M.; Wani, I. A.; Ghorai, M. K. J. Org. Chem. 2017, 82, 4. https://doi.org/10.1021/acs.joc.6b01731

72. Hirner J. J.; Roth K. E.; Shi, Y.; Blum, S. A. Organometallics 2012, 31, 6843. https://doi.org/10.1021/om300671j

73. Pulipaka, A. B.; Bergmeier, S. C. J. Org. Chem. 2008, 73, 1462. https://doi.org/10.1021/jo702444c

74. Gyermek, L. Pharmacology of Antimuscarinic Agents, CRC Press LLC, Florida, United States of America. 1997, p 47.

75. Cohen, F.; Alicke, B.; Elliott, L. O.; Flygare, J. A.; Goncharov, T.; Keteltas, S. F.; Franklin, M. C.; Frankovitz, S.; Stephan, J. P.; Tsui, V.; Vucic, D.; Wong, H.; Fairbrother, W. J. J. Med. Chem. 2009, 52, 1723. https://doi.org/10.1021/jm801450c

76. Zhou, J.; Yeung, Y. Y. Org. Biomol. Chem. 2014, 12, 7482. 
https://doi.org/10.1039/C4OB01384K

77. Dolfen, J.; Vervisch, K.; De Kimpe, N.; D’hooghe, M. Chem.-Eur. J. 2016, 22, 4945.

https://doi.org/10.1002/chem.201504853

78. Caruano, J.; Muccioli, G. G.; Robietti, R. Org. Biomol. Chem. 2016, 14, 10134.

https://doi.org/10.1039/C6OB01349J

79. Lee, B. K.; Choi, H. G.; Roh, E. J.; Lee, W. K.; Sim, T. Tetrahedron Lett. 2013, 54, 553.

https://doi.org/10.1016/i.tetlet.2012.11.087

80. Ye, L. W.; Shu, C.; Gagosz, F. Org. Biomol. Chem. 2014, 12, 1833.

https://doi.org/10.1039/C30B42181C

81. Ghorai, M. K.; Tiwari, D. K. J. Org. Chem. 2010, 75, 6173.

https://doi.org/10.1021/jo101004x

82. Sengoden, M.; Vijay, M.; Balakumar, E.; Punniyamurthy, T. RSC Advances 2014, 4, 54149.

https://doi.org/10.1039/C4RA08902B

83. Sengoden, M.; Vijay, M.; Balakumar, E.; Punniyamurthy, T. Angew. Chem., Int. Ed 2013, 125, 600. https://doi.org/10.1002/ange.201207746

84. Colpaert, F.; Mangelinckx, S.; Giubellina, N.; De Kimpe, N. Tetrahedron 2011, 67, 1258. https://doi.org/10.1016/i.tet.2010.11.082

85. Kuszpit, M. R.; Wulff, W. D.; Tepe, J. J. J. Org. Chem. 2011, 76, 2913.

https://doi.org/10.1021/jo200101q

86. Sengoden, M.; Bhowmick, A.; Punniyamurthy, T. Org. Lett. 2017, 19, 158.

https://doi.org/10.1021/acs.orglett.6b03458

87. Takeda, Y.; Kawai, H.; Minakata, S. Chem. Eur. J. 2013, 19, 13479.

https://doi.org/10.1002/chem.201301617

88. Tabarki, M. A.; Besbes, R. Tetrahedron Lett. 2015, 56, 1837.

https://doi.org/10.1016/j.tetlet.2015.02.085

89. Tabarki, M. A.; Besbes, R. Tetrahedron Lett. 2016, 57, 3832.

https://doi.org/10.1016/j.tetlet.2016.07.040

90. Craig, II, R. A.; O’Connor, N. R.; Goldberg, A. F. G.; Stoltz, B. M. Chem. Eur. J. 2014, 20, 4806. https://doi.org/10.1002/chem.201303699

91. Samimi, H. A.; Dadvar, F. Synthesis 2015, 47, 1899.

https://doi.org/10.1055/s-0034-1380518

92. Chosal, N. C.; Santra, S.; Zyryanov, G.; Hajra, A.; Majee, A. Tetrahedron Lett. 2016, 57, 3551. https://doi.org/10.1016/j.tetlet.2016.06.119

93. Wu, X.; Lia L.; Zhang, J. Chem. Commun. 2011, 47, 7824.

https://doi.org/10.1039/c1cc12189h

94. Yang, H. T.; Xing, M. L.; Zhu, Y. F.; Sun, X. Q.; Cheng, J.; Miao, C. B.; Li, F. B. J. Org. Chem. 2014, $79,1487$. https://doi.org/10.1021/jo4025573

95. http://en.wikipedia.org/wiki/2-Oxazolidone. Wikipedia, the free encyclopedia. Date accessed15/09/2013.

96. Reck, F.; Zhou F.; Eyermann, C. J.; Kern, G.; Carcanague, D.; Ioannidis, G.; Illingworth, R.; Poon, G.; Gravestock, M. B. J. Med. Chem. 2007, 50, 4868.

https://doi.org/10.1021/jm070428+

97. Locke, J. B.; Finn J.; Hilgers, M.; Morales, G.; Rahawi, S.; Kedar, G. C.; Picazo, J. J.; Im, W.; Shaw, K. J.; Stein, J. L. Antimicrob. Agents Chemother. 2010, 54, 5337.

https://doi.org/10.1128/AAC.00663-10 
98. Ament, P. W.; Jamshed, N.; Horne, J. P. Am. Fam. Phys. 2002, 65, 663.

99. Agami, C.; Couty, F. Tetrahedron. 2002, 58, 2701. https://doi.org/10.1016/S0040-4020(02)00131-X

100. Kaabi, A.; Besbes, R. Synth. Commun. 2015, 45, 111. https://doi.org/10.1080/00397911.2014.961197

101. Du, Y.; Wu, Y.; Liu, A. H.; He, L.N. J. Org. Chem. 2008, 73, 4709. https://doi.org/10.1021/j0800269v

102. Wu, Y.; He, L. N.; Du, Y.; Wang, J. Q.; Miao, C.X.; Li, W. Tetrahedron 2009, 65, 6204. https://doi.org/10.1016/i.tet.2009.05.034

103. Phung, C.; Pinhas, A. R. Tetrahedron Lett. 2010, 51, 4552. https://doi.org/10.1016/j.tetlet.2010.06.110

104. Yang, Z. Z.; He, L. N.; Peng, S. Y.; Liu, A. H. Green Chem. 2010, 12, 1850. https://doi.org/10.1039/c0gc00286k

105. Yang, Z. Z.; Li, Y. N.; Wei, Y. Y.; He, L. N. Green Chem. 2011, 13, 2351. https://doi.org/10.1039/c1gc15581d

106. Rahul, A. W.; Dattatraya, B. B.; Yogesh, P. P.; Bhalchandra, M. B. Tetrahedron Lett. 2011, 52, 6383. https://doi.org/10.1016/j.tetlet.2011.09.056

107. Wu, Y.; Liu, G. Tetrahedron Lett. 2011, 52, 6450. https://doi.org/10.1016/i.tetlet.2011.09.092

108. Zhao, Y. N.; Yang, Z. Z.; Luo, S. H.; He, L. N. Catal. Today 2015, $200,2$. https://doi.org/10.1016/i.cattod.2012.04.006

109. Liu, H.; Hua, R. Tetrahedron 2016, 1200. https://doi.org/10.1016/i.tet.2016.01.015

110. Lin, X. Z.; Yang, Z. Z.; Heb, L. N.; Yuan, Z. Y. Green Chem. 2015, 17,795. https://doi.org/10.1039/C4GC01709A

111. Watile, R. A.; Bagal, D. B.; Deshmukh, K. M.; Dhake, K. P.; Bhanage, B. M. J. Mol. Catal. A: Chem. 2011, 196.

https://doi.org/10.1016/i.molcata.2011.10.007

112. Parker, R. E.; Isaacs N. S. Chem. Rev. 1959, 59, 737. https://doi.org/10.1021/cr50028a006

113. Gao, J.; Song Q. W.; He, L. N.; Liu, C.; Yang, Z. Z.; Han, X.; Li, X. D.; Song, Q. C.; Tetrahedron 2012, 68, 3835.

https://doi.org/10.1016/j.tet.2012.03.048

114. Fontana, F.; Chen C. C.; Aggarwal V. K.; Org. Lett. 2011, 13, 3454. https://doi.org/10.1021/ol201193d

115. Samimi, H. A.; Yamin, B. M. Tetrahedron Lett. 2016, 57, 223. https://doi.org/10.1016/j.tetlet.2015.12.025

116. Tabarki, M. A.; Besbes, R. Tetrahedron 2014, 70, 1060. https://doi.org/10.1016/j.tet.2013.12.052

117. Bhattacharyya, A.; Kavitha, C. V.; Ghorai, M. K. J. Org. Chem. 2016, 81, 6433. https://doi.org/10.1021/acs.joc.6b01551

118. Sengoden, M.; Irie, R.; Punniyamurthy, T. J. Org. Chem. 2016, 81, 11508. https://doi.org/10.1021/acs.joc.6b02190

119. Tummanapalli, S.; Muthuraman. P; Vangapandu D. N. Tetrahedron Lett. 2014, 55, 6787. 
120. Xing, S.; Ren, J.; Wang, K.; Cui, H.; Li, W.; Yan, H. Tetrahedron 2015, 71, 6290. https://doi.org/10.1016/i.tet.2015.06.013

121. Branchadell, V.; Moreno-Manas, M.; Pleixats, R. Organometallics 2002, 21, 2407. https://doi.org/10.1021/om0106940

122. Samanta, K.; Panda, G. Asian J. Chem. 2011, 6, 189. https://doi.org/10.1002/asia.201000554

123. Trinchera, P.; Musio, B; Degennaro, L.; Moliterni, A.; Falcicchio, A.; Luisi, R. Org. Biomol. Chem. 2012, 10, 1962. https://doi.org/10.1039/c2ob07099e

124. Zheng, D.; Wu, J. Eur. J. Org. Chem. 2014, 767. https://doi.org/10.1002/ejoc.201301426

125. Wang, L.; Yang, D.; Li, D.; Wang, R. Org. Lett. 2015, 17, 3004. https://doi.org/10.1021/acs.orglett.5b01291

126. http://en.wikipedia.org/wiki/Oxazines. Wikipedia, the free encyclopedia. Date accessed 16/12/2013.

127. Dhanya, S.; Savitha, U. S. H; Rama, M. Res. J. Pharm. Sci. 2013, 2, 15.

128. Mayekar, A. N.; Yathirajan, H. S.; Narayana, B.; Sarojini, B. K.; Kumari, N. S.; Harrison, W. T. A. Int. J. Chem. 2011, 3, 74. https://doi.org/10.5539/ijc.v3n1p74

129. Verma, V.; Singh, K.; Kumar, D.; Klapötke, T. M.; Stierstorfer, J.; Narasimhan, B.; Qazi, A. K.; Hamid, A; Jaglan, S. Eur. J. Med. Chem. 2012, 56, 195.

https://doi.org/10.1016/i.ejmech.2012.08.018

130. Belz, T.; Ihmaid, S.; Al-Rawi, J.; Petrovski, S. Int. J. Med. Chem. 2013, DOI: org/10:155/2013/436397.

131. Hsu, L. Y; Lin, C. H. Heterocycles 1996, 43, 2687. https://doi.org/10.3987/COM-96-7607

132. Duffin, W. M.; Rollo, I. Br. J. Pharmacol. 1957, 12, 171.

133. Cocuzza, A. J.; Chidester, D. R.; Cordova, B. C.; Jeffrey, S.; Parsons, R. L.; Bacheler, L. T.; Erickson-Viitanen, S.; Trainor, G. L.; Ko, S. S. Bioorg. Med. Chem. Lett. 2001, 11, 1177. https://doi.org/10.1016/S0960-894X(01)00192-5

134. Prasad, D.; Rohilla, R. K.; Roy, N.; Nath, M. Indian J. Chem. 2012. 51B, 739.

135. Wang, L.; Liu Q. B.; Wang, D. S.; Li, X.; Han, X. W.; Xiao, W. J.; Zhou, Y. G. Org. Lett. 2009, 11, 1119. https://doi.org/10.1021/ol802862p

136. Zhang, S.; Shan, C.; Zhang, S.; Yuan, L.; Wang, J.; Tung, C.-H.; Xing, I.-B.; Xu, Z. Org. Biomol. Chem. 2016, $14,10973$.

https://doi.org/10.1039/C60B02284G

137. Bhadra, S.; Adak, L.; Samanta, S.; Islam, A. K. M. M.; Mukherjee, M.; Ranu, B.C. J. Org. Chem. 2010, 75, 8533.

https://doi.org/10.1021/jo101916e

138. Bhadra, S.; Sreedhar, B.; Ranu, B. C. Adv. Synth. Catal. 2009, 351, 2369.

https://doi.org/10.1002/adsc.200900358

139. Bornholdt, J.; Felding, J.; Kristensen, J. L. J. Org. Chem. 2010, 75, 7454. https://doi.org/10.1021/jo101339g

140. Ghorai, M. K.; Kumar, A.; Tiwari, D. P. J. Org. Chem. 2010, 75, 137. https://doi.org/10.1021/jo902244y

141. Ghorai, M. K.; Tiwari, D. P.; Kumar, A. Das, K. J. Chem. Sci. 2011, 123, 951. 
https://doi.org/10.1007/s12039-011-0178-0

142. Ghorai, M. K.; Shukla, D.; Bhattacharyya, A. J. Org. Chem. 2012, 77, 3740. https://doi.org/10.1021/jo300002u

143. McGhee, A.; Cochran, B. M.; Stenmark, T. A. Michael, F. E. Chem. Commun. 2013, 49, 6800. https://doi.org/10.1039/c3cc44117b

144. Sun, H.; Huang, B.; Lin, R.; Yang, C.; Xia, W. Beilstein J. Org. Chem. 2015, 11, 524. https://doi.org/10.3762/bjoc.11.59

145. Samzadeh-Kermani, A. Synlett 2014, 25, 1839. https://doi.org/10.1055/s-0034-1378277

146. Pathipati, S. R.; Singh, V.; Eriksson, L.; Selander, N. Org. Lett. 2015, 17, 4506. https://doi.org/10.1021/acs.orglett.5b02195

147. Beng, T. K; Wilkerson-Hill, M. S.; Sarpong, R. Org. Lett. 2014, 16, 916. https://doi.org/10.1021/ol403671s

148. Shih, T. L.; Liang, M. T.; Wu, K. D.; Lin, C. H. Carbohydr. Res. 2011, 346, 183. https://doi.org/10.1016/i.carres.2010.11.014

149. Vervisch, K.; D’hooghe, M.; Tornroos, K. W.; De Kimpe, N. J. Org. Chem. 2010, 75, 7734. https://doi.org/10.1021/jo101646u

150. Kanno, E.; Yamano, K.; Koya, S.; Azumaya, I.; Masu, H.; Yamasaki, R.; Saito, S. J. Org. Chem. 2012, 77, 2142.

https://doi.org/10.1021/jo201959a

151. Ghorai, M. K.; Shahi, C. K.; Bhattacharyya, A.; Sayyad, M.; Mal, A.; Wani, I. A.; Chauhan, N. Asian J. Org. Chem. 2015, 10, 1103. https://doi.org/10.1002/ajoc.201500224

152. Ghorai, M.; Sahoo, A. K.; Bhattacharyya, A. J. Org. Chem. 2014, 79, 6468. https://doi.org/10.1021/jo500888j

153. Shahi, C. K.; Bhattacharyya, A.; Nanaji, Y. Ghorai, M. K. J. Org. Chem. 2017, 82, 37. https://doi.org/10.1021/acs.joc.6b01919

\section{Authors' Biographies}

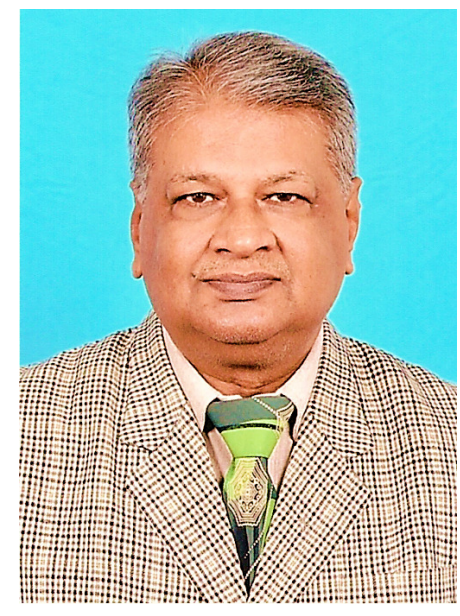

Girija S. Singh was born in Sasaram (Bihar), India. He received his B. Sc. and M. Sc. degrees from the U. P. College (then Gorakhpur University), Varanasi, India, in 1977 and 1979, respectively. He received his Ph. D. 
degree from the Banaras Hindu University (BHU), India, completing his doctoral thesis on the reactions of diazoalkanes and diazoketones with imines, amines and hydrazones in October, 1984. Since then he has occupied teaching and research positions in various universities such as Banaras Hindu University, India (JRF, SRF, PDF, Research Associate, Pool-Officer, Reader), Osaka University, Japan (PDF), University of Zambia (Lecturer), and University of Botswana (Lecturer, Senior Lecturer, Associate Professor). He is currently working as Professor of Chemistry at the University of Botswana. He has authored ninety eight publications in books and in peer-reviewed journals. He is member of the American Chemical Society, Chemical Research Society of India, and Indian Chemical Society. He is on the editorial board of over half a dozen chemistry journals. His research interests include the study of synthesis and reactivity of biologically important heterocycles, reactions of carbenoids, metal-catalyzed oxidations and organic chemistry education.

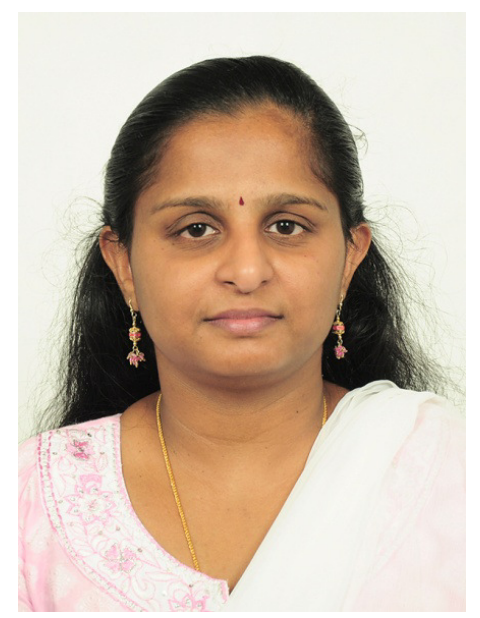

Siji Sudheesh was born in Thrissur (Kerala), India. She obtained her B. Sc. and M. Sc. degrees from Calicut University, India, in 2002 and 2006, respectively. After working briefly as a demonstrator in Chemistry Department of the University of Botswana, she joined the Ph. D. program of the department in 2011. She was awarded Ph. D. degree in 2015. She is currently working as a demonstrator in the chemistry Department of the University of Botswana. Her research focuses on the interaction, hysteresis and reactions of mixed Langmuir monolayers over air/aqueous interface. She has so far coauthored five publications.

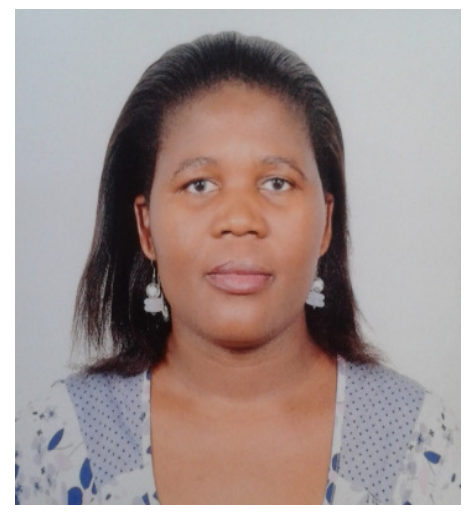

Ngonye Keroletswe was born in Maun, Botswana. She obtained her B. Ed. (Science) and M. Sc. (Organic Chemistry) degrees from the University of Botswana, in 2004 and 2007, respectively. After working as a Chemistry Teacher at Swaneng Hill School in Serowe, Botswana from January 2007 to July 2008 and as a demonstrator in Chemistry Department of University of Botswana from August 2008 to May 2011, she enrolled for her Ph. D. degree in the Chemistry Department and graduated in 2015. Currently, she is working as a 
Researcher in natural resources and materials at the Botswana Institute for Technology Research and Innovation from August 2014. Her research interests include isolation of plant metabolites of biological importance, polymer isolation from natural products and synthesis of polymers. She has authored one book chapter and five research papers in peer-reviewed journals. She is a member of the Botswana Academy of Science (BAS). 